\title{
Synthesis of B-Difluoroalkylated Acrylonitriles in the Presence of Copper Powder
}

\author{
Yu-Tao He, ${ }^{\dagger}$ Lian-Hua Li ${ }^{\dagger}$ Qiang Wang, ${ }^{\dagger}$ Wangsuo $\mathrm{Wu},{ }^{\dagger}$ and Yong-Min Liang $*, \dagger, \S$ \\ ${ }^{\dagger}$ State Key Laboratory of Applied Organic Chemistry, Lanzhou University, Lanzhou 730000, \\ P.R. China \\ ${ }^{1}$ Radiochemistry Laboratory, School of Nuclear Science and Technology, Lanzhou \\ University, Lanzhou 730000, Gansu, P. R. China. \\ ${ }^{\S}$ State Key Laboratory of Solid Lubrication, Lanzhou Institute of Chemical Physics, Chinese \\ Academy of Science, Lanzhou, 730000, P.R. China \\ E-mail:liangym@lzu.edu.cn
}

\section{Table of Contents}

1 General Remarks $\quad$ S2

2 General Experimental Procedure $\quad$ S2

3 Characterization Data of 3a-s, 4a, 5a S2-9

4 Crystallographic Data of 3c $\quad$ S10

$5{ }^{1}$ H NMR 、 ${ }^{13} \mathrm{C}$ NMR $、{ }^{19}$ F NMR Spectra for Substrates 3a-s, 4a, 5a 


\section{General Remarks}

For Column chromatography, 200-300 mesh silica gel was employed. Analytical TLC was performed with silica gel GF254 plates. ${ }^{1} \mathrm{H}$ NMR $(400 \mathrm{MHz}),{ }^{13} \mathrm{C} \mathrm{NMR}$ $(100 \mathrm{MHz})$ and ${ }^{19} \mathrm{~F} \mathrm{NMR}(376 \mathrm{MHz})$ were recorded in $\mathrm{CDCl}_{3}$ using TMS as internal standard. All products were further characterized by high resolution mass spectra (HRMS); copies of their ${ }^{1} \mathrm{H}$ NMR, ${ }^{13} \mathrm{C}$ NMR and ${ }^{19} \mathrm{~F}$ NMR spectra are provided. Unless otherwise noted, reactions were carried out under an argon atmosphere. DMSO was distilled from $\mathrm{CaH}_{2}$ under reduced pressure before used. All compounds were purified by flash column chromatography on silica gel (PE/EA).

\section{General Experimental Procedure}

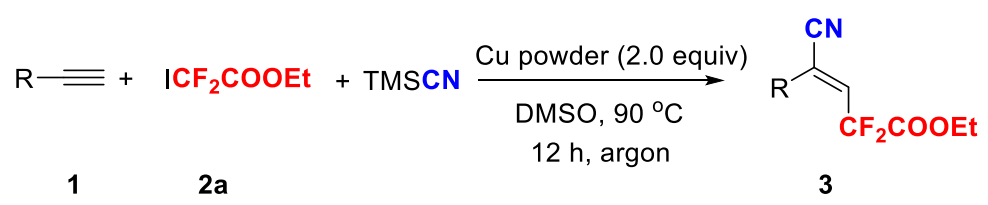

An oven-dried tube was charged with copper powder $(0.4 \mathrm{mmol})$. The tube was evacuated and backfilled with argon (repeated three times). Then, alkynes 1 (0.2 mmol) dissolved in DMSO $(1.0 \mathrm{~mL})$, ethyl difluoroiodoacetate $(0.3 \mathrm{mmol})$, and TMSCN $(0.4 \mathrm{mmol})$ were added into the tube. The reaction mixture was stirring at $90{ }^{\circ} \mathrm{C}$ for $12 \mathrm{~h}$ and extracted with DCM. The combined organic layers were washed with saturated brine, dried over $\mathrm{Na}_{2} \mathrm{SO}_{4}$, concentrated in vacuumand purified by flash column chromatography on silica gel (PE/EA) to afford final the product.

\section{Characterization Data of 3a-s, 4a, 5a}<smiles>CCOC(=O)C=CC(C#N)c1ccccc1</smiles>

3a

ethyl (E)-4-cyano-2,2-difluoro-4-phenylbut-3-enoate, purified by flash column chromatography on silica gel $(\mathrm{PE} / \mathrm{EA}=80 / 1)$, Colorless oil, $37.0 \mathrm{mg}, 74 \%$ yield.

${ }^{1} \mathbf{H}$ NMR $\left(400 \mathrm{MHz}, \mathrm{CDCl}_{3}\right) \delta 7.44-7.42(\mathrm{~m}, 5 \mathrm{H}), 6.65(\mathrm{t}, J=11.6 \mathrm{~Hz}, 1 \mathrm{H}), 4.01$ (q, $J=7.2 \mathrm{~Hz}, 2 \mathrm{H}$ ), 1.15 (t, $J=7.2 \mathrm{~Hz}, 3 \mathrm{H}$ ).

${ }^{13}$ C NMR $\left(100 \mathrm{MHz}, \mathrm{CDCl}_{3}\right) \delta 161.5(\mathrm{t}, J=32.4 \mathrm{~Hz}), 134.7(\mathrm{t}, J=29.0 \mathrm{~Hz}), 130.7$, $130.1,128.8,128.6(\mathrm{t}, J=21.0 \mathrm{~Hz}), 124.6(\mathrm{t}, J=9.0 \mathrm{~Hz}), 117.2,110.5(\mathrm{t}, J=247.0$ $\left.\mathrm{Hz}, \mathrm{CF}_{2}\right), 63.6,13.5$.

${ }^{19}$ F NMR $\left(376 \mathrm{MHz}, \mathrm{CDCl}_{3}\right) \delta-94.5$ (s).

HRMS (ESI) Calcd for $\mathrm{C}_{13} \mathrm{H}_{11} \mathrm{~F}_{2} \mathrm{NO}_{2}:[\mathrm{M}]+\mathrm{Na}=274.0650$. Found: 274.0655. 


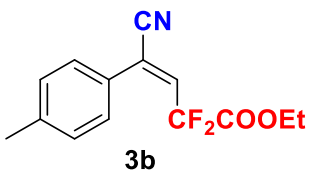

ethyl (E)-4-cyano-2,2-difluoro-4-(p-tolyl)but-3-enoate, purified by flash column chromatography on silica gel (PE/EA =60/1), Colorless oil, $39.3 \mathrm{mg}, 74 \%$ yield.

${ }^{1} \mathbf{H}$ NMR $\left(400 \mathrm{MHz}, \mathrm{CDCl}_{3}\right) \delta 7.32(\mathrm{~d}, J=8.0 \mathrm{~Hz}, 2 \mathrm{H}), 7.22(\mathrm{~d}, J=8.0 \mathrm{~Hz}, 2 \mathrm{H}), 6.59$ $(\mathrm{t}, J=11.6 \mathrm{~Hz}, 1 \mathrm{H}), 4.03(\mathrm{q}, J=7.2 \mathrm{~Hz}, 2 \mathrm{H}), 2.38(\mathrm{~s}, 3 \mathrm{H}), 1.15(\mathrm{t}, J=7.2 \mathrm{~Hz}, 3 \mathrm{H})$.

${ }^{13}$ C NMR $\left(100 \mathrm{MHz}, \mathrm{CDCl}_{3}\right) \delta 161.6(\mathrm{t}, J=32.6 \mathrm{~Hz}), 141.2,133.9(\mathrm{t}, J=29.0 \mathrm{~Hz})$, $129.4,128.6(\mathrm{t}, J=2.4 \mathrm{~Hz}), 127.3,124.6(\mathrm{t}, J=9.0 \mathrm{~Hz}), 117.4,110.6(\mathrm{t}, J=246.6 \mathrm{~Hz}$, $\left.\mathrm{CF}_{2}\right), 63.5,21.3,13.5$.

${ }^{19}$ F NMR $\left(376 \mathrm{MHz}, \mathrm{CDCl}_{3}\right) \delta-94.3(\mathrm{~s})$.

HRMS (ESI) Calcd for $\mathrm{C}_{14} \mathrm{H}_{13} \mathrm{~F}_{2} \mathrm{NO}_{2}$ : [M] + $\mathrm{Na}=288.0807$. Found: 288.0812.<smiles>CCOC(=O)C(F)(F)/C=C(\C#N)c1ccc(-c2ccccc2)cc1</smiles>

ethyl (E)-4-([1,1'-biphenyl]-4-yl)-4-cyano-2,2-difluorobut-3-enoate, purified by flash column chromatography on silica gel $(\mathrm{PE} / \mathrm{EA}=40 / 1)$, White solid, $47.0 \mathrm{mg}$, $72 \%$ yield.

${ }^{1} \mathbf{H}$ NMR $\left(400 \mathrm{MHz}, \mathrm{CDCl}_{3}\right) \delta 7.64(\mathrm{~d}, J=8.4 \mathrm{~Hz}, 2 \mathrm{H}), 7.59(\mathrm{~d}, J=7.2 \mathrm{~Hz}, 2 \mathrm{H}), 7.51$ $(\mathrm{d}, J=8.0 \mathrm{~Hz}, 2 \mathrm{H}), 7.46$ (t, $J=7.2 \mathrm{~Hz}, 2 \mathrm{H}), 7.39$ (t, $J=7.2 \mathrm{~Hz}, 1 \mathrm{H}), 6.65$ (t, $J=11.6$ $\mathrm{Hz}, 1 \mathrm{H}), 4.06(\mathrm{q}, J=7.2 \mathrm{~Hz}, 2 \mathrm{H}), 1.15(\mathrm{t}, J=7.2 \mathrm{~Hz}, 3 \mathrm{H})$.

${ }^{13}$ C NMR $\left(100 \mathrm{MHz}, \mathrm{CDCl}_{3}\right) \delta 161.6(\mathrm{t}, J=32.4 \mathrm{~Hz}), 143.6,139.4,134.3(\mathrm{t}, J=28.8$ $\mathrm{Hz}), 129.2(\mathrm{t}, J=2.1 \mathrm{~Hz}), 129.2,128.9,128.2,127.3,127.0,124.3(\mathrm{t}, J=8.7 \mathrm{~Hz})$, $117.3,110.5\left(\mathrm{t}, J=247.2 \mathrm{~Hz}, \mathrm{CF}_{2}\right), 63.7,13.5$.

${ }^{19}$ F NMR $\left(376 \mathrm{MHz}, \mathrm{CDCl}_{3}\right) \delta-94.7(\mathrm{~s})$.

HRMS (ESI) Calcd for $\mathrm{C}_{19} \mathrm{H}_{15} \mathrm{~F}_{2} \mathrm{NO}_{2}$ : [M] + $\mathrm{Na}=350.0963$. Found: 350.0969 .<smiles>CCOC(=O)/C=C(\C#N)c1ccc(C(C)(C)C)cc1</smiles>

ethyl (E)-4-(4-(tert-butyl)phenyl)-4-cyano-2,2-difluorobut-3-enoate, purified by flash column chromatography on silica gel $(\mathrm{PE} / \mathrm{EA}=80 / 1)$, Colorless oil, $44.8 \mathrm{mg}$, $73 \%$ yield.

${ }^{1} \mathbf{H}$ NMR $\left(400 \mathrm{MHz}, \mathrm{CDCl}_{3}\right) \delta 7.44(\mathrm{~d}, J=8.4 \mathrm{~Hz}, 2 \mathrm{H}), 7.37(\mathrm{~d}, J=8.4 \mathrm{~Hz}, 2 \mathrm{H}), 6.59$ $(\mathrm{t}, J=11.2 \mathrm{~Hz}, 1 \mathrm{H}), 3.99(\mathrm{q}, J=7.2 \mathrm{~Hz}, 2 \mathrm{H}), 1.32(\mathrm{~s}, 9 \mathrm{H}), 1.10(\mathrm{t}, J=7.2 \mathrm{~Hz}, 3 \mathrm{H})$.

${ }^{13}$ C NMR $\left(100 \mathrm{MHz}, \mathrm{CDCl}_{3}\right) \delta 161.6(\mathrm{t}, J=32.5 \mathrm{~Hz}), 154.4,133.9(\mathrm{t}, J=29.2 \mathrm{~Hz})$, $128.5(\mathrm{t}, J=2.1 \mathrm{~Hz}), 127.3,125.8,124.6(\mathrm{t}, J=9.2 \mathrm{~Hz}), 117.4,110.6(\mathrm{t}, J=246.5 \mathrm{~Hz}$, $\left.\mathrm{CF}_{2}\right), 63.5,34.9,31.0,13.5$.

${ }^{19}$ F NMR $\left(376 \mathrm{MHz}, \mathrm{CDCl}_{3}\right) \delta-93.9$ (s).

HRMS (ESI) Calcd for $\mathrm{C}_{17} \mathrm{H}_{19} \mathrm{~F}_{2} \mathrm{NO}_{2}$ : [M] + $\mathrm{Na}=330.1276$. Found: 330.1285 . 


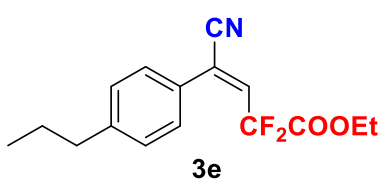

ethyl (E)-4-cyano-2,2-difluoro-4-(4-propylphenyl)but-3-enoate, purified by flash column chromatography on silica gel $(\mathrm{PE} / \mathrm{EA}=80 / 1)$, Colorless oil, $41.1 \mathrm{mg}, 70 \%$ yield.

${ }^{1} \mathbf{H}$ NMR $\left(400 \mathrm{MHz}, \mathrm{CDCl}_{3}\right) \delta 7.35(\mathrm{~d}, J=8.0 \mathrm{~Hz}, 2 \mathrm{H}), 7.23(\mathrm{~d}, J=8.0 \mathrm{~Hz}, 2 \mathrm{H}), 6.59$ (t, $J=11.2 \mathrm{~Hz}, 1 \mathrm{H}), 4.00(\mathrm{q}, J=11.2 \mathrm{~Hz}, 2 \mathrm{H}), 2.61(\mathrm{t}, J=7.2 \mathrm{~Hz}, 2 \mathrm{H}), 1.68-1.59(\mathrm{~m}$, $2 \mathrm{H}), 1.13(\mathrm{t}, J=7.2 \mathrm{~Hz}, 3 \mathrm{H}), 0.94(\mathrm{t}, J=7.2 \mathrm{~Hz}, 3 \mathrm{H})$.

${ }^{13}$ C NMR $\left(100 \mathrm{MHz}, \mathrm{CDCl}_{3}\right) \delta 161.6(\mathrm{t}, J=32.6 \mathrm{~Hz}), 146.0,133.9(\mathrm{t}, J=29.2 \mathrm{~Hz})$, $128.9,128.6(\mathrm{t}, J=8.0 \mathrm{~Hz}), 127.5,124.7(\mathrm{t}, J=9.2 \mathrm{~Hz}), 117.4,110.6(\mathrm{t}, J=246.5 \mathrm{~Hz}$, $\left.\mathrm{CF}_{2}\right), 63.5,37.7,24.2,13.6,13.5$.

${ }^{19}$ F NMR (376 MHz, $\left.\mathrm{CDCl}_{3}\right) \delta-94.0(\mathrm{~s})$.

HRMS (ESI) Calcd for $\mathrm{C}_{16} \mathrm{H}_{17} \mathrm{~F}_{2} \mathrm{NO}_{2}$ : [M] + Na= 316.1120. Found: 316.1125 .<smiles>CCOC(=O)/C=C(\C#N)c1ccc(OCC)cc1</smiles>

ethyl (E)-4-cyano-2,2-difluoro-4-(4-propoxyphenyl)but-3-enoate, purified by flash column chromatography on silica gel $(\mathrm{PE} / \mathrm{EA}=80 / 1)$, Colorless oil, $51.3 \mathrm{mg}, 76 \%$ yield.

${ }^{1} \mathbf{H}$ NMR $\left(400 \mathrm{MHz}, \mathrm{CDCl}_{3}\right) \delta 7.38(\mathrm{~d}, J=8.8 \mathrm{~Hz}, 2 \mathrm{H}), 6.91(\mathrm{~d}, J=8.8 \mathrm{~Hz}, 2 \mathrm{H}), 6.52$ (t, $J=7.6 \mathrm{~Hz}, 1 \mathrm{H}), 4.05(\mathrm{q}, J=7.2 \mathrm{~Hz}, 2 \mathrm{H}), 3.97(\mathrm{t}, J=6.4 \mathrm{~Hz}, 2 \mathrm{H}), 1.83-1.76(\mathrm{~m}$, $2 \mathrm{H}), 1.46-1.36(\mathrm{~m}, 4 \mathrm{H}), 1.15(\mathrm{t}, J=7.2 \mathrm{~Hz}, 3 \mathrm{H}), 0.94(\mathrm{t}, J=7.2 \mathrm{~Hz}, 3 \mathrm{H})$.

${ }^{13}$ C NMR $\left(100 \mathrm{MHz}, \mathrm{CDCl}_{3}\right) \delta 161.7(\mathrm{t}, J=32.7 \mathrm{~Hz}), 161.1,132.5(\mathrm{t}, J=28.8 \mathrm{~Hz})$, $130.4(\mathrm{t}, J=2.6 \mathrm{~Hz}), 124.3(\mathrm{t}, J=9.1 \mathrm{~Hz}), 122.1,117.5,114.6,110.7(\mathrm{t}, J=246.2 \mathrm{~Hz}$, $\left.\mathrm{CF}_{2}\right), 68.2,63.5,28.7,28.0,22.3,13.9,13.5$.

${ }^{19}$ F NMR $\left(376 \mathrm{MHz}, \mathrm{CDCl}_{3}\right) \delta-94.0(\mathrm{~s})$.

HRMS (ESI) Calcd for $\mathrm{C}_{18} \mathrm{H}_{21} \mathrm{~F}_{2} \mathrm{NO}_{3}:[\mathrm{M}]+\mathrm{Na}=360.1382$. Found: 360.1389 .<smiles>CCOC(=O)/C=C(\C#N)c1ccc(OC)cc1</smiles>

ethyl (E)-4-cyano-2,2-difluoro-4-(4-methoxyphenyl)but-3-enoate, purified by flash column chromatography on silica gel $(\mathrm{PE} / \mathrm{EA}=40 / 1)$, Colorless oil, $39.9 \mathrm{mg}, 71 \%$ yield.

${ }^{1}$ H NMR $\left(400 \mathrm{MHz}, \mathrm{CDCl}_{3}\right) \delta 7.40(\mathrm{~d}, J=8.8 \mathrm{~Hz}, 2 \mathrm{H}), 6.93(\mathrm{~d}, J=8.8 \mathrm{~Hz}, 2 \mathrm{H}), 6.53$ $(\mathrm{t}, J=11.6 \mathrm{~Hz}, 1 \mathrm{H}), 4.06(\mathrm{q}, J=7.2 \mathrm{~Hz}, 2 \mathrm{H}), 3.83(\mathrm{~s}, 3 \mathrm{H}), 1.16(\mathrm{t}, J=7.2 \mathrm{~Hz}, 3 \mathrm{H})$.

${ }^{13}$ C NMR $\left(100 \mathrm{MHz}, \mathrm{CDCl}_{3}\right) \delta 161.7(\mathrm{t}, J=32.5 \mathrm{~Hz}), 161.5,132.7(\mathrm{t}, J=28.8 \mathrm{~Hz})$, $130.4(\mathrm{t}, J=2.3 \mathrm{~Hz}), 124.3(\mathrm{t}, J=9.0 \mathrm{~Hz}), 122.4,117.5,114.2,110.7(\mathrm{t}, J=246.5 \mathrm{~Hz}$, $\left.\mathrm{CF}_{2}\right), 63.6,55.4,13.6$.

${ }^{19}$ F NMR $\left(376 \mathrm{MHz}, \mathrm{CDCl}_{3}\right) \delta-94.3$ (s).

HRMS (ESI) Calcd for $\mathrm{C}_{14} \mathrm{H}_{13} \mathrm{~F}_{2} \mathrm{NO}_{3}:[\mathrm{M}]+\mathrm{Na}=304.0756$. Found: 304.0756. 
<smiles>CCOC(=O)/C=C/C(=C\C(=O)OCC)c1cccc(C)c1</smiles>

ethyl (E)-4-cyano-2,2-difluoro-4-(m-tolyl)but-3-enoate, purified by flash column chromatography on silica gel (PE/EA $=60 / 1)$, Colorless oil, $36.0 \mathrm{mg}, 68 \%$ yield.

${ }^{1} \mathbf{H}$ NMR $\left(400 \mathrm{MHz}, \mathrm{CDCl}_{3}\right) \delta$ 7.33-7.22 (m, 4H), $6.62(\mathrm{~d}, J=11.2 \mathrm{~Hz}, 1 \mathrm{H}), 3.99$ (q, $J=7.2 \mathrm{~Hz}, 2 \mathrm{H}), 2.38(\mathrm{~s}, 3 \mathrm{H}), 1.14(\mathrm{t}, J=7.2 \mathrm{~Hz}, 3 \mathrm{H})$.

${ }^{13}$ C NMR $\left(100 \mathrm{MHz}, \mathrm{CDCl}_{3}\right) \delta 161.5(\mathrm{t}, J=32.4 \mathrm{~Hz}), 138.8,134.5(\mathrm{t}, J=29.2 \mathrm{~Hz})$, $131.5,130.1,129.1,128.7,125.7,124.7$ (t, $J=9.3 \mathrm{~Hz}), 117.3,110.5$ (t, $J=246.5 \mathrm{~Hz}$, $\left.\mathrm{CF}_{2}\right), 63.5,21.2,13.5$.

${ }^{19}$ F NMR $\left(376 \mathrm{MHz}, \mathrm{CDCl}_{3}\right) \delta-94.1$.

HRMS (ESI) Calcd for $\mathrm{C}_{14} \mathrm{H}_{13} \mathrm{~F}_{2} \mathrm{NO}_{2}$ : [M] + $\mathrm{Na}=288.0807$. Found: 288.0812.<smiles>CCOC(=O)C(=CC=C(C#N)c1cccc(OC)c1)C(F)(F)F</smiles>

ethyl (E)-4-cyano-2,2-difluoro-4-(3-methoxyphenyl)but-3-enoate, purified by flash column chromatography on silica gel $(\mathrm{PE} / \mathrm{EA}=40 / 1)$, Colorless oil, $39.4 \mathrm{mg}, 70 \%$ yield.

${ }^{1} \mathbf{H}$ NMR $\left(400 \mathrm{MHz}, \mathrm{CDCl}_{3}\right) \delta 7.33(\mathrm{t}, J=8.0 \mathrm{~Hz}, 1 \mathrm{H}), 7.02-6.98(\mathrm{~m}, 2 \mathrm{H}), 6.94(\mathrm{~d}, J$ $=1.6 \mathrm{~Hz}, 1 \mathrm{H}), 6.63(\mathrm{t}, J=11.2 \mathrm{~Hz}, 1 \mathrm{H}), 4.02(\mathrm{q}, J=7.2 \mathrm{~Hz}, 2 \mathrm{H}), 3.83(\mathrm{~s}, 3 \mathrm{H}), 1.15(\mathrm{t}$, $J=7.2 \mathrm{~Hz}, 3 \mathrm{H})$.

${ }^{13}$ C NMR $\left(100 \mathrm{MHz}, \mathrm{CDCl}_{3}\right) \delta 161.5(\mathrm{t}, J=32.3 \mathrm{~Hz}), 159.6,134.8(\mathrm{t}, J=29.4 \mathrm{~Hz})$, $131.2,130.0,124.5(\mathrm{t}, J=9.2 \mathrm{~Hz}), 120.8,117.1,116.9,113.6,110.5(\mathrm{t}, J=246.6 \mathrm{~Hz}$, $\left.\mathrm{CF}_{2}\right), 63.6,55.3,13.5$.

${ }^{19}$ F NMR $\left(376 \mathrm{MHz}, \mathrm{CDCl}_{3}\right) \delta-94.2$.

HRMS (ESI) Calcd for $\mathrm{C}_{14} \mathrm{H}_{13} \mathrm{~F}_{2} \mathrm{NO}_{3}:[\mathrm{M}]+\mathrm{Na}=304.0756$. Found: 304.0762.<smiles>CCOC(=O)[C-](C#N)/C=C(\C#N)c1ccc(F)cc1</smiles>

3j

ethyl (E)-4-cyano-2,2-difluoro-4-(4-fluorophenyl)but-3-enoate, purified by flash column chromatography on silica gel $(\mathrm{PE} / \mathrm{EA}=80 / 1)$, Colorless oil, $33.4 \mathrm{mg}, 62 \%$ yield.

${ }^{1} \mathbf{H}$ NMR $\left(400 \mathrm{MHz}, \mathrm{CDCl}_{3}\right) \delta$ 7.47-7.43 (m, 2H), 7.15-7.11 (m, 2H), $6.64(\mathrm{t}, J=11.6$ $\mathrm{Hz}, 1 \mathrm{H}), 4.12(\mathrm{q}, J=7.2 \mathrm{~Hz}, 2 \mathrm{H}), 1.21(\mathrm{t}, J=7.2 \mathrm{~Hz}, 3 \mathrm{H})$.

${ }^{13}$ C NMR $\left(100 \mathrm{MHz}, \mathrm{CDCl}_{3}\right) \delta 163.9(\mathrm{~d}, J=251.3 \mathrm{~Hz}), 161.6(\mathrm{t}, J=32.4 \mathrm{~Hz}), 134.7$ $(\mathrm{t}, J=28.3 \mathrm{~Hz}), 131.0\left(\mathrm{dt}, J_{l}=8.8 \mathrm{~Hz}, J_{2}=2.4 \mathrm{~Hz}\right.$ ), $126.2(\mathrm{~d}, J=3.5 \mathrm{~Hz}), 123.6(\mathrm{t}, J$ $=8.3 \mathrm{~Hz}), 117.1,116.0(\mathrm{~d}, J=22.0 \mathrm{~Hz}), 110.4\left(\mathrm{t}, J=247.9 \mathrm{~Hz}, \mathrm{CF}_{2}\right), 63.8,13.6$.

${ }^{19}$ F NMR (376 MHz, $\left.\mathrm{CDCl}_{3}\right) \delta-95.4(\mathrm{~s}),-108.3(\mathrm{~s})$.

HRMS (ESI) Calcd for $\mathrm{C}_{13} \mathrm{H}_{10} \mathrm{~F}_{3} \mathrm{NO}_{2}$ : [M] + $\mathrm{H}=270.0736$. Found: 270.0742 . 


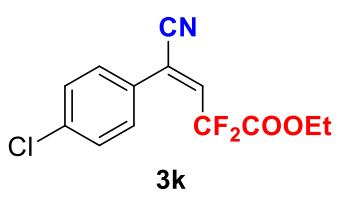

ethyl (E)-4-(4-chlorophenyl)-4-cyano-2,2-difluorobut-3-enoate, purified by flash column chromatography on silica gel $(\mathrm{PE} / \mathrm{EA}=80 / 1)$, Colorless oil, $36.5 \mathrm{mg}, 64 \%$ yield.

${ }^{1} \mathbf{H}$ NMR $\left(400 \mathrm{MHz}, \mathrm{CDCl}_{3}\right) \delta 7.58\left(\mathrm{dd}, J_{l}=6.8 \mathrm{~Hz}, J_{l}=2.0 \mathrm{~Hz}, 2 \mathrm{H}\right), 7.31(\mathrm{~d}, J=8.4$ $\mathrm{Hz}, 2 \mathrm{H}), 6.66(\mathrm{t}, J=11.6 \mathrm{~Hz}, 1 \mathrm{H}), 4.14(\mathrm{q}, J=7.2 \mathrm{~Hz}, 2 \mathrm{H}), 1.22(\mathrm{t}, J=7.2 \mathrm{~Hz}, 3 \mathrm{H})$.

${ }^{13}$ C NMR $\left(100 \mathrm{MHz}, \mathrm{CDCl}_{3}\right) \delta 161.6(\mathrm{t}, J=32.3 \mathrm{~Hz}), 135.0(\mathrm{t}, J=28.2 \mathrm{~Hz}), 132.1$, 130.2, 129.0, 125.4, $123.6(\mathrm{t}, J=8.0 \mathrm{~Hz}), 116.8,110.4\left(\mathrm{t}, J=248.4 \mathrm{~Hz}, \mathrm{CF}_{2}\right), 63.9$, 13.6 .

${ }^{19}$ F NMR $\left(376 \mathrm{MHz}, \mathrm{CDCl}_{3}\right) \delta-95.7$ (s).

HRMS (ESI) Calcd for $\mathrm{C}_{13} \mathrm{H}_{10} \mathrm{ClF}_{2} \mathrm{NO}_{2}:[\mathrm{M}]+\mathrm{Na}=308.0260$. Found: 308.0265.<smiles>CCOC(=O)/C=C(\C#N)c1ccc(Br)cc1</smiles>

ethyl (E)-4-(4-bromophenyl)-4-cyano-2,2-difluorobut-3-enoate, purified by flash column chromatography on silica gel $(\mathrm{PE} / \mathrm{EA}=80 / 1)$, Colorless oil, $41.5 \mathrm{mg}, 63 \%$ yield.

${ }^{1} \mathbf{H}$ NMR $\left(400 \mathrm{MHz}, \mathrm{CDCl}_{3}\right) \delta 7.42(\mathrm{~d}, J=8.8 \mathrm{~Hz}, 2 \mathrm{H}), 7.38(\mathrm{~d}, J=8.8 \mathrm{~Hz}, 2 \mathrm{H}), 6.66$ $(\mathrm{t}, J=12.0 \mathrm{~Hz}, 1 \mathrm{H}), 4.13(\mathrm{q}, J=7.2 \mathrm{~Hz}, 2 \mathrm{H}), 1.22(\mathrm{t}, J=7.2 \mathrm{~Hz}, 3 \mathrm{H})$.

${ }^{13}$ C NMR $\left(100 \mathrm{MHz}, \mathrm{CDCl}_{3}\right) \delta 161.5(\mathrm{t}, J=32.4 \mathrm{~Hz}), 137.1,135.0(\mathrm{t}, J=28.3 \mathrm{~Hz})$, $130.1(\mathrm{t}, J=2.3 \mathrm{~Hz}), 129.1,128.5,123.5(\mathrm{t}, J=8.2 \mathrm{~Hz}), 116.9,110.4(\mathrm{t}, J=248.2 \mathrm{~Hz}$, $\left.\mathrm{CF}_{2}\right), 63.8,13.6$.

${ }^{19}$ F NMR $\left(376 \mathrm{MHz}, \mathrm{CDCl}_{3}\right) \delta-95.7$ (s).

HRMS (ESI) Calcd for $\mathrm{C}_{13} \mathrm{H}_{10} \mathrm{BrF}_{2} \mathrm{NO}_{2}:[\mathrm{M}]+\mathrm{Na}=351.9755$. Found: 351.9764 .

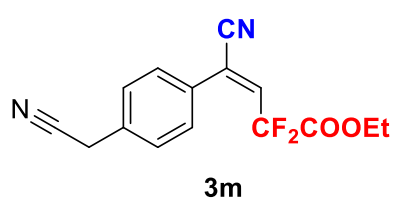

ethyl (E)-4-cyano-4-(4-(cyanomethyl)phenyl)-2,2-difluorobut-3-enoate, purified by flash column chromatography on silica gel (PE/EA =6/1), Colorless oil, $33.7 \mathrm{mg}$, $58 \%$ yield.

${ }^{1} \mathbf{H}$ NMR $\left(400 \mathrm{MHz}, \mathrm{CDCl}_{3}\right) \delta 7.47(\mathrm{~d}, J=8.2 \mathrm{~Hz}, 2 \mathrm{H}), 7.42(\mathrm{~d}, J=8.2 \mathrm{~Hz}, 2 \mathrm{H}), 6.68$ (t, $J=11.6 \mathrm{~Hz}, 1 \mathrm{H}), 4.13(\mathrm{q}, J=7.2 \mathrm{~Hz}, 2 \mathrm{H}), 3.81(\mathrm{~s}, 2 \mathrm{H}), 1.22(\mathrm{t}, J=7.2 \mathrm{~Hz}, 3 \mathrm{H})$.

${ }^{13}$ C NMR $\left(100 \mathrm{MHz}, \mathrm{CDCl}_{3}\right) \delta 161.5(\mathrm{t}, J=32.4 \mathrm{~Hz}), 135.1(\mathrm{t}, J=28.2 \mathrm{~Hz}), 132.8$, $130.0,129.4(\mathrm{t}, J=2.2 \mathrm{~Hz}), 128.3,123.7(\mathrm{t}, J=8.1 \mathrm{~Hz}), 116.9,116.9,110.4(\mathrm{t}, J=$ $\left.248.3 \mathrm{~Hz}, \mathrm{CF}_{2}\right), 63.8,23.4,13.6$.

${ }^{19}$ F NMR $\left(376 \mathrm{MHz}, \mathrm{CDCl}_{3}\right) \delta-95.8(\mathrm{~s})$.

HRMS (ESI) Calcd for $\mathrm{C}_{15} \mathrm{H}_{12} \mathrm{~F}_{2} \mathrm{~N}_{2} \mathrm{O}_{2}$ : [M] $+\mathrm{H}=291.0940$. Found: 291.0945 . 
<smiles>CCOC(=O)C(=CC=C(C#N)c1cccc(F)c1)C(F)(F)F</smiles>

ethyl (E)-4-cyano-2,2-difluoro-4-(3-fluorophenyl)but-3-enoate, purified by flash column chromatography on silica gel $(\mathrm{PE} / \mathrm{EA}=80 / 1)$, Colorless oil, $30.1 \mathrm{mg}, 56 \%$ yield.

${ }^{1} \mathbf{H}$ NMR $\left(400 \mathrm{MHz}, \mathrm{CDCl}_{3}\right) \delta 7.33(\mathrm{t}, J=8.0 \mathrm{~Hz}, 1 \mathrm{H}), 7.02-6.98(\mathrm{~m}, 2 \mathrm{H}), 6.94(\mathrm{~d}, J$ $=1.6 \mathrm{~Hz}, 1 \mathrm{H}), 6.63(\mathrm{t}, J=11.2 \mathrm{~Hz}, 1 \mathrm{H}), 4.02(\mathrm{q}, J=7.2 \mathrm{~Hz}, 2 \mathrm{H}), 3.83(\mathrm{~s}, 3 \mathrm{H}), 1.15(\mathrm{t}$, $J=7.2 \mathrm{~Hz}, 3 \mathrm{H})$.

${ }^{13}$ C NMR $\left(100 \mathrm{MHz}, \mathrm{CDCl}_{3}\right) \delta 162.3(\mathrm{~d}, J=247.0 \mathrm{~Hz}), 161.5(\mathrm{t}, J=32.0 \mathrm{~Hz}), 135.6$ $(\mathrm{t}, J=29.0 \mathrm{~Hz}), 131.9(\mathrm{~d}, J=8.0 \mathrm{~Hz}), 130.6(\mathrm{~d}, J=8.0 \mathrm{~Hz}), 124.6(\mathrm{~d}, J=5.0 \mathrm{~Hz})$, $123.3(\mathrm{t}, J=8.0 \mathrm{~Hz}), 117.8(\mathrm{~d}, J=21.0 \mathrm{~Hz}), 116.8,115.9(\mathrm{~d}, J=23.0 \mathrm{~Hz}), 110.3(\mathrm{t}, J$ $\left.=248.0 \mathrm{~Hz}, \mathrm{CF}_{2}\right), 63.9,13.6$.

${ }^{19}$ F NMR (376 MHz, $\left.\mathrm{CDCl}_{3}\right) \delta$-95.6, -110.9.

HRMS (ESI) Calcd for $\mathrm{C}_{13} \mathrm{H}_{10} \mathrm{~F}_{3} \mathrm{NO}_{2}$ : [M] + $\mathrm{Na}=292.0556$. Found: 292.0559 .<smiles>CCOC(F)(F)/C=C(\C#N)c1ccc2cc(OC)ccc2c1</smiles>

ethyl (E)-4-cyano-2,2-difluoro-4-(6-methoxynaphthalen-2-yl)but-3-enoate, purified by flash column chromatography on silica gel $(\mathrm{PE} / \mathrm{EA}=20 / 1)$, White solid, $38.4 \mathrm{mg}, 58 \%$ yield.

${ }^{1} \mathbf{H}$ NMR $\left(400 \mathrm{MHz}, \mathrm{CDCl}_{3}\right) \delta 7.84(\mathrm{~s}, 1 \mathrm{H}), 7.84-7.74(\mathrm{~m}, 2 \mathrm{H}), 7.45\left(\mathrm{dd}, J_{1}=8.4 \mathrm{~Hz}\right.$, $\left.J_{2}=1.6 \mathrm{~Hz}, 1 \mathrm{H}\right), 7.21\left(\mathrm{dd}, J_{1}=8.8 \mathrm{~Hz}, J_{2}=1.6 \mathrm{~Hz}, 1 \mathrm{H}\right), 7.12(\mathrm{~d}, J=2.4 \mathrm{~Hz}, 1 \mathrm{H})$, $6.66(\mathrm{t}, J=11.2 \mathrm{~Hz}, 1 \mathrm{H}), 3.92(\mathrm{~s}, 3 \mathrm{H}), 3.87(\mathrm{q}, J=7.2 \mathrm{~Hz}, 2 \mathrm{H}), 1.01(\mathrm{t}, J=7.2 \mathrm{~Hz}$, $3 \mathrm{H})$.

${ }^{13}$ C NMR (100 MHz, $\left.\mathrm{CDCl}_{3}\right) \delta 161.6(\mathrm{t}, J=32.4 \mathrm{~Hz}), 159.3,135.3,133.9(\mathrm{t}, J=29.2$ $\mathrm{Hz}), 130.1,129.1,127.8,127.4,125.3,125.2,124.8(\mathrm{t}, J=9.2 \mathrm{~Hz}), 120.2,117.4$, $110.7\left(\mathrm{t}, J=246.5 \mathrm{~Hz}, \mathrm{CF}_{2}\right), 105.6,63.5,55.3,13.4$.

${ }^{19}$ F NMR $\left(376 \mathrm{MHz}, \mathrm{CDCl}_{3}\right) \delta-93.6$.

HRMS (ESI) Calcd for $\mathrm{C}_{18} \mathrm{H}_{15} \mathrm{~F}_{2} \mathrm{NO}_{3}:[\mathrm{M}]+\mathrm{Na}=354.0912$. Found: 354.0918.<smiles>CCOC(=O)C(F)=CC=C(C#N)c1ccc(C(=O)c2ccccc2)cc1</smiles>

ethyl (E)-4-(4-benzoylphenyl)-4-cyano-2,2-difluorobut-3-enoate, purified by flash column chromatography on silica gel $(\mathrm{PE} / \mathrm{EA}=10 / 1)$, White solid, $18.5 \mathrm{mg}, 26 \%$ yield.

${ }^{1} \mathbf{H}$ NMR $\left(400 \mathrm{MHz}, \mathrm{CDCl}_{3}\right) \delta 7.85(\mathrm{~d}, J=8.4 \mathrm{~Hz}, 2 \mathrm{H}), 7.80(\mathrm{~d}, J=7.2 \mathrm{~Hz}, 2 \mathrm{H}), 7.63$ (t, $J=7.2 \mathrm{~Hz}, 1 \mathrm{H}), 7.57(\mathrm{~d}, J=8.0 \mathrm{~Hz}, 2 \mathrm{H}), 7.49(\mathrm{t}, J=7.2 \mathrm{~Hz}, 2 \mathrm{H}), 6.74$ (t, $J=12.0$ $\mathrm{Hz}, 1 \mathrm{H}), 4.17(\mathrm{q}, J=7.2 \mathrm{~Hz}, 2 \mathrm{H}), 1.25(\mathrm{t}, J=7.2 \mathrm{~Hz}, 3 \mathrm{H})$.

${ }^{13}$ C NMR $\left(100 \mathrm{MHz}, \mathrm{CDCl}_{3}\right) \delta 161.6(\mathrm{t}, J=32.2 \mathrm{~Hz}), 139.3,136.8,135.8(\mathrm{t}, J=27.9$ $\mathrm{Hz}), 133.7,133.0,130.2,130.0,128.7$ (t, $J=2.2 \mathrm{~Hz}), 128.7,128.5,123.7$ (t, $J=7.8$ 
$\mathrm{Hz}), 116.8,110.4\left(\mathrm{t}, J=248.7 \mathrm{~Hz}, \mathrm{CF}_{2}\right), 63.9,13.7$.

${ }^{19}$ F NMR $\left(376 \mathrm{MHz}, \mathrm{CDCl}_{3}\right) \delta-96.0$.

HRMS (ESI) Calcd for $\mathrm{C}_{20} \mathrm{H}_{15} \mathrm{~F}_{2} \mathrm{NO}_{3}:[\mathrm{M}]+\mathrm{Na}=378.0912$. Found: 378.0919.<smiles>CCOC(=O)C=C(C#N)CCOC(=O)c1ccc(Cl)cc1</smiles>

(E)-3-cyano-6-ethoxy-5,5-difluoro-6-oxohex-3-en-1-yl 4-chlorobenzoate, purified by flash column chromatography on silica gel (PE/EA = 10/1), White solid, $28.6 \mathrm{mg}$, $40 \%$ yield.

${ }^{1} \mathbf{H}$ NMR $\left(400 \mathrm{MHz}, \mathrm{CDCl}_{3}\right) \delta 8.00(\mathrm{~d}, J=8.4 \mathrm{~Hz}, 2 \mathrm{H}), 7.42(\mathrm{~d}, J=8.4 \mathrm{~Hz}, 2 \mathrm{H}), 6.54$ (t, $J=12.8 \mathrm{~Hz}, 1 \mathrm{H}), 4.55(\mathrm{t}, J=6.0 \mathrm{~Hz}, 2 \mathrm{H}), 4.34(\mathrm{q}, J=7.2 \mathrm{~Hz}, 2 \mathrm{H}), 2.98-2.95(\mathrm{~m}$, $2 \mathrm{H}), 1.35(\mathrm{t}, J=7.2 \mathrm{~Hz}, 3 \mathrm{H})$.

${ }^{13}$ C NMR (100 MHz, $\left.\mathrm{CDCl}_{3}\right) \delta 165.3,162.0(\mathrm{t}, J=32.8 \mathrm{~Hz}), 139.7,136.9(\mathrm{t}, J=27.1$ $\mathrm{Hz}$ ), 131.1, 128.8, 127.9, 122.7 (t, $J=6.0 \mathrm{~Hz}), 117.1,110.9$ (t, $J=250.4 \mathrm{~Hz}, \mathrm{CF}_{2}$ ), 64.1, 62.1, 29.8, 13.8.

${ }^{19}$ F NMR $\left(376 \mathrm{MHz}, \mathrm{CDCl}_{3}\right) \delta-99.9(\mathrm{~s})$.

HRMS (ESI) Calcd for $\mathrm{C}_{16} \mathrm{H}_{14} \mathrm{ClF}_{2} \mathrm{NO}_{4}:[\mathrm{M}]+\mathrm{Na}=380.0472$. Found: 380.0479 .<smiles>CCOC(=O)C=C(C#N)CCOC(=O)c1ccc(OC)cc1</smiles>

(E)-3-cyano-6-ethoxy-5,5-difluoro-6-oxohex-3-en-1-yl 4-methoxybenzoate, purified by flash column chromatography on silica gel $(\mathrm{PE} / \mathrm{EA}=5 / 1)$, White solid, $14.1 \mathrm{mg}, 20 \%$ yield.

${ }^{1} \mathbf{H}$ NMR $\left(400 \mathrm{MHz}, \mathrm{CDCl}_{3}\right) \delta 8.04(\mathrm{~d}, J=9.0 \mathrm{~Hz}, 2 \mathrm{H}), 6.94(\mathrm{~d}, J=9.0 \mathrm{~Hz}, 2 \mathrm{H}), 6.54$ $(\mathrm{t}, J=13.1 \mathrm{~Hz}, 1 \mathrm{H}), 4.54(\mathrm{t}, J=6.0 \mathrm{~Hz}, 2 \mathrm{H}), 4.35(\mathrm{q}, J=7.1 \mathrm{~Hz}, 2 \mathrm{H}), 3.88(\mathrm{~s}, 3 \mathrm{H})$ $2.97(\mathrm{td}, J=6.1,1.2 \mathrm{~Hz}, 2 \mathrm{H}), 1.36(\mathrm{t}, J=7.2 \mathrm{~Hz}, 3 \mathrm{H})$.

${ }^{13}$ C NMR $\left(126 \mathrm{MHz}, \mathrm{CDCl}_{3}\right) \delta 165.9,163.6,162.1(\mathrm{t}, J=33.2 \mathrm{~Hz}), 136.8,(\mathrm{t}, J=27.3$ $\mathrm{Hz}), 131.8,123.0(\mathrm{t}, J=6.3 \mathrm{~Hz}), 121.9,117.2,113.7,111.0\left(\mathrm{t}, J=251.8 \mathrm{~Hz}, \mathrm{CF}_{2}\right)$, 64.1, 61.7, 55.5, 29.9, 13.9 .

${ }^{19}$ F NMR (376 MHz, $\mathrm{CDCl}_{3}$ ) $\delta-99.9(\mathrm{~s})$.

HRMS (ESI) Calcd for $\mathrm{C}_{17} \mathrm{H}_{17} \mathrm{~F}_{2} \mathrm{NO}_{5}$ : [M] + $\mathrm{H}=354.1148$. Found: 354.1141 .<smiles>CCOC(=O)C=CC(C#N)=CCc1ccccc1</smiles>

ethyl (E)-4-cyano-2,2-difluoro-6-phenylhex-3-enoate, purified by flash column chromatography on silica gel $(\mathrm{PE} / \mathrm{EA}=30 / 1)$, Colorless oil, $8.4 \mathrm{mg}, 15 \%$ yield.

${ }^{1} \mathbf{H}$ NMR $\left(400 \mathrm{MHz}, \mathrm{CDCl}_{3}\right) \delta 7.33(\mathrm{t}, J=7.3 \mathrm{~Hz}, 2 \mathrm{H}), 7.26(\mathrm{t}, J=7.3 \mathrm{~Hz}, 1 \mathrm{H}), 7.19$ $(\mathrm{d}, J=7.1 \mathrm{~Hz}, 2 \mathrm{H}), 6.13(\mathrm{t}, J=11.6 \mathrm{~Hz}, 1 \mathrm{H}), 4.36(\mathrm{q}, J=7.1 \mathrm{~Hz}, 2 \mathrm{H}), 2.96(\mathrm{t}, J=7.6$ $\mathrm{Hz}, 2 \mathrm{H}), 2.69(\mathrm{td}, J=7.6,1.3 \mathrm{~Hz}, 2 \mathrm{H}), 1.37(\mathrm{t}, J=7.1 \mathrm{~Hz}, 3 \mathrm{H})$.

${ }^{13} \mathrm{C}$ NMR $\left(126 \mathrm{MHz}, \mathrm{CDCl}_{3}\right) \delta 162.1(\mathrm{t}, J=33.2 \mathrm{~Hz}), 138.6,134.6$, (t, $\left.J=26.8 \mathrm{~Hz}\right)$, $128.7,128.5,126.8,121.7(\mathrm{t}, J=7.1 \mathrm{~Hz}), 114.6,110.1\left(\mathrm{t}, J=251.6 \mathrm{~Hz}, \mathrm{CF}_{2}\right), 63.8$, 
37.7, 33.5, 13.9.

${ }^{19}$ F NMR $\left(376 \mathrm{MHz}, \mathrm{CDCl}_{3}\right) \delta-101.4(\mathrm{~s})$.

HRMS (ESI) Calcd for $\mathrm{C}_{15} \mathrm{H}_{15} \mathrm{~F}_{2} \mathrm{NO}_{2}:[\mathrm{M}]+\mathrm{H}=280.1144$. Found: 280.1140 .<smiles>CCOC(=O)C=C(C)c1ccccc1</smiles>

ethyl (E)-2,2-difluoro-4-iodo-4-phenylbut-3-enoate, purified by flash column chromatography on silica gel (PE/EA $=80 / 1)$, Colorless oil.

${ }^{1}$ H NMR $\left(400 \mathrm{MHz}, \mathrm{CDCl}_{3}\right) \delta 7.36-7.28(\mathrm{~m}, 5 \mathrm{H}), 6.72(\mathrm{t}, J=11.2 \mathrm{~Hz}, 1 \mathrm{H}), 3.97(\mathrm{q}$, $J=7.2 \mathrm{~Hz}, 2 \mathrm{H}), 1.19(\mathrm{t}, J=7.2 \mathrm{~Hz}, 3 \mathrm{H})$.

${ }^{13}$ C NMR $\left(100 \mathrm{MHz}, \mathrm{CDCl}_{3}\right) \delta 162.5(\mathrm{t}, J=33.0 \mathrm{~Hz}), 140.7,133.0(\mathrm{t}, J=28.2 \mathrm{~Hz})$, 129.4, 128.0, 127.8, $110.8\left(\mathrm{t}, J=248.6 \mathrm{~Hz}, \mathrm{CF}_{2}\right), 108.7(\mathrm{t}, J=10.0 \mathrm{~Hz}), 63.1,13.7$.

${ }^{19} \mathbf{F}$ NMR $\left(376 \mathrm{MHz}, \mathrm{CDCl}_{3}\right) \delta-93.9(\mathrm{~d}, J=8.6)$.

HRMS (ESI) Calcd for $\mathrm{C}_{12} \mathrm{H}_{11} \mathrm{~F}_{2} \mathrm{IO}_{2}:[\mathrm{M}]+\mathrm{Na}=374.9664$. Found: 374.9670 .<smiles>CCOC(=O)C=Cc1ccccc1</smiles>

ethyl (Z)-2,2-difluoro-4-phenylbut-3-enoate, purified by flash column chromatography on silica gel (PE/EA = 100/1), Colorless oil, $22.1 \mathrm{mg}, 49 \%$ yield.

${ }^{1}$ H NMR $\left(400 \mathrm{MHz}, \mathrm{CDCl}_{3}\right) \delta 7.46-7.37(\mathrm{~m}, 2 \mathrm{H}), 7.36-7.34(\mathrm{~m}, 3 \mathrm{H}), 7.10-7.05$ $(\mathrm{m}, 1 \mathrm{H}), 4.34$ (q, $J=7.2 \mathrm{~Hz}, 2 \mathrm{H}), 1.36(\mathrm{t}, J=7.2 \mathrm{~Hz}, 3 \mathrm{H})$.

${ }^{13}$ C NMR $\left(100 \mathrm{MHz}, \mathrm{CDCl}_{3}\right) \delta 163.9(\mathrm{t}, J=34.6 \mathrm{~Hz}), 136.8(\mathrm{t}, J=9.3 \mathrm{~Hz}), 134.1$, 129.6, 128.8, 127.4, $118.8(\mathrm{t}, J=24.8 \mathrm{~Hz}), 112.7\left(\mathrm{t}, J=247.0 \mathrm{~Hz}, \mathrm{CF}_{2}\right), 63.1,13.7$.

${ }^{19} \mathbf{F}$ NMR $\left(376 \mathrm{MHz}, \mathrm{CDCl}_{3}\right) \delta-103.3(\mathrm{~s})$.

HRMS (ESI) Calcd for $\mathrm{C}_{12} \mathrm{H}_{12} \mathrm{~F}_{2} \mathrm{O}_{2}:[\mathrm{M}]+\mathrm{Na}=249.0698$. Found: 249.0703 . 


\section{Crystallographic Data of 3c}<smiles>CCOC(=O)C(F)(F)/C=C(/C#N)c1ccc(-c2ccccc2)cc1</smiles>

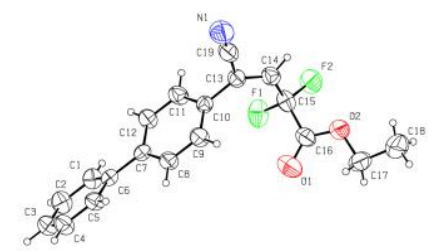

\section{Datablock:}

Bond precision: $\quad \mathrm{C}-\mathrm{C}=0.0067 \mathrm{~A}$

Wavelength $=0.71073$

$\begin{array}{lll}\text { Ce11: } & a=9.9991(9) \quad b=10.0274(15) & c=18.196(3) \\ & a l p h a=82.194(12) b e t a=79.357(9) & \text { gamma }=68.521(11)\end{array}$

Temperature: $291 \mathrm{~K}$

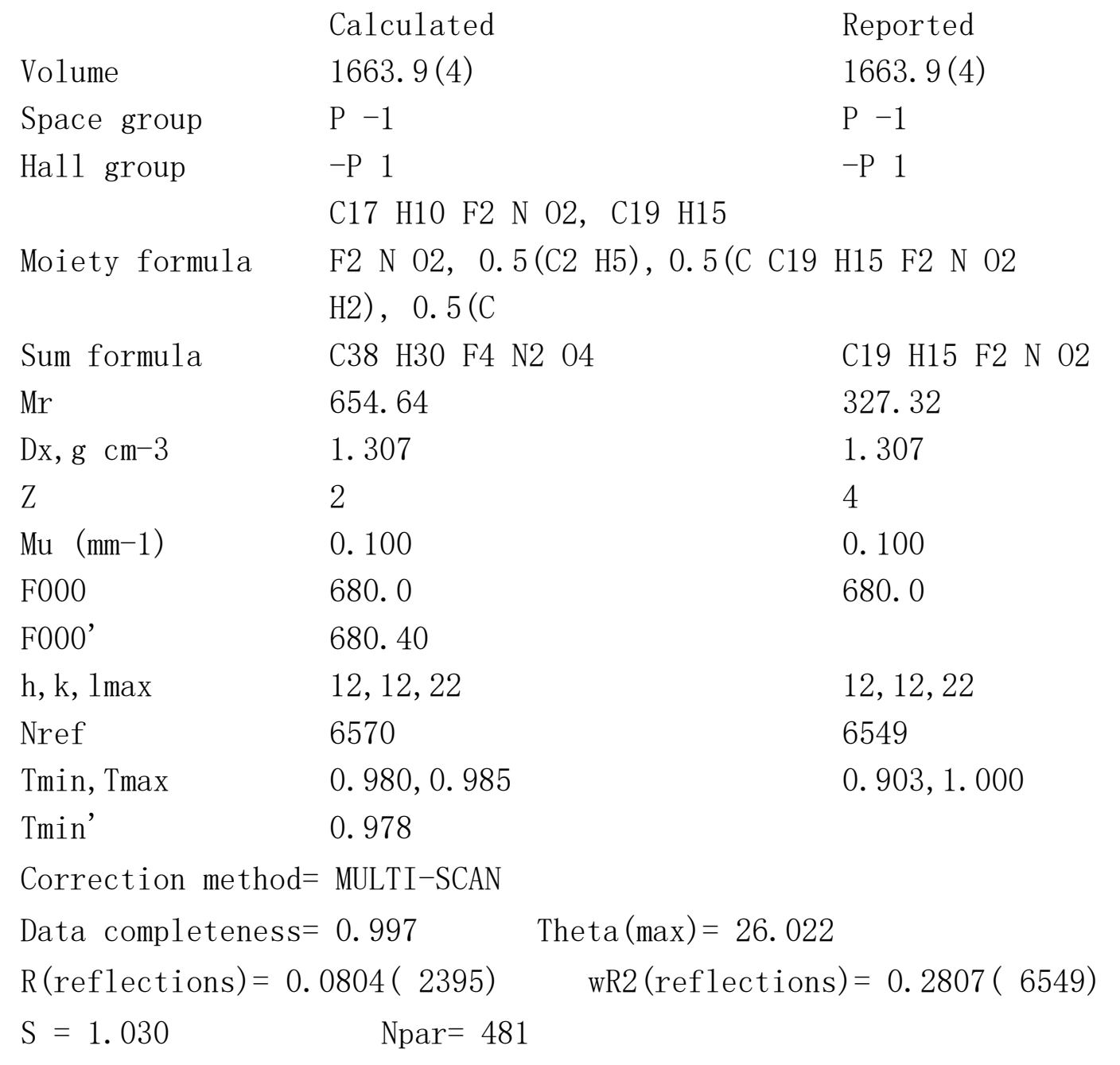


5、 ${ }^{1} \mathrm{H}$ NMR $、{ }^{13} \mathrm{C}$ NMR 、 ${ }^{19} \mathrm{~F}$ NMR Spectra for Substrates 3a-s, 4a, 5a,

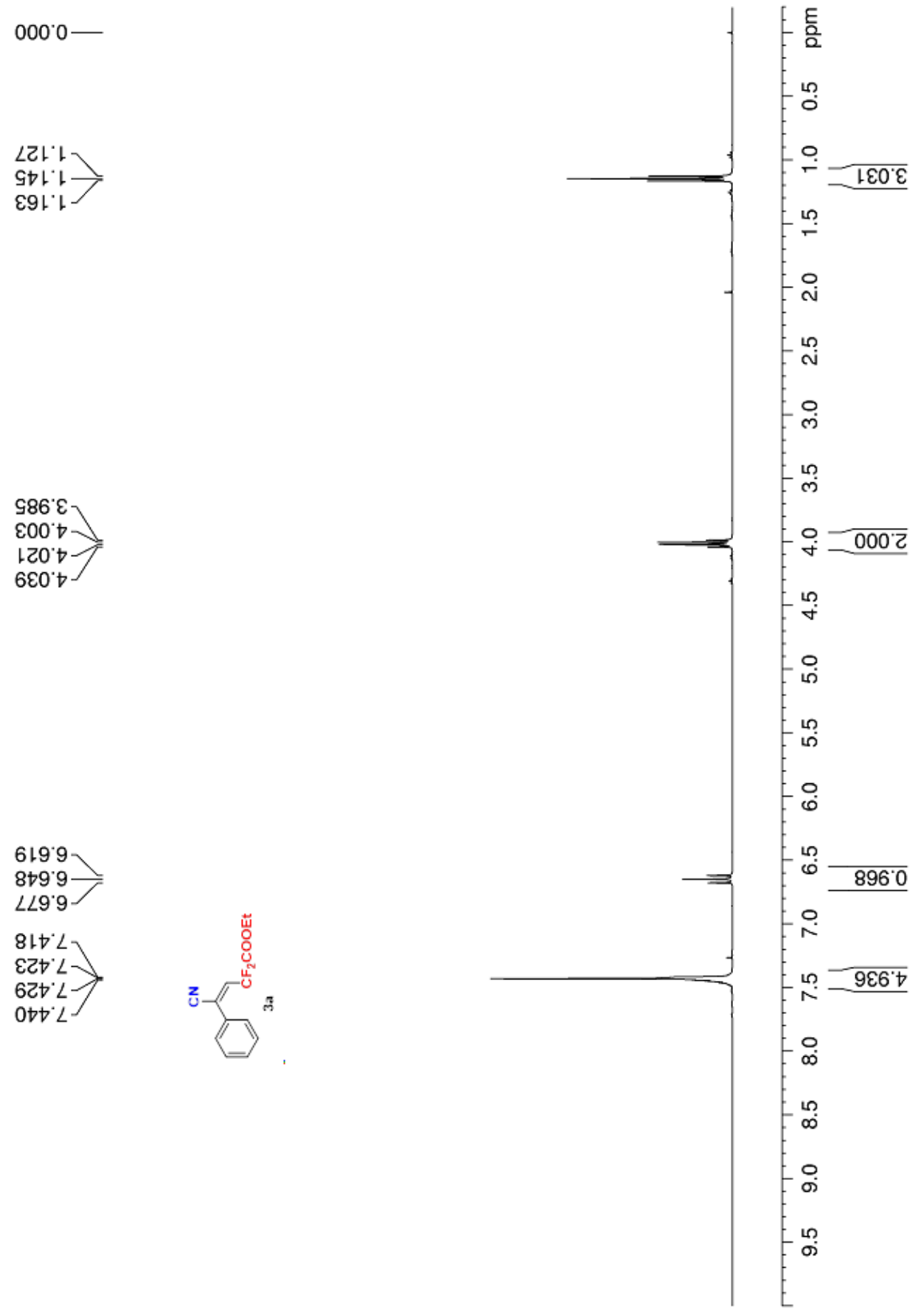


$\varepsilon 6 \nabla^{\circ} \varepsilon$

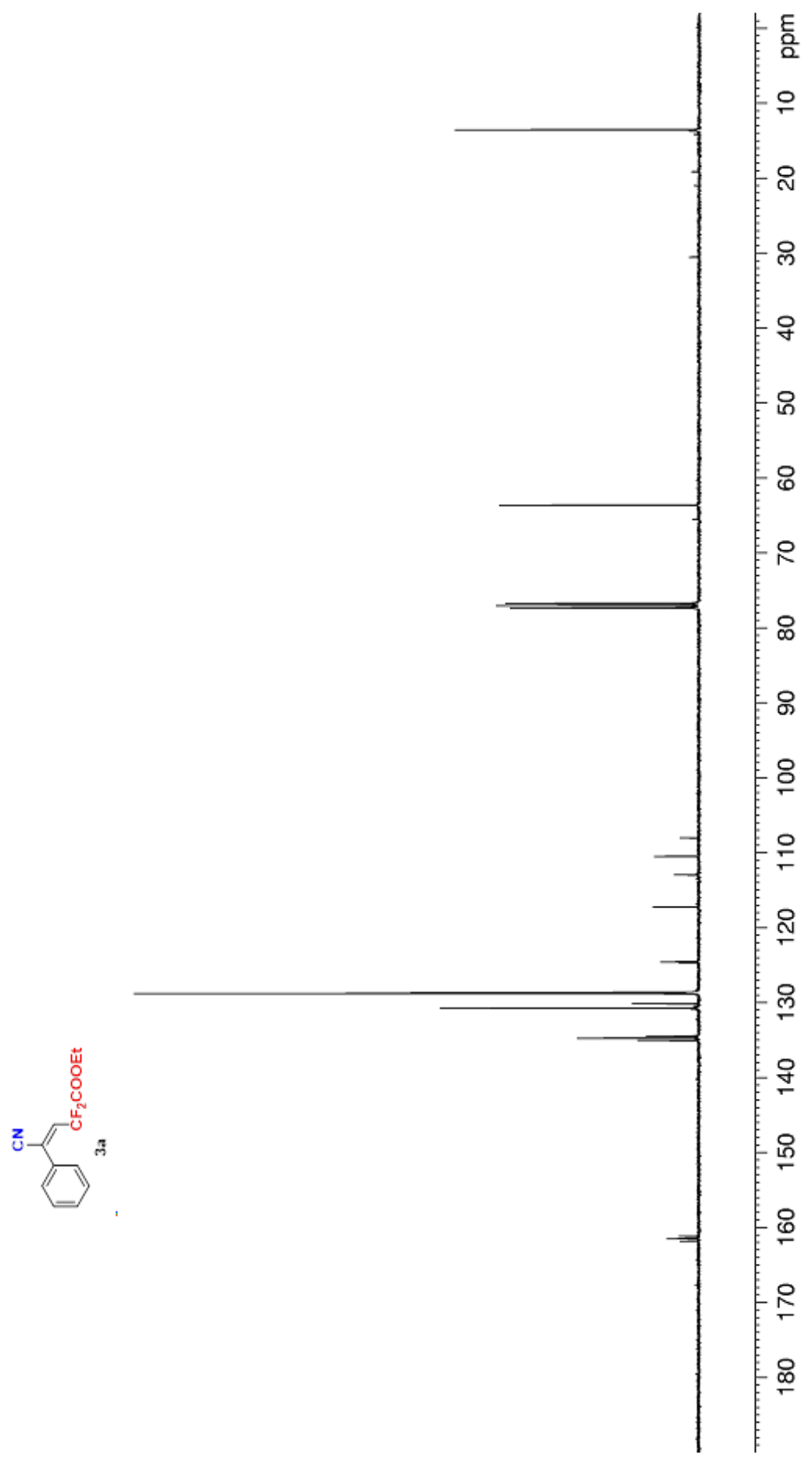


ย8เ เ6--

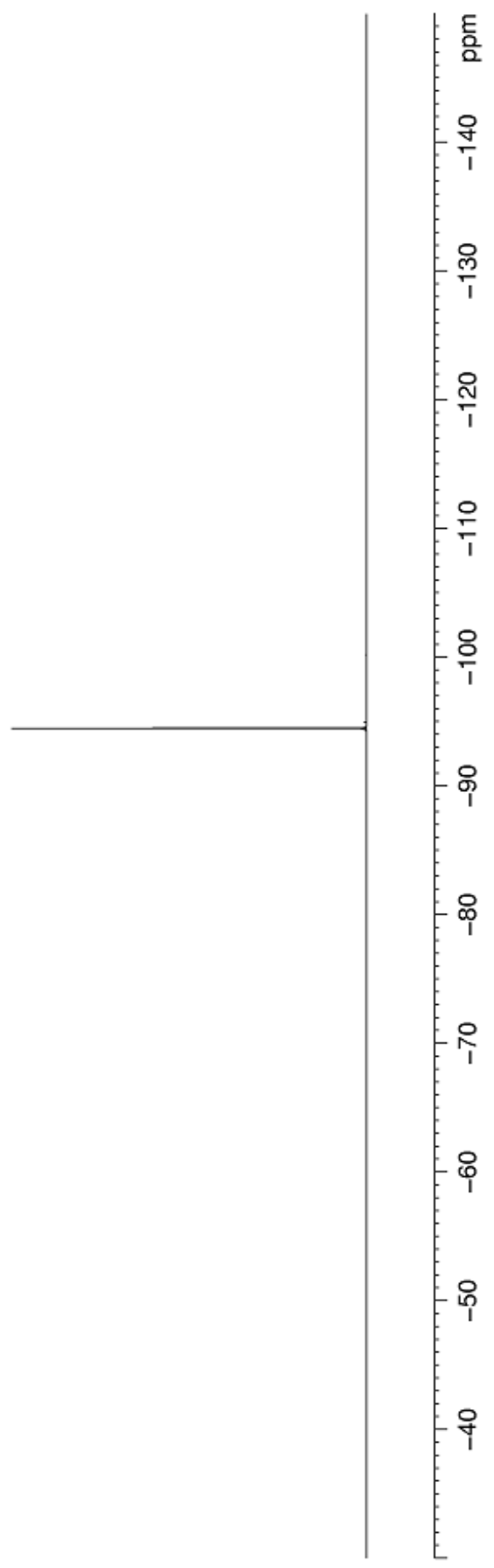




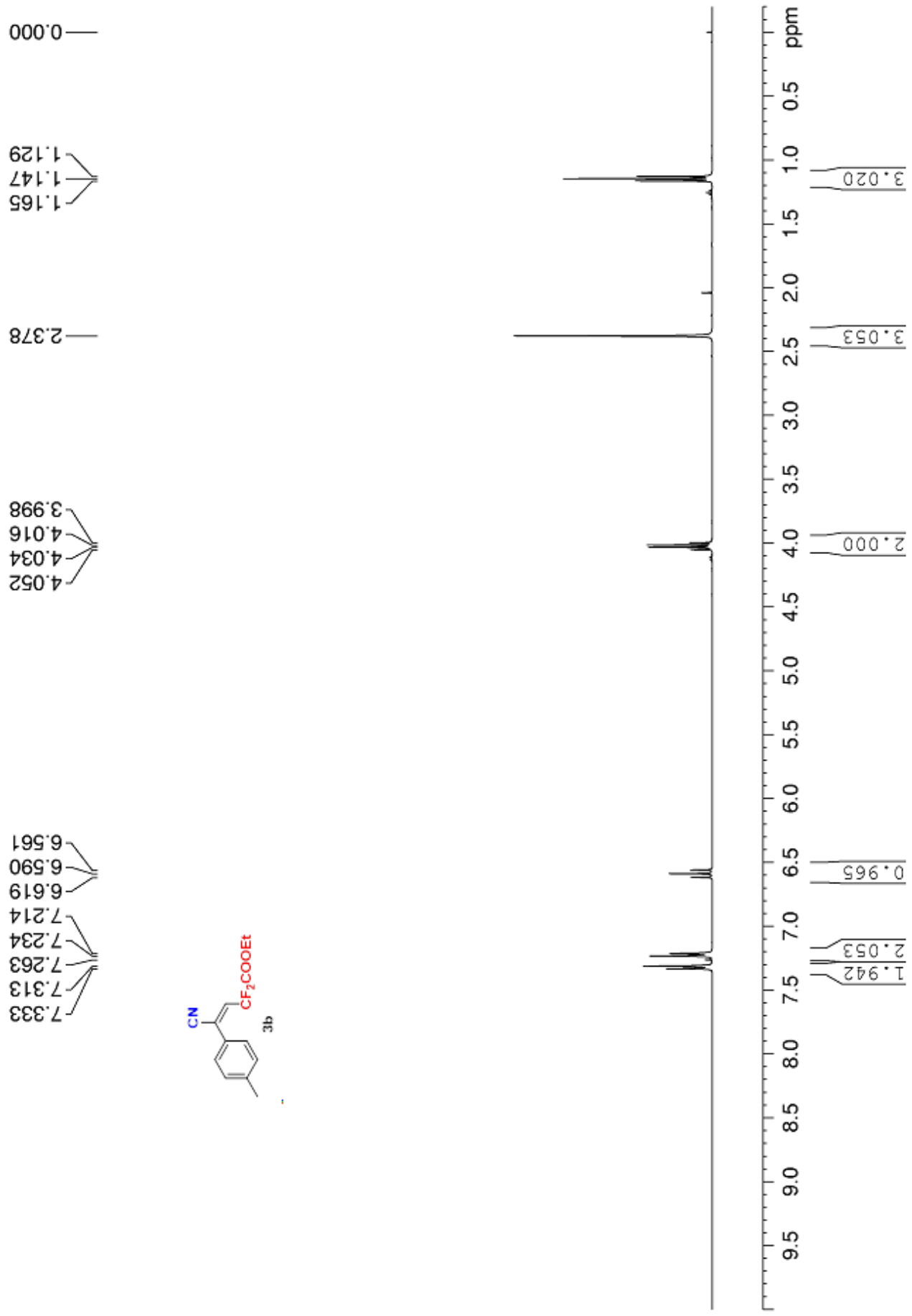



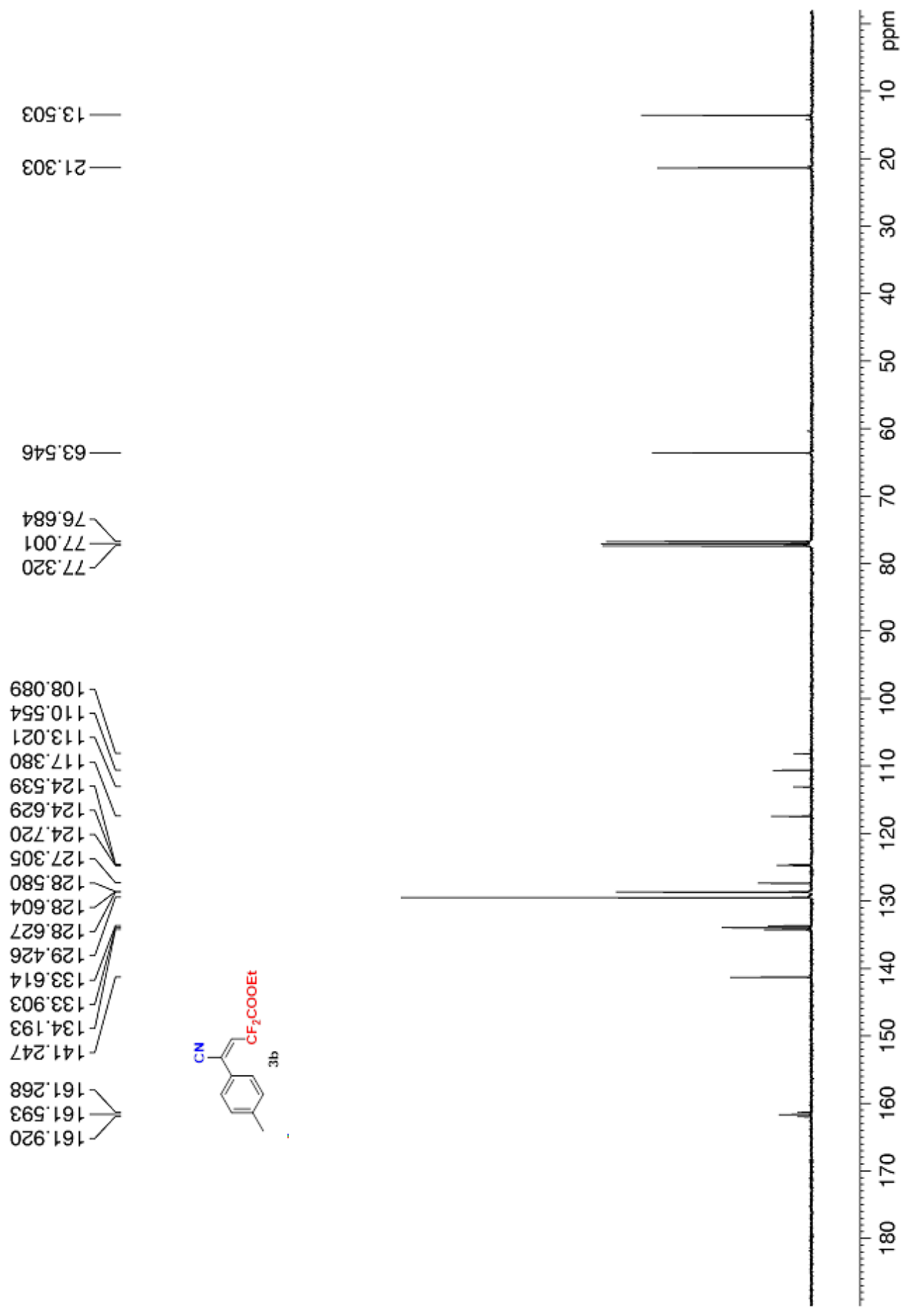


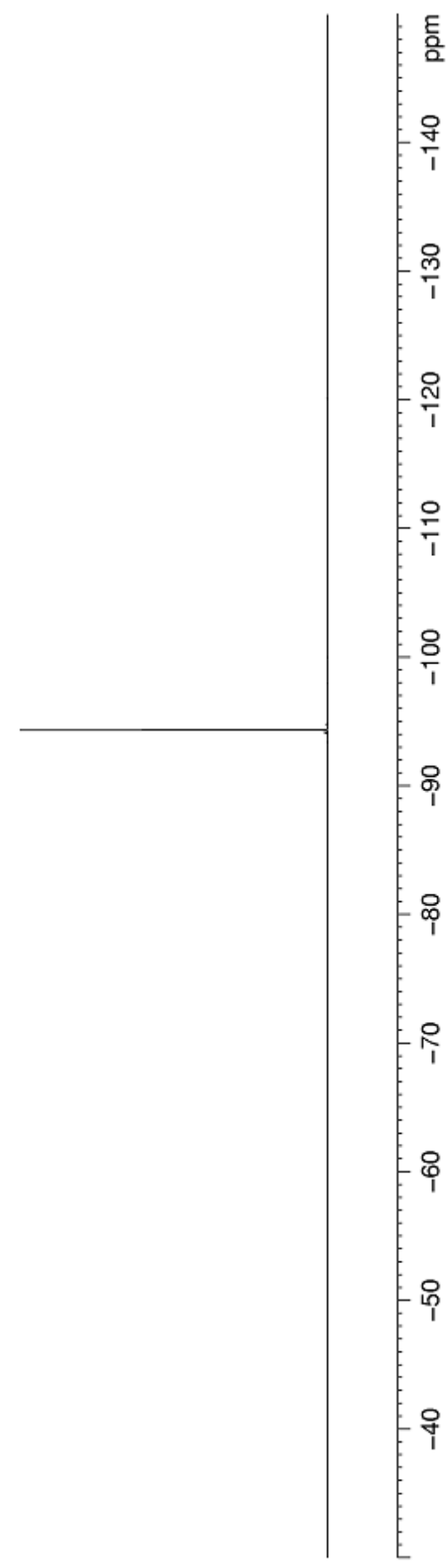




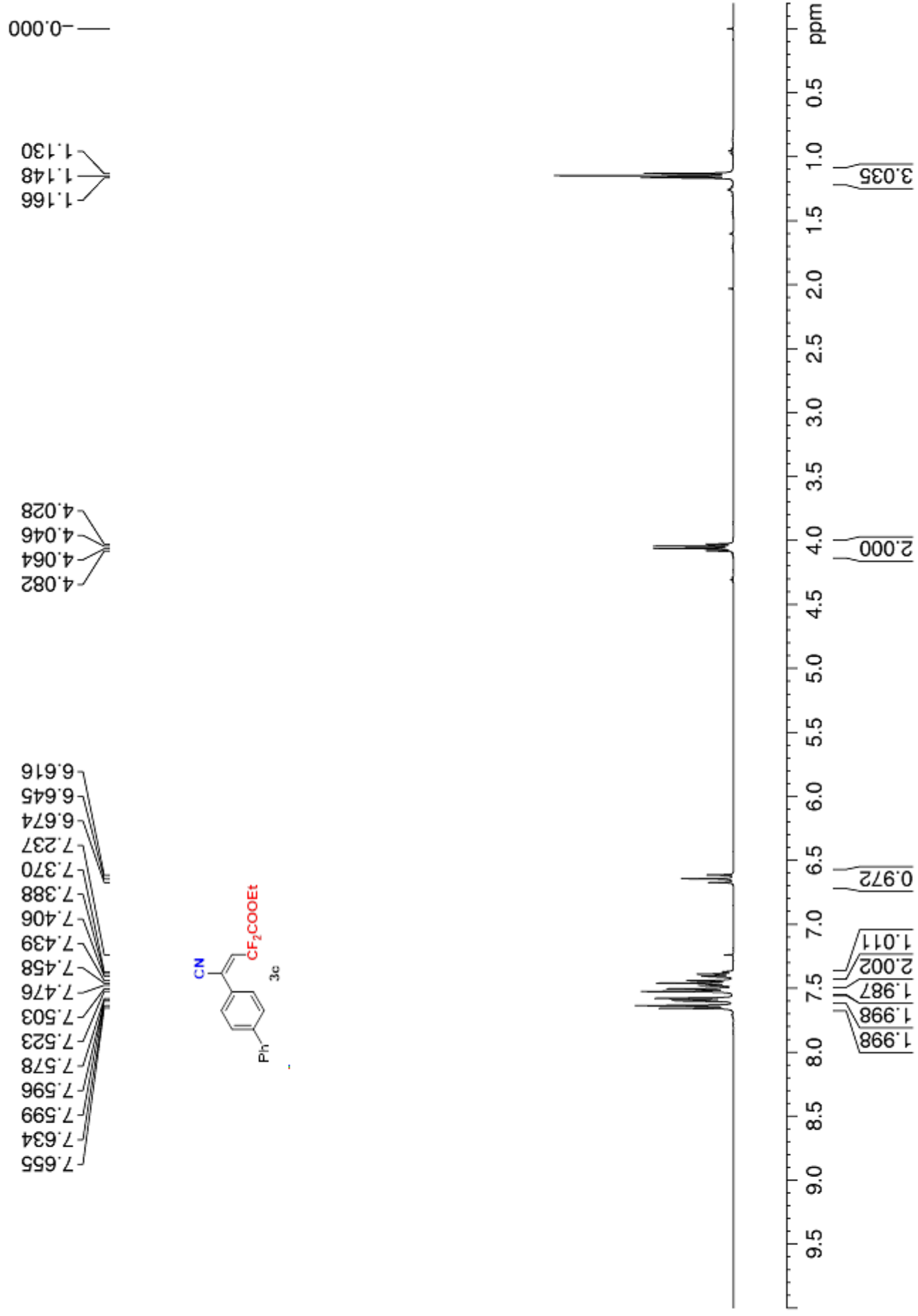


$8 \varepsilon \mathcal{S}^{\circ} \varepsilon \vdash$

099 $89-$

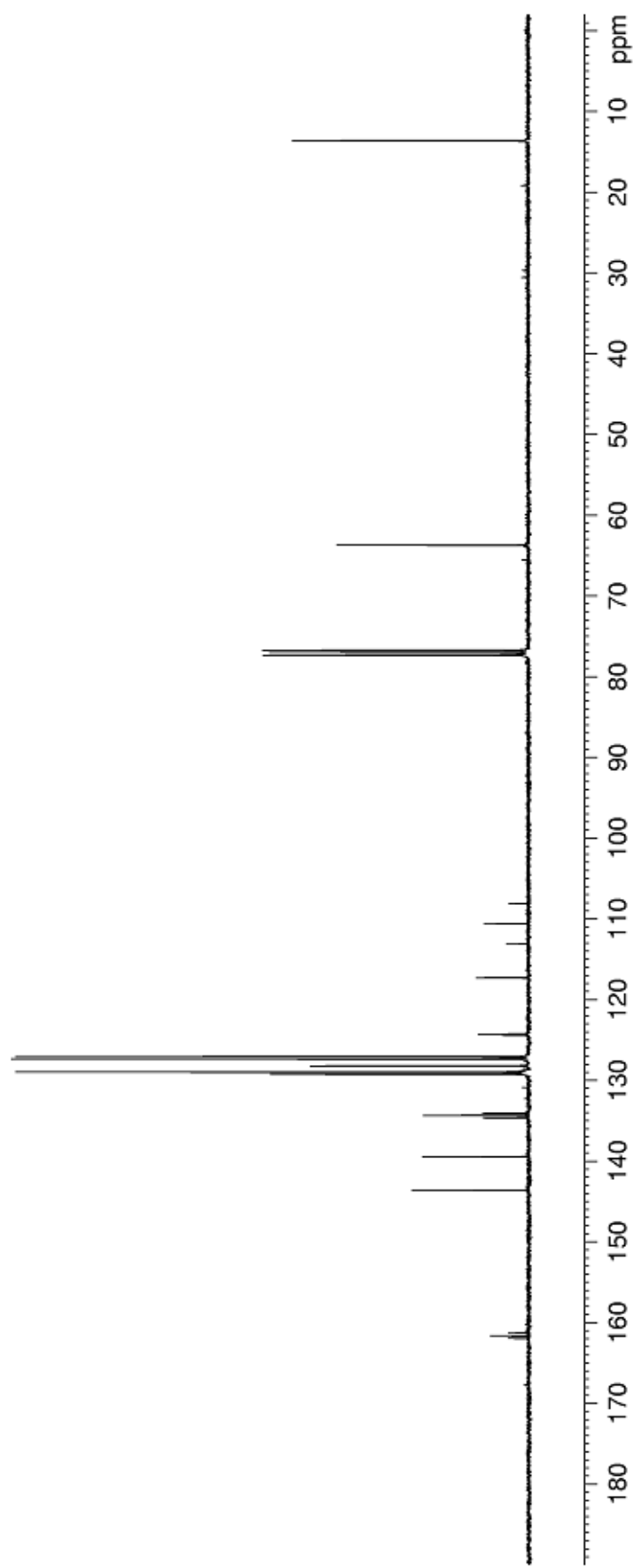

$\angle 66$ ' 94

$\rightarrow I E L L$

$9 \angle 0.80 \mathrm{~L}$

$\angle \supset \mathcal{G}^{\circ} \mathrm{OH}$

6เ0ำเ

29己 Lᄂ

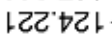

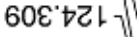

$96 \varepsilon^{\prime} \triangleright Z \downarrow$

$1 \rightarrow 0^{\circ} L C+$

$0 เ \varepsilon ' \angle Z \vdash$

$891^{\circ} 8 \mathrm{~L}$ -

886.82 ।

LLI'6CL-

$861^{\circ} 6 \mathrm{~L}$ -

6 เट 621

$\varsigma \varepsilon 0$ ' $\bullet$

$\triangleright 乙 \varepsilon^{\prime} \triangleright \varepsilon$

L $19^{\circ} \downarrow \varepsilon+$ -

Gเt $6 \varepsilon$.

$\succ 8 \mathrm{C}^{\circ} \varepsilon \mathrm{L}$

$\angle 8 Z$ เ9!

0.9. 19เ

ธع6. เ91 


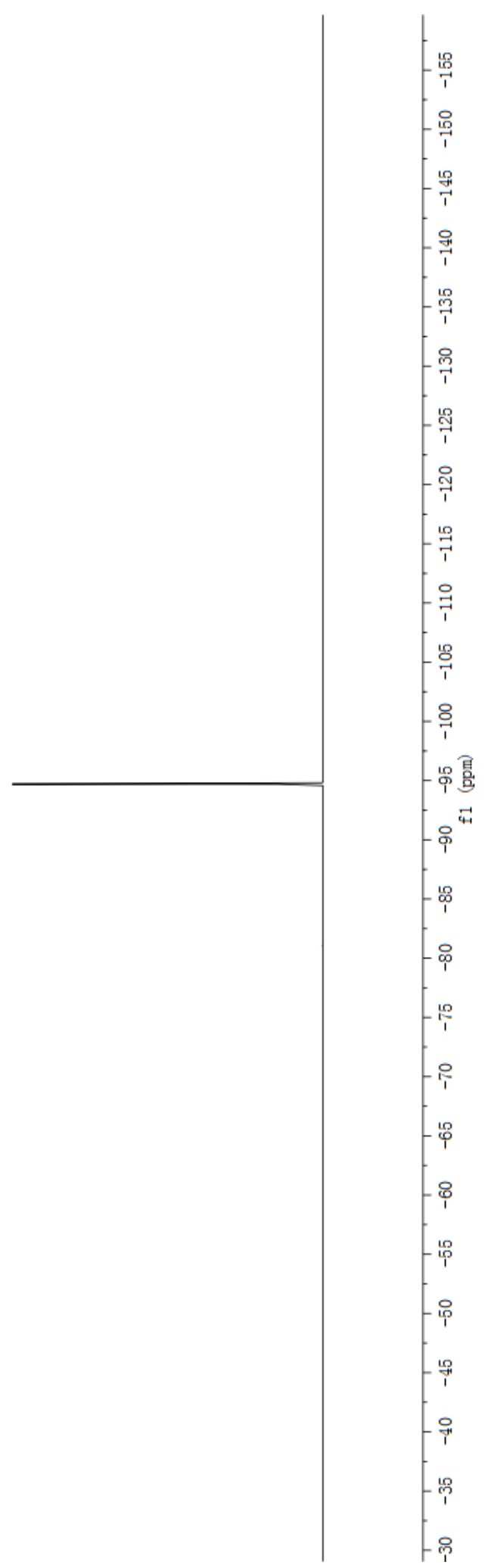




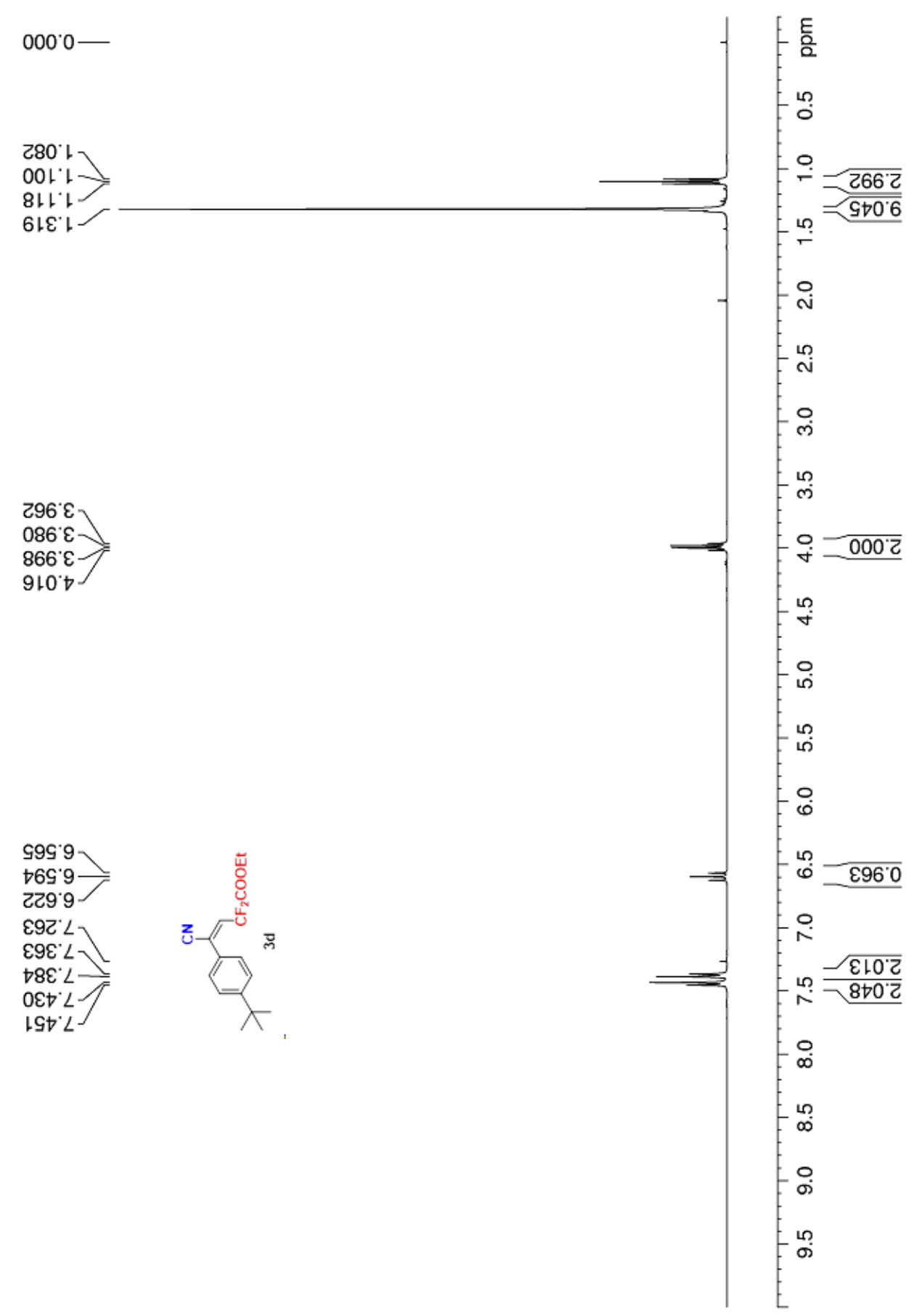




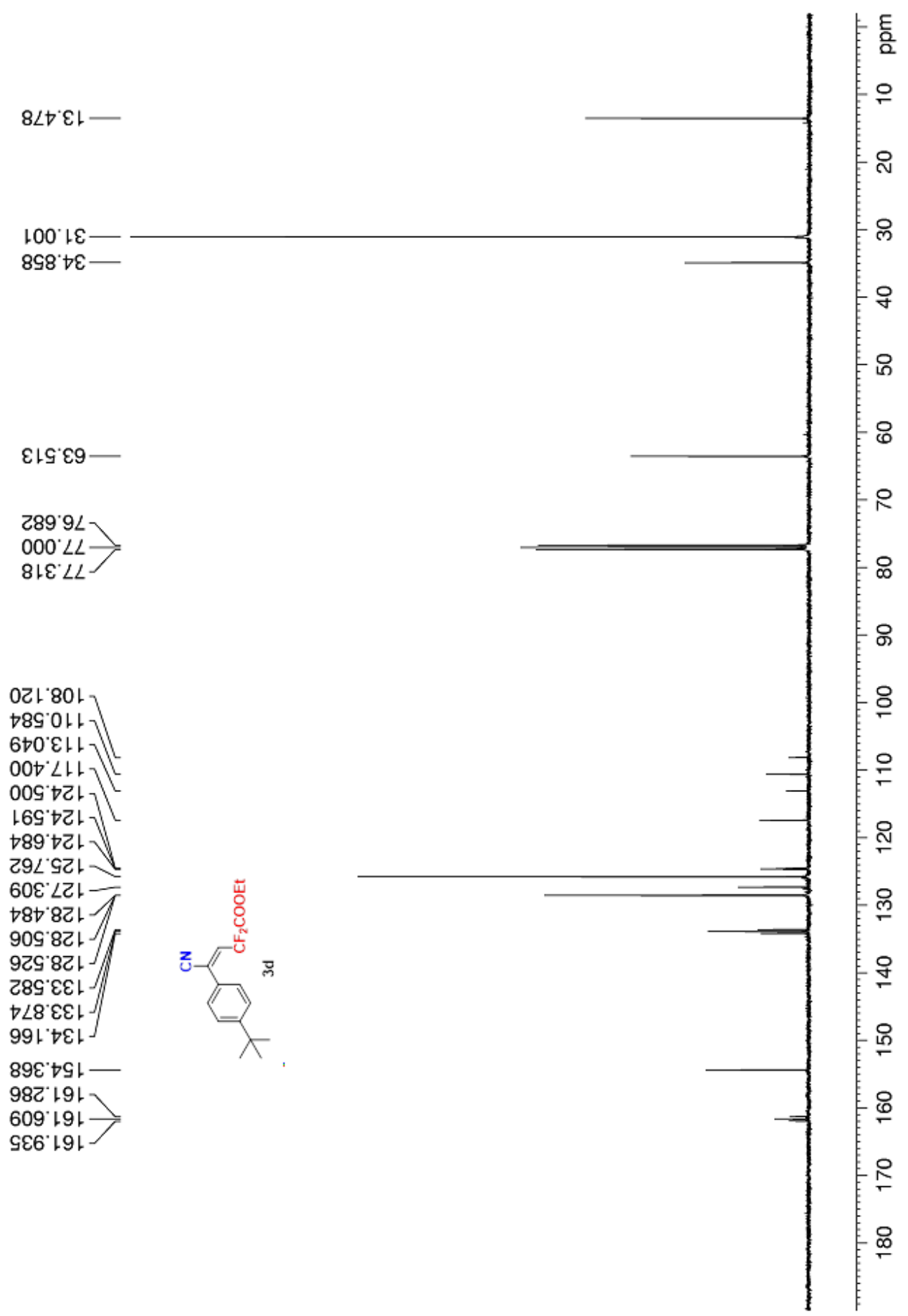




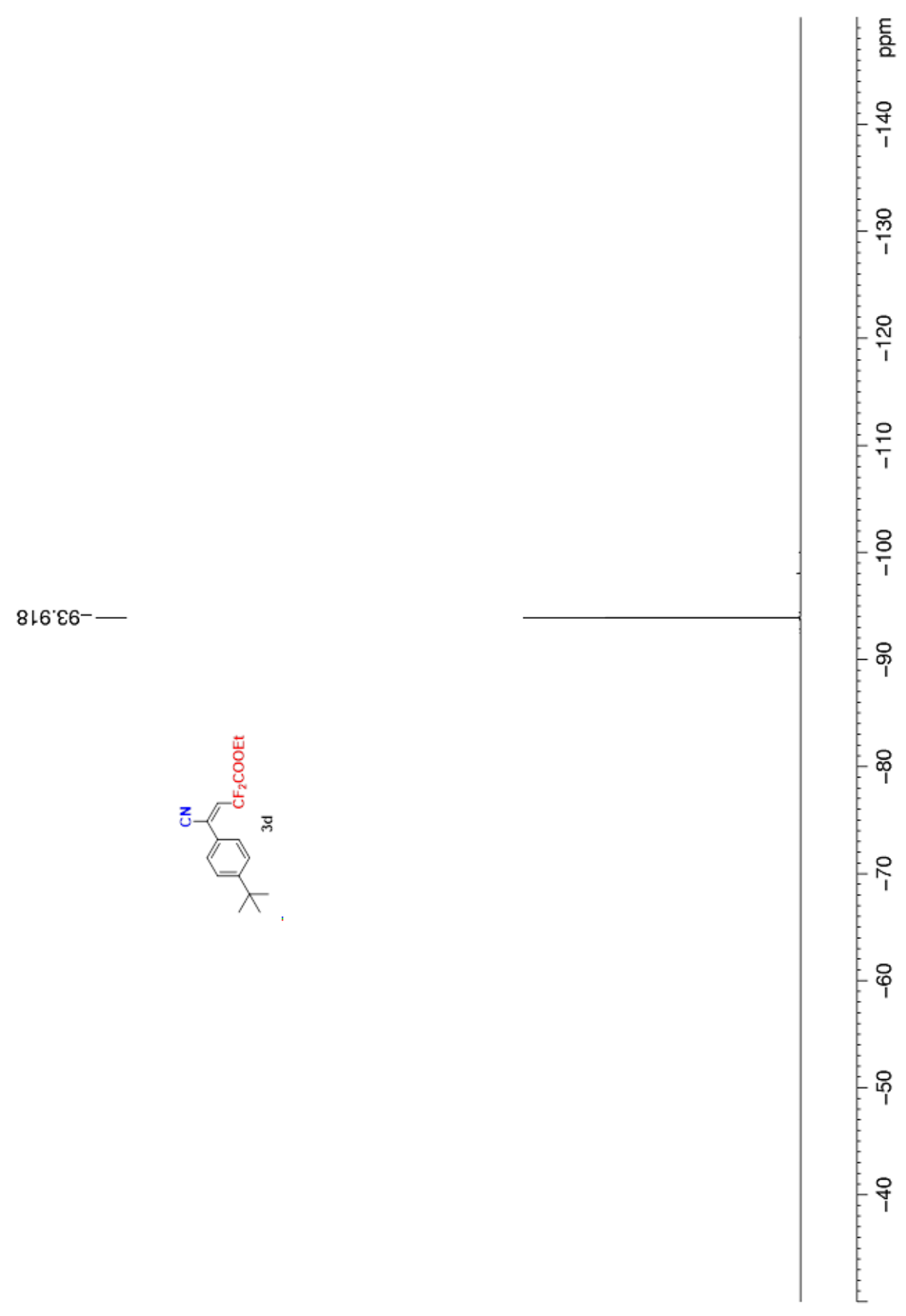



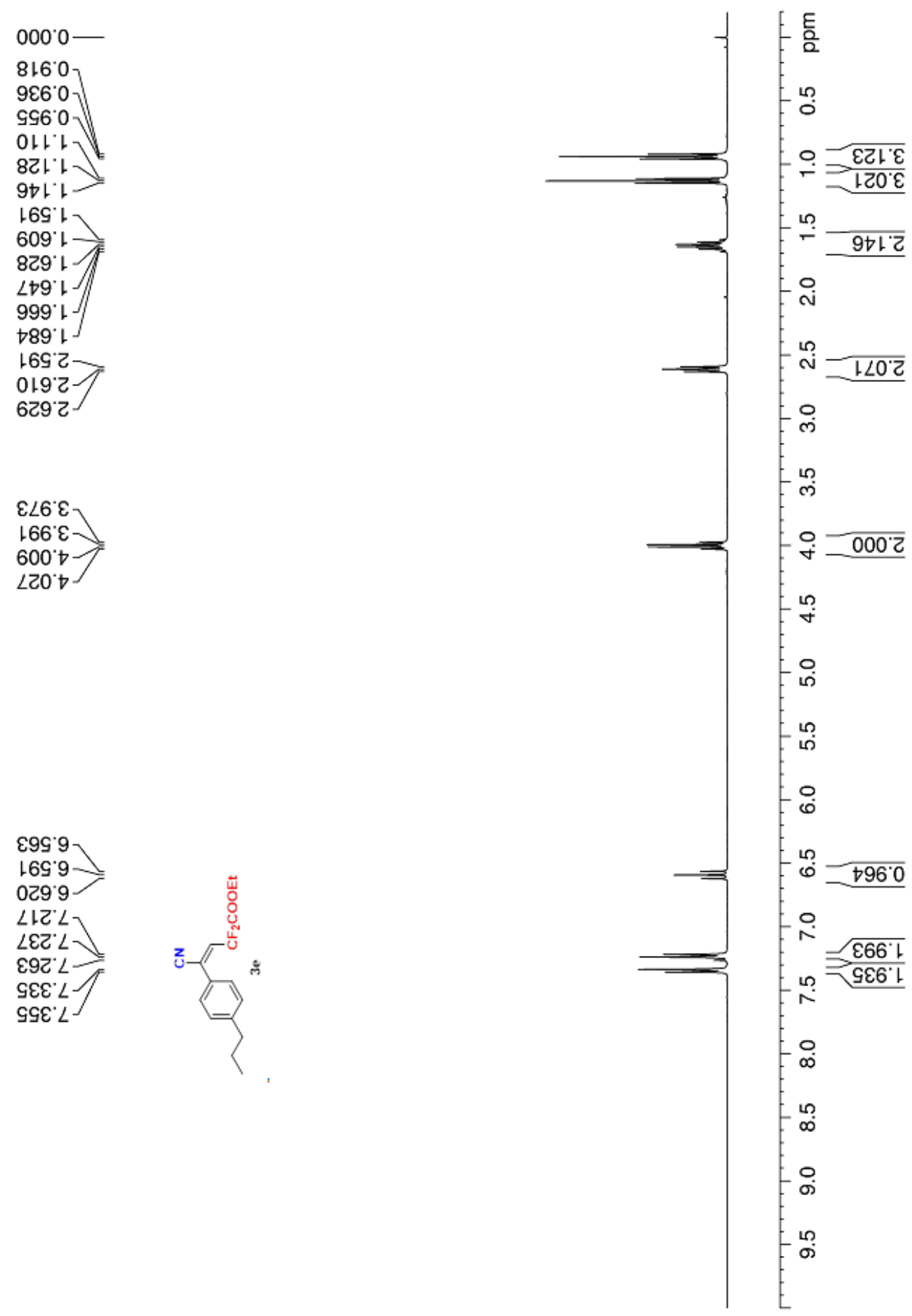
हटવ'६เ

ट†9' $\varepsilon$

$\angle O{ }^{\circ} \triangleright 乙-$

SIL LE -

†૮' \&9-

189.92

$000 \angle L$

$\angle L E^{\prime} \angle L$

$90+80$ เ

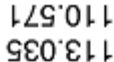

$\checkmark 2 t<L$

$\angle 8 G^{\circ} \sqcup Z$ L

$8 \angle 9^{\circ} \triangleright Z L$

$1 \angle L ' \square Z$ ।

9EG $\angle Z L$

टट9.8ट।

$\nabla 79.82$ เ

999.8Z

$088^{\circ} 8 \mathrm{Z}$ ।

$\angle 09^{\circ} \varepsilon \varepsilon$

668' $\varepsilon \varepsilon$ ।

$06 เ \cdot \nabla \varepsilon+$

S00 $9 \mathrm{tl}$

8Gट เ9เ

G89' เ9।

606 . 9 ।

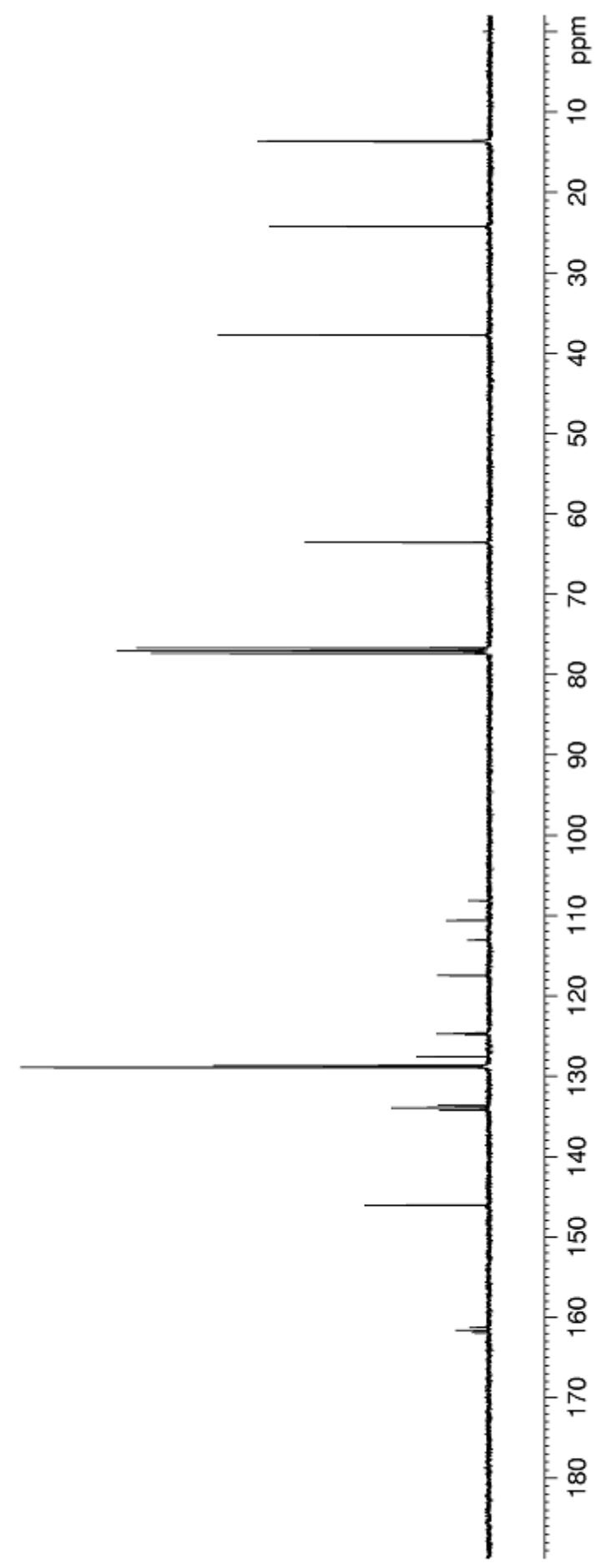




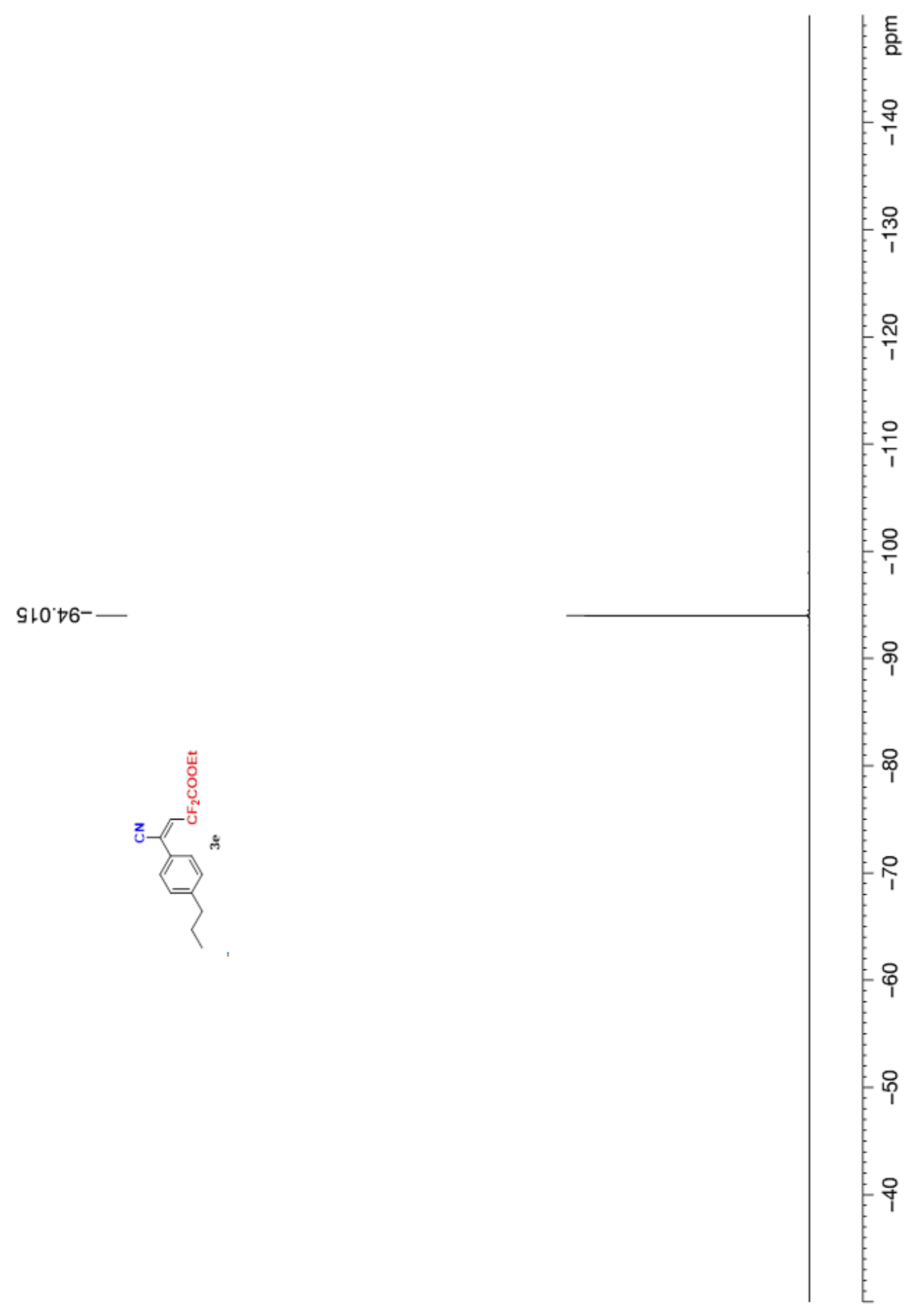



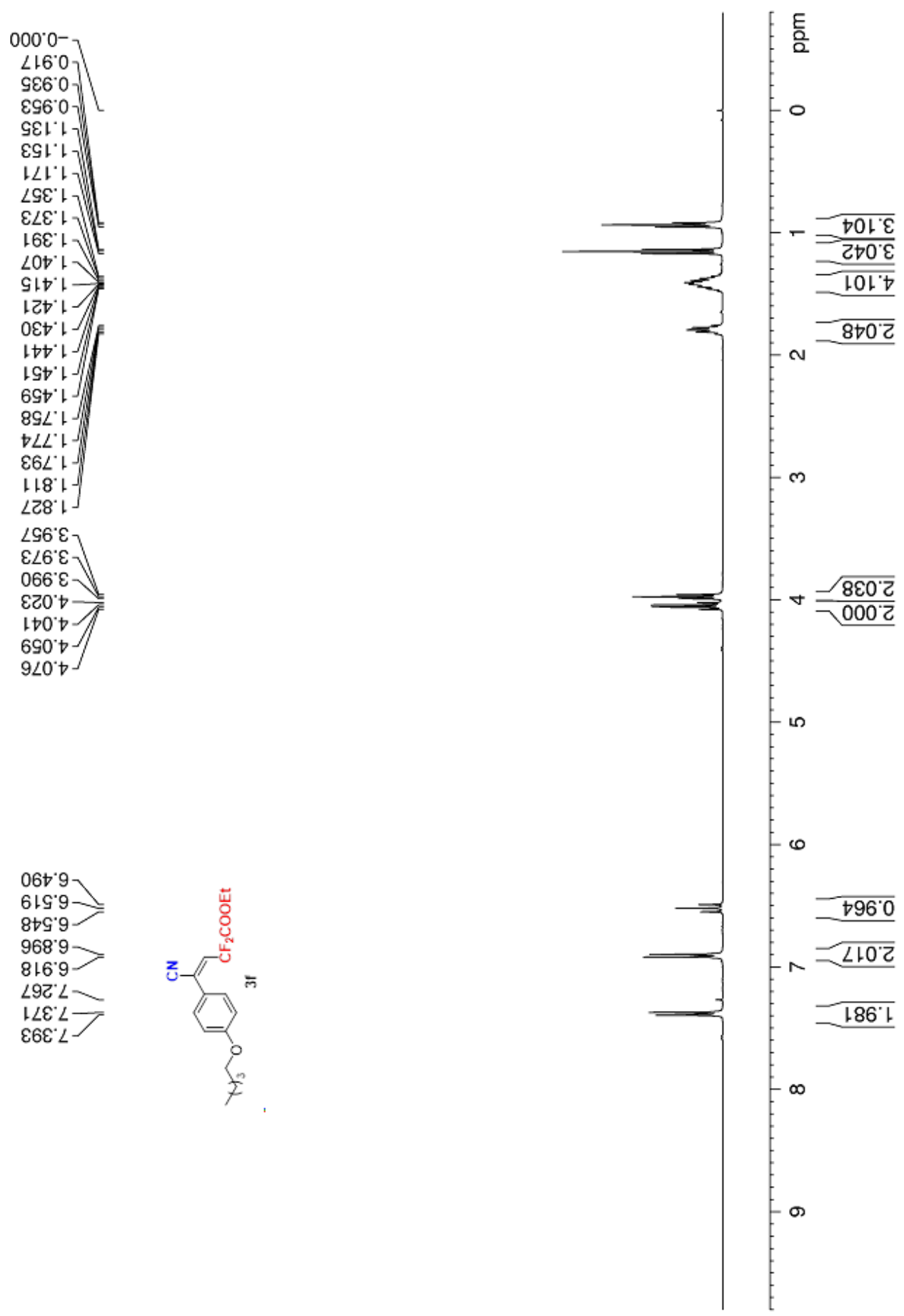

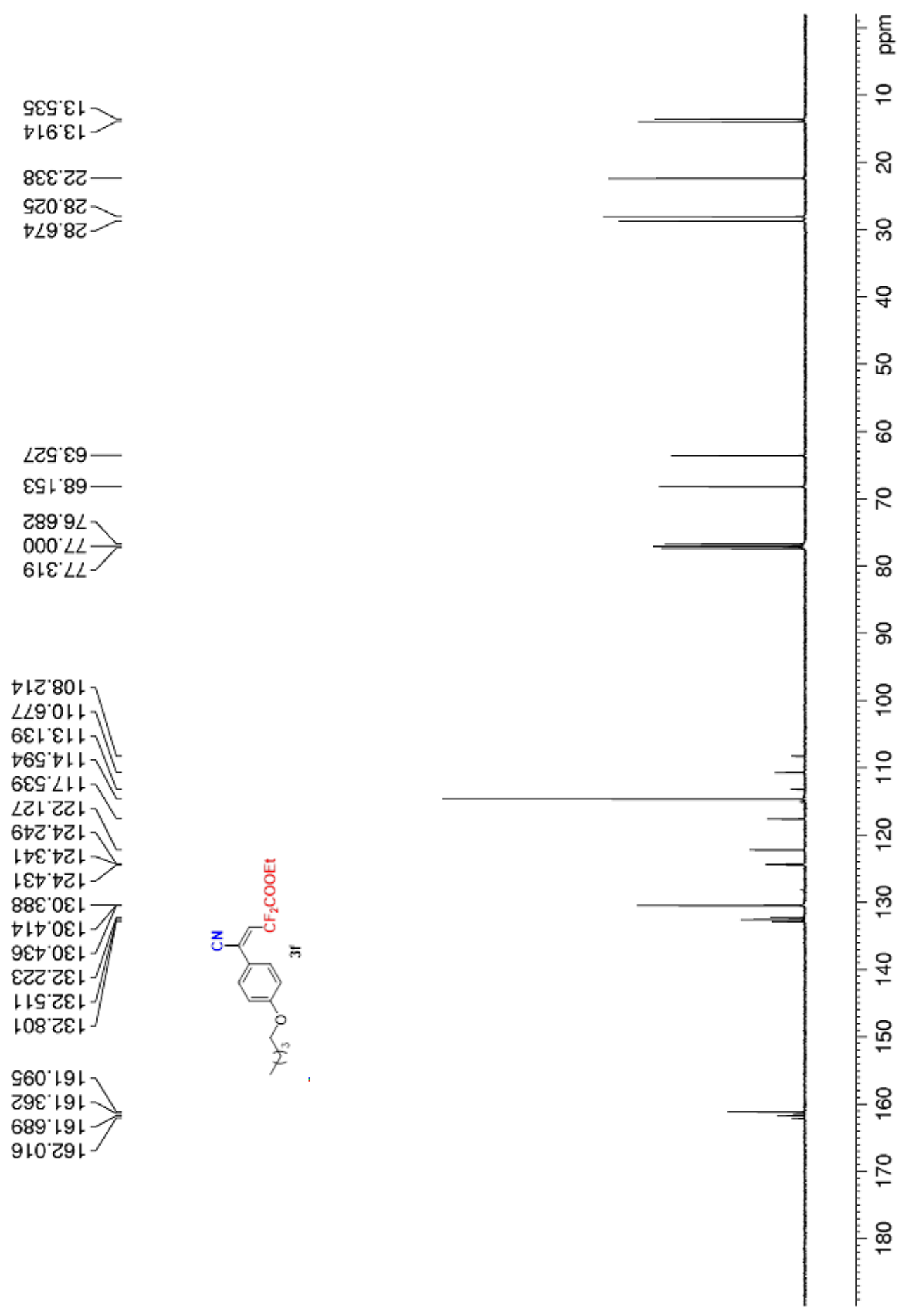
$270^{\circ} \triangleright 6^{-}$

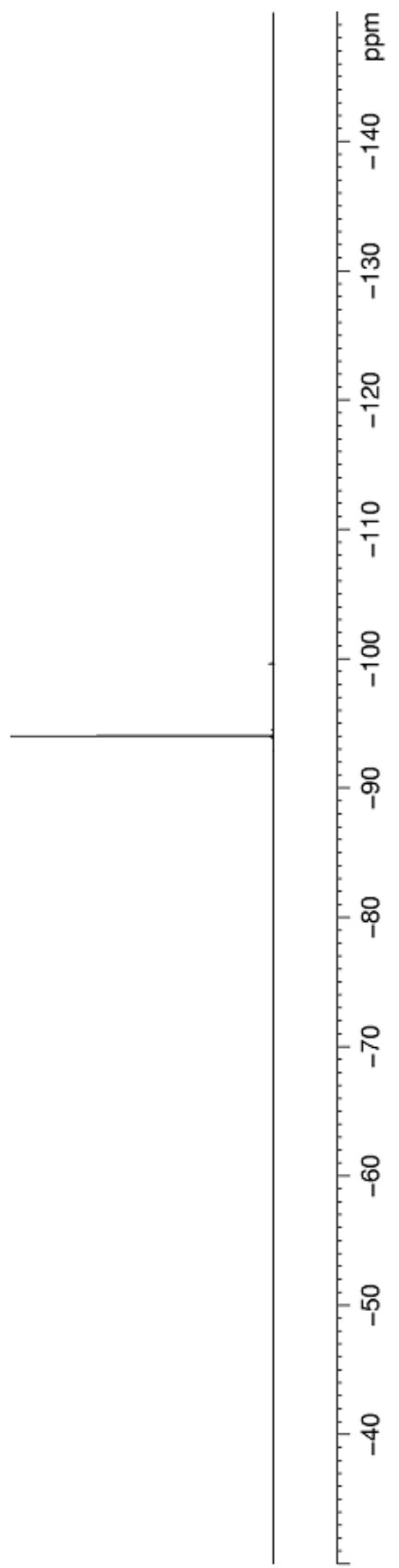




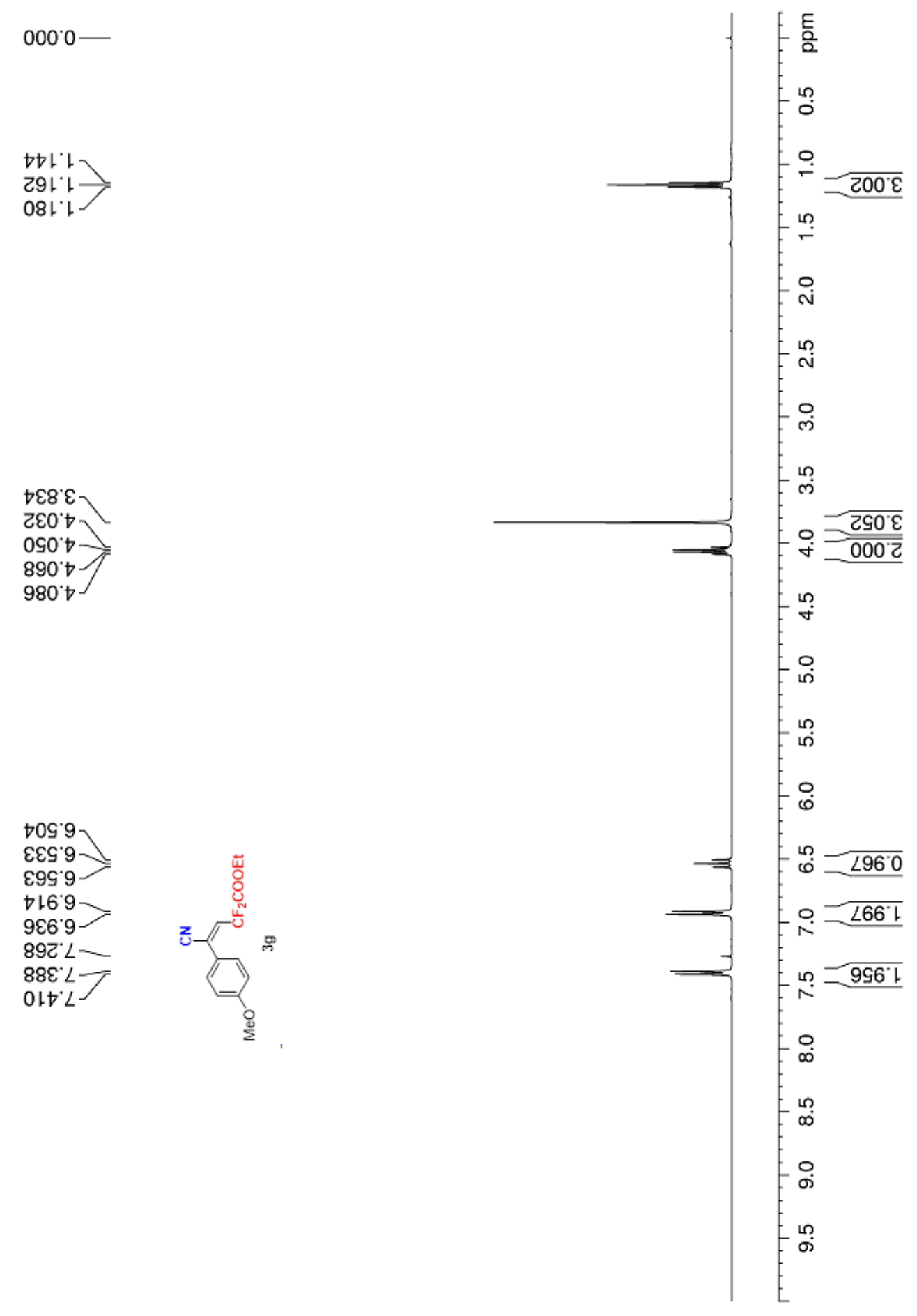


$299^{\circ} \varepsilon$
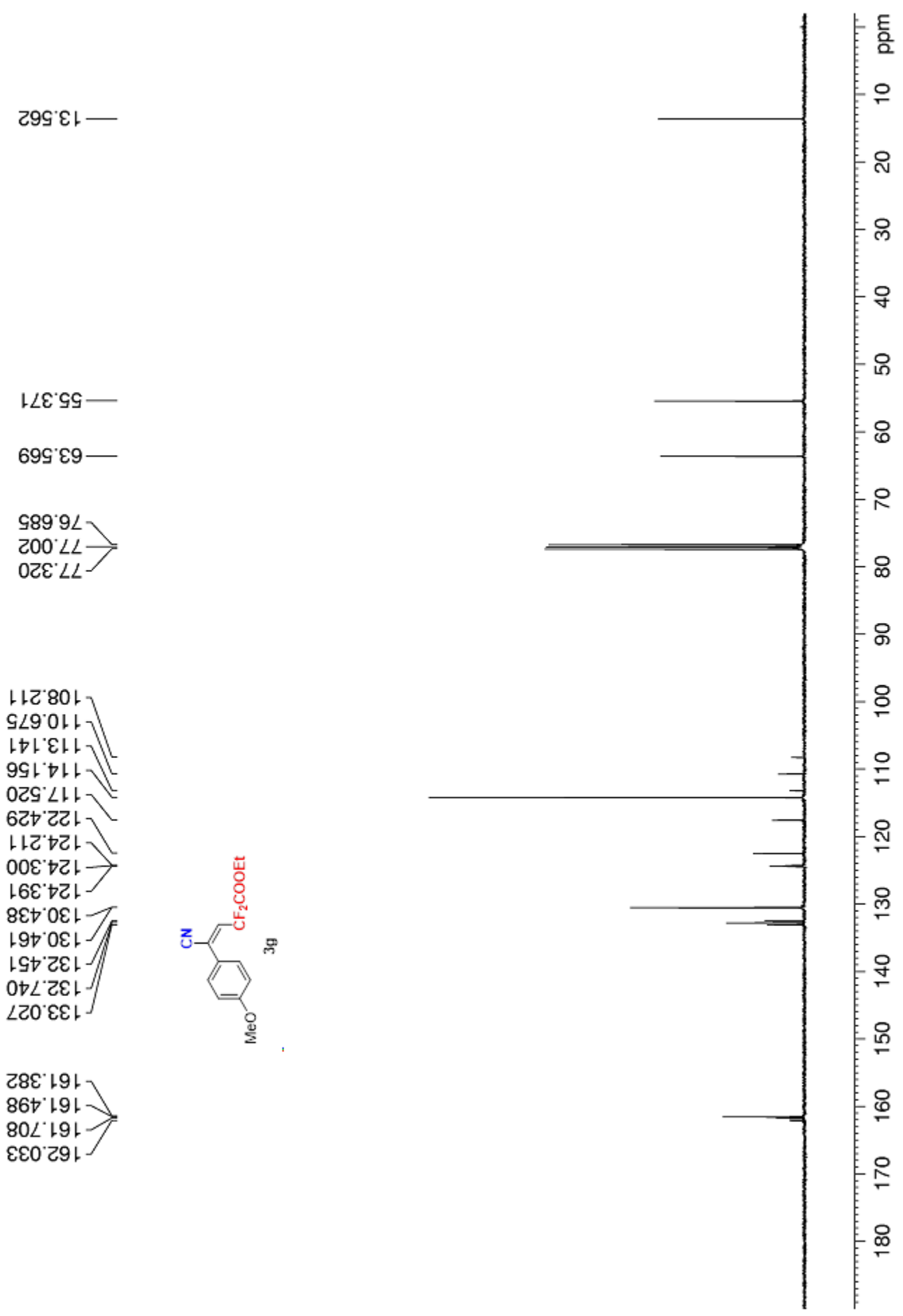


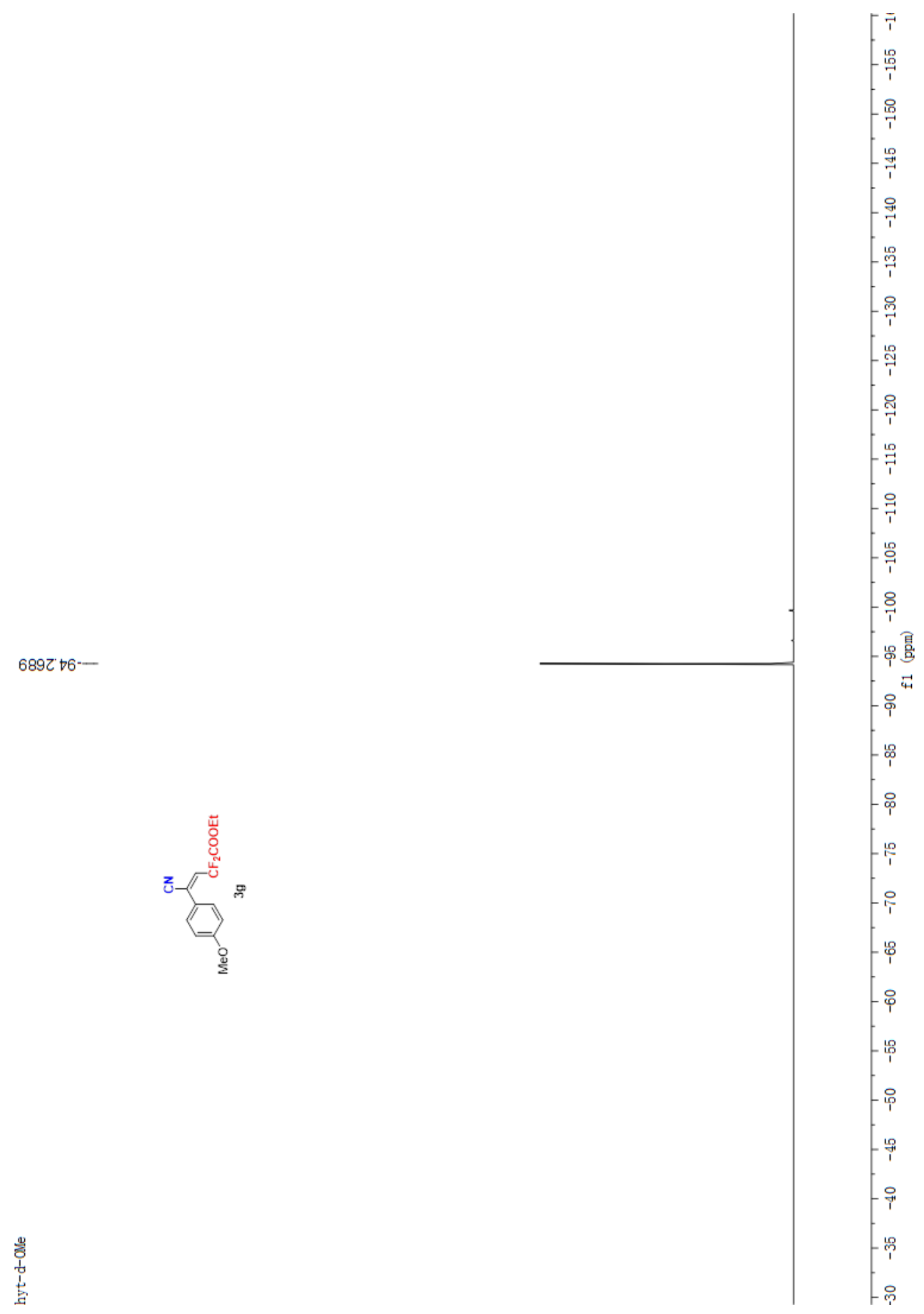




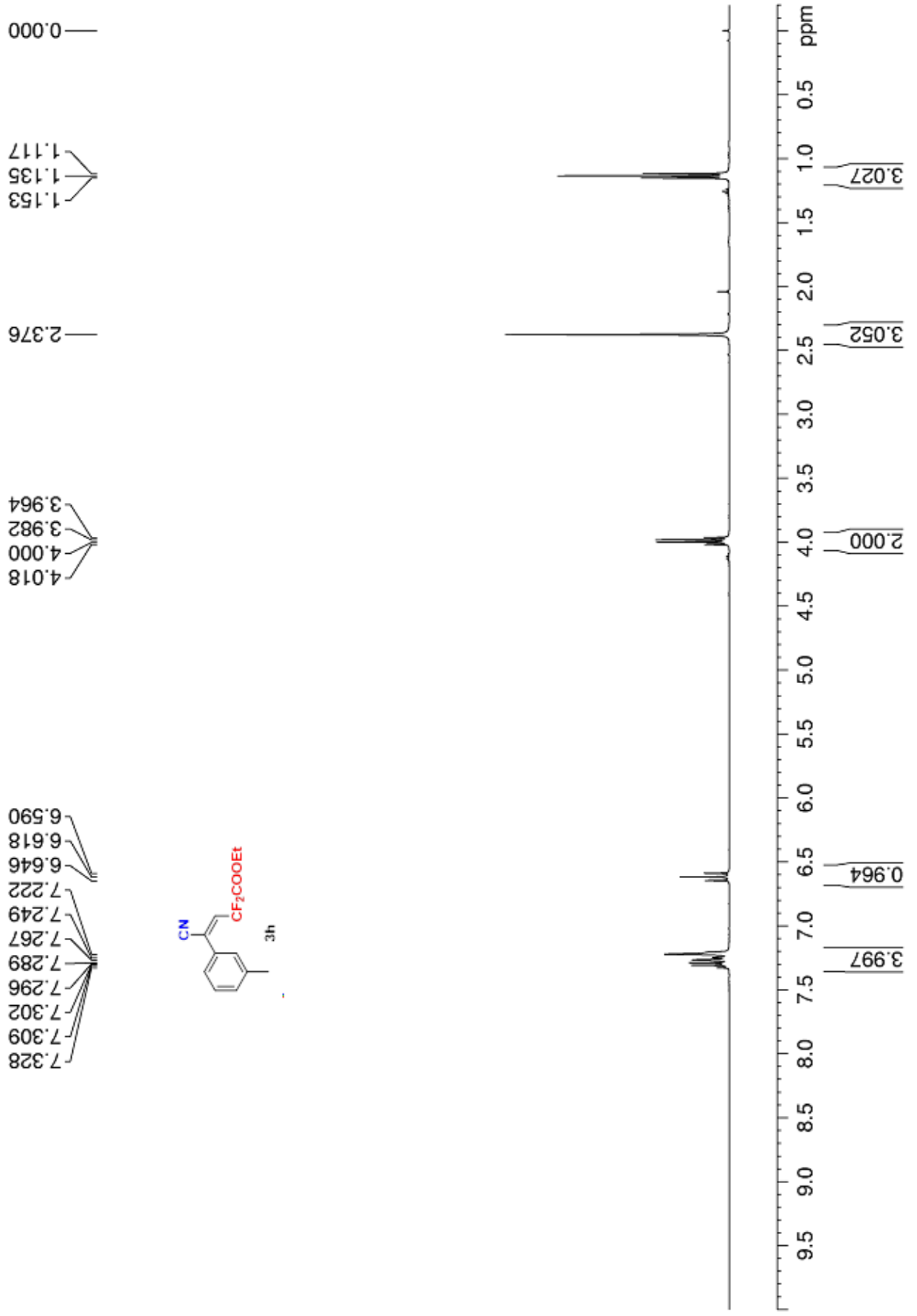


98t $\varepsilon+$

$68 เ レ 2$

टว9'

289' $9 L$

$000^{\circ} \angle L$

$81 \varepsilon^{\prime} L L$

เE0 80 เ

96t아

296'나

26Z $\angle 1$ L

$669^{\circ} \sqcup \mathrm{D}$

Z69' $\downarrow$ ट

$98 \angle \supset Z L$

OZL $\mathrm{GL}$

889.8Z

$\angle 1 \cdot 621$

S90'0ह -

$6 \angle t^{\circ}\llcorner\varepsilon\llcorner/$

$6 乙 Z \downarrow \varepsilon \downarrow$.

LCG' $\downarrow \varepsilon \mid-$

$\varepsilon เ 8^{\prime} \downarrow \varepsilon เ$

$6 G L \cdot 8 \varepsilon\llcorner$

SLL'아

66t. เ91

๕ट8 เ9เ

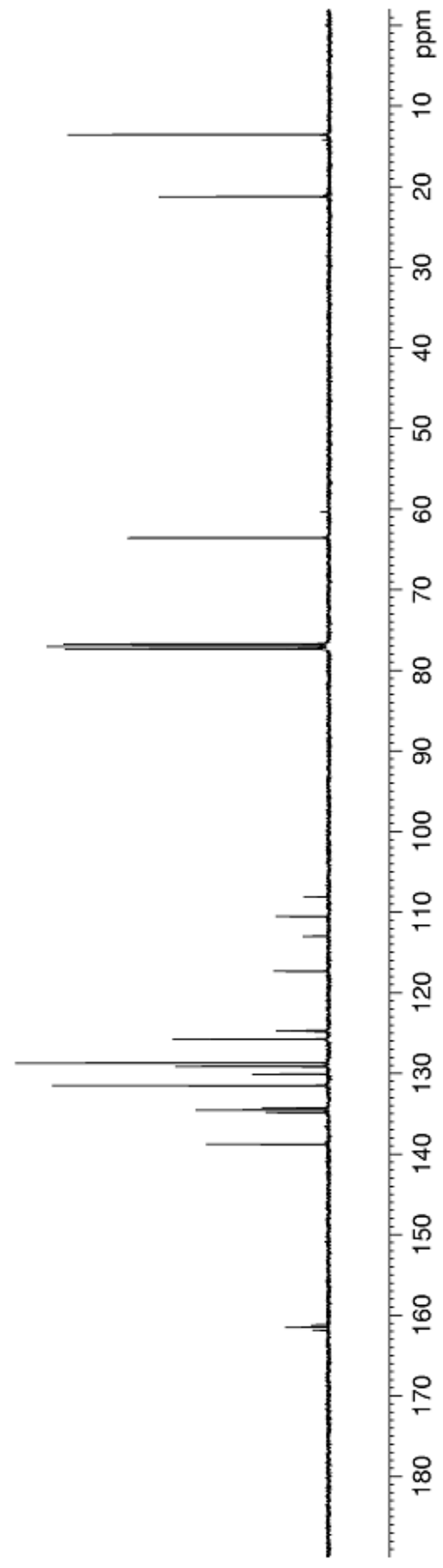




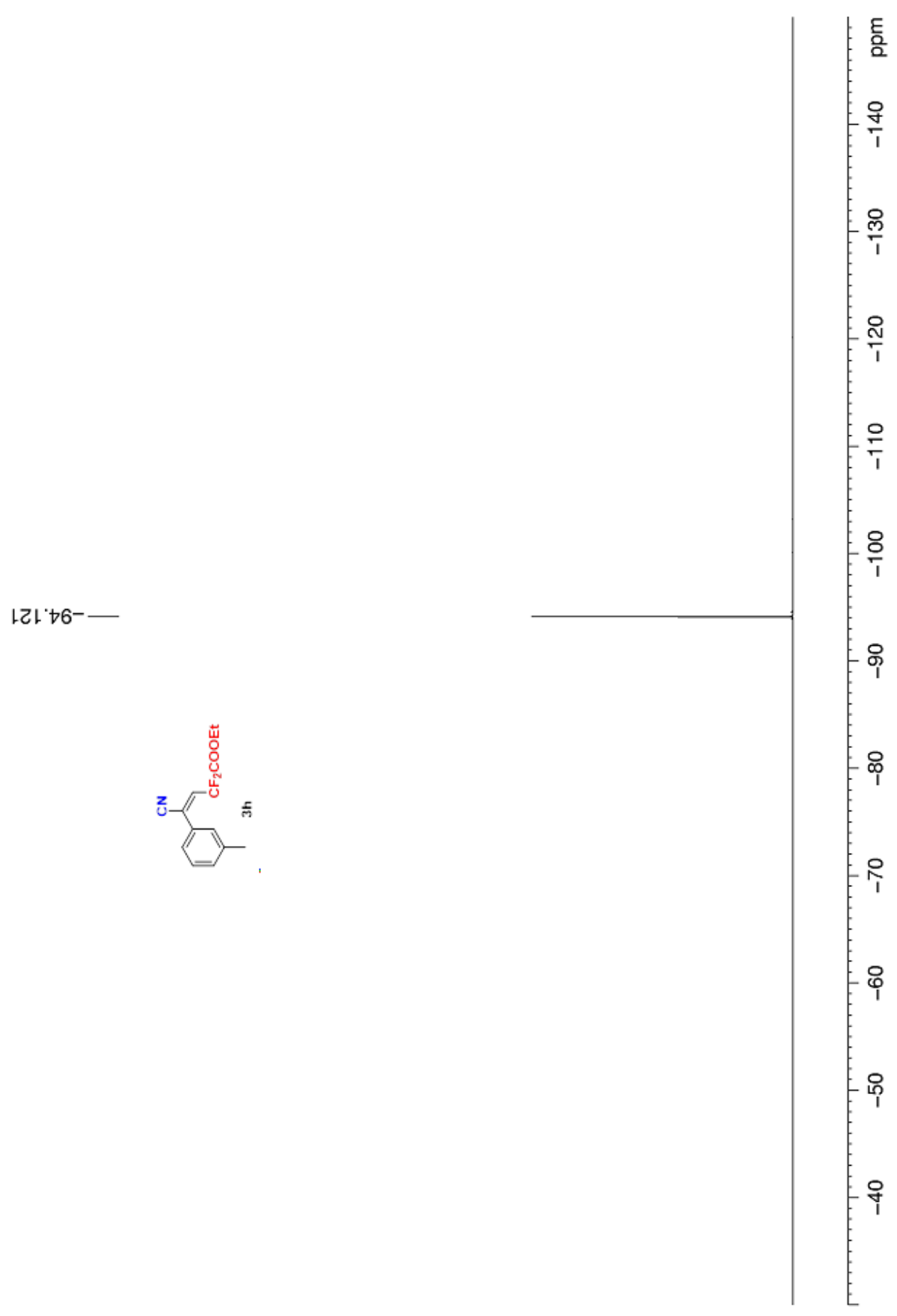




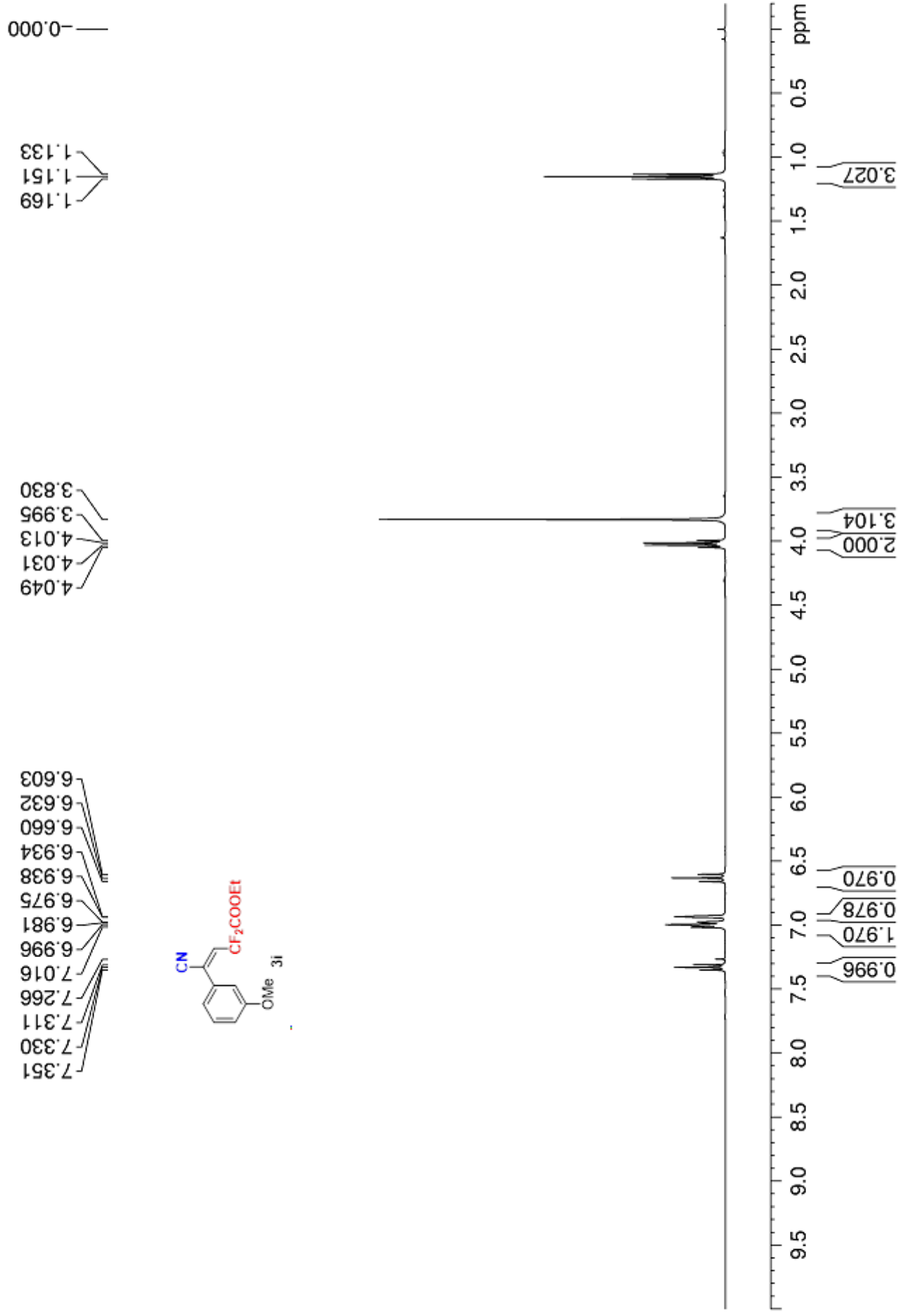


$60 \mathcal{S}^{\prime} \varepsilon \vdash$

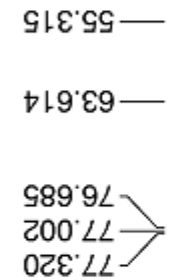

$620.80 \mathrm{~L}$

9670 나

296'2।

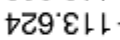

$\angle 86^{\circ} 91 /$

$8 \varepsilon+\angle K L-1$

$978^{\circ} 0 \mathrm{~L}$

$\angle S E \circ Z$ -

OSャ'七ट।

เG6 $6 \mathrm{~L}$ -

$\downarrow \succ G^{\prime} \downarrow \varepsilon \downarrow$

$8 \varepsilon 8$ ' $\downarrow \varepsilon \vdash$

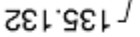

$6 \angle \mathcal{G}^{\circ} 6 \mathrm{G}$.

$\angle L+191$

$66+191\}$

EZ8' เ9.

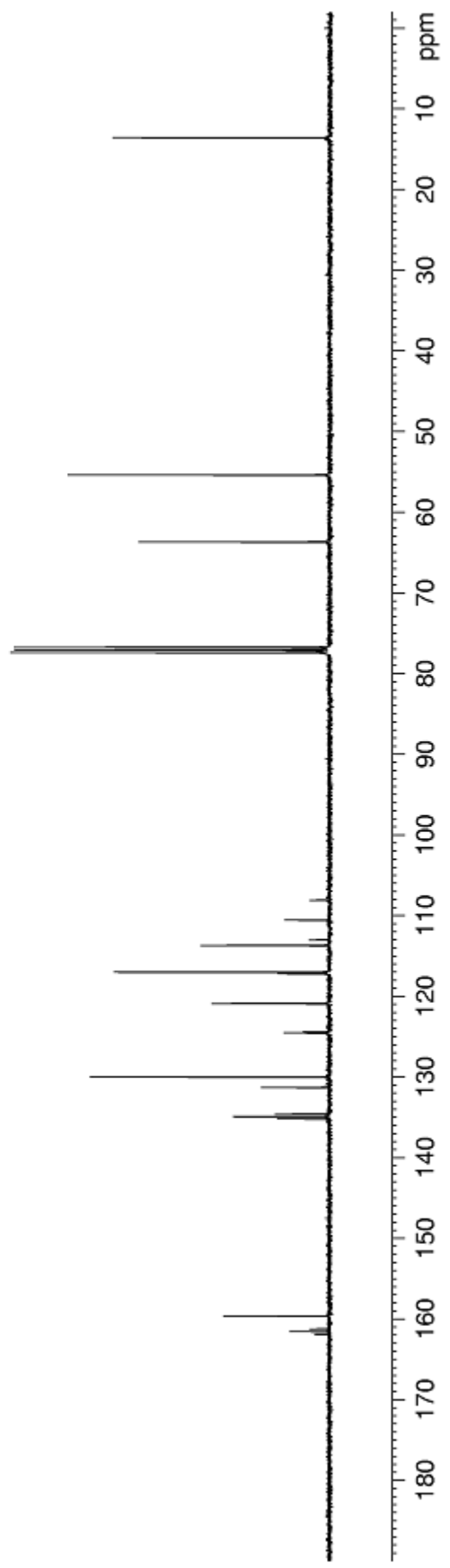




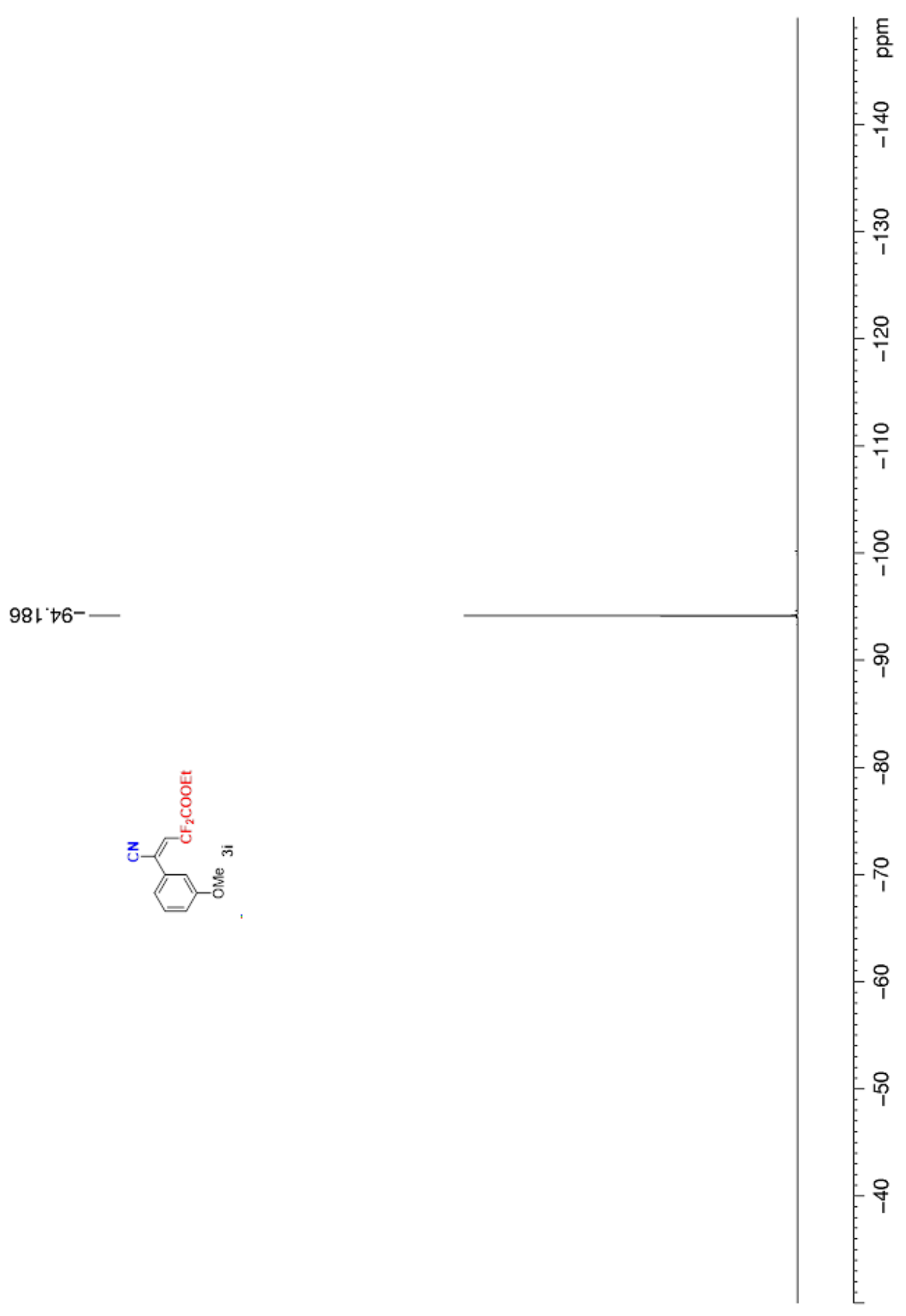




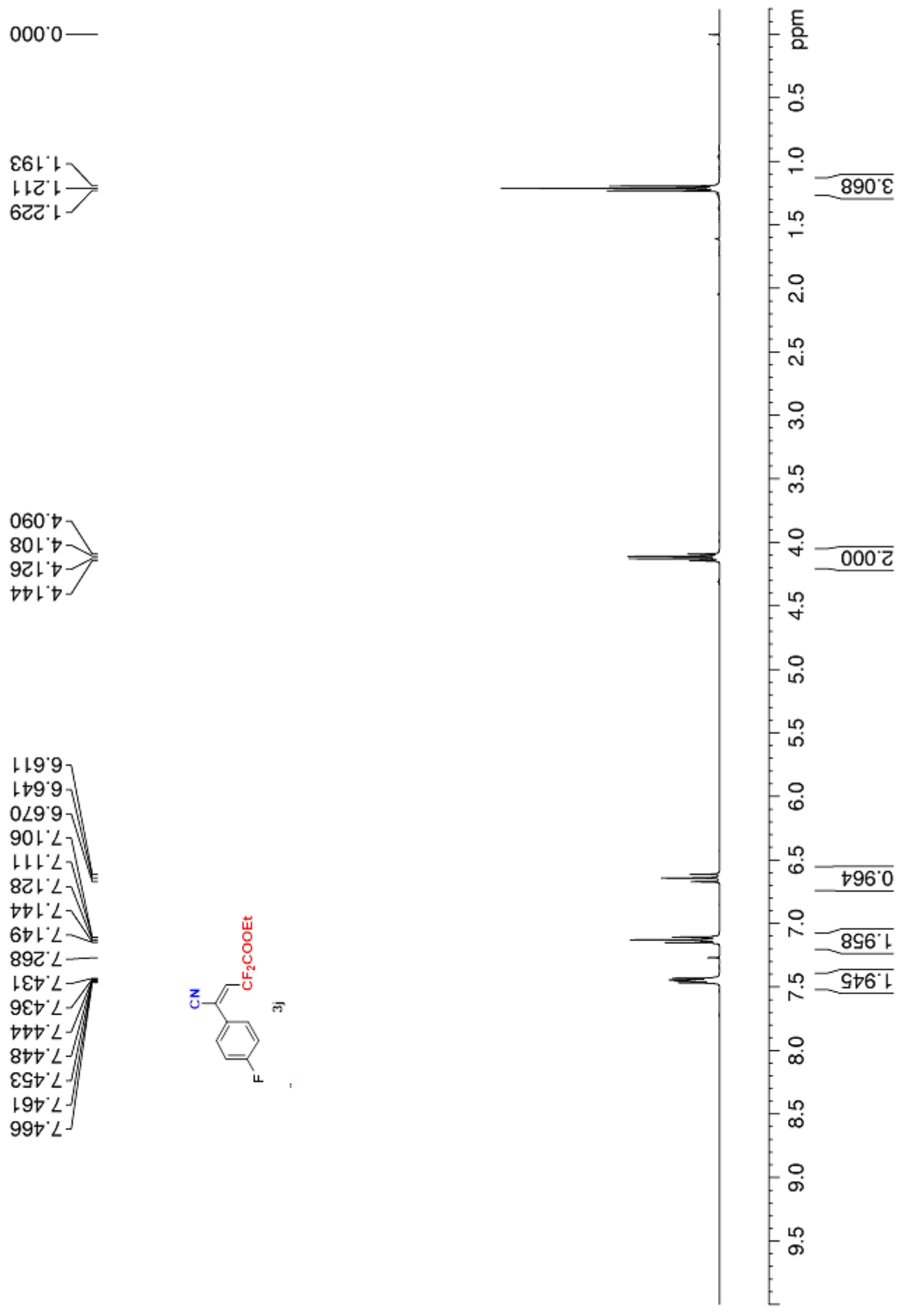




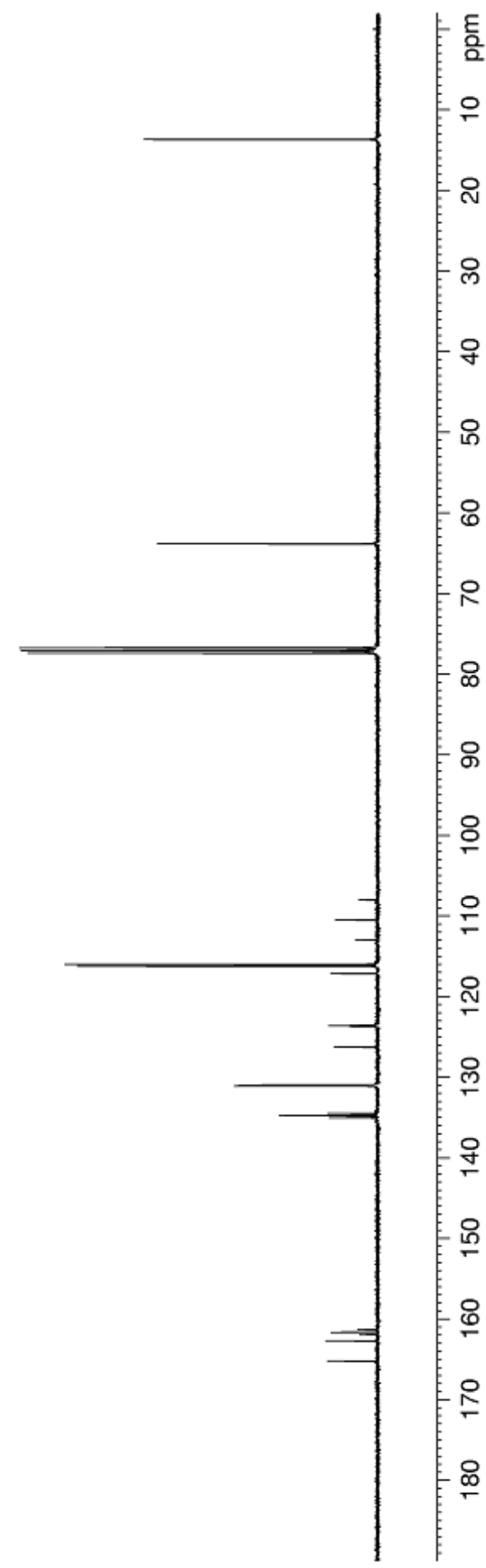




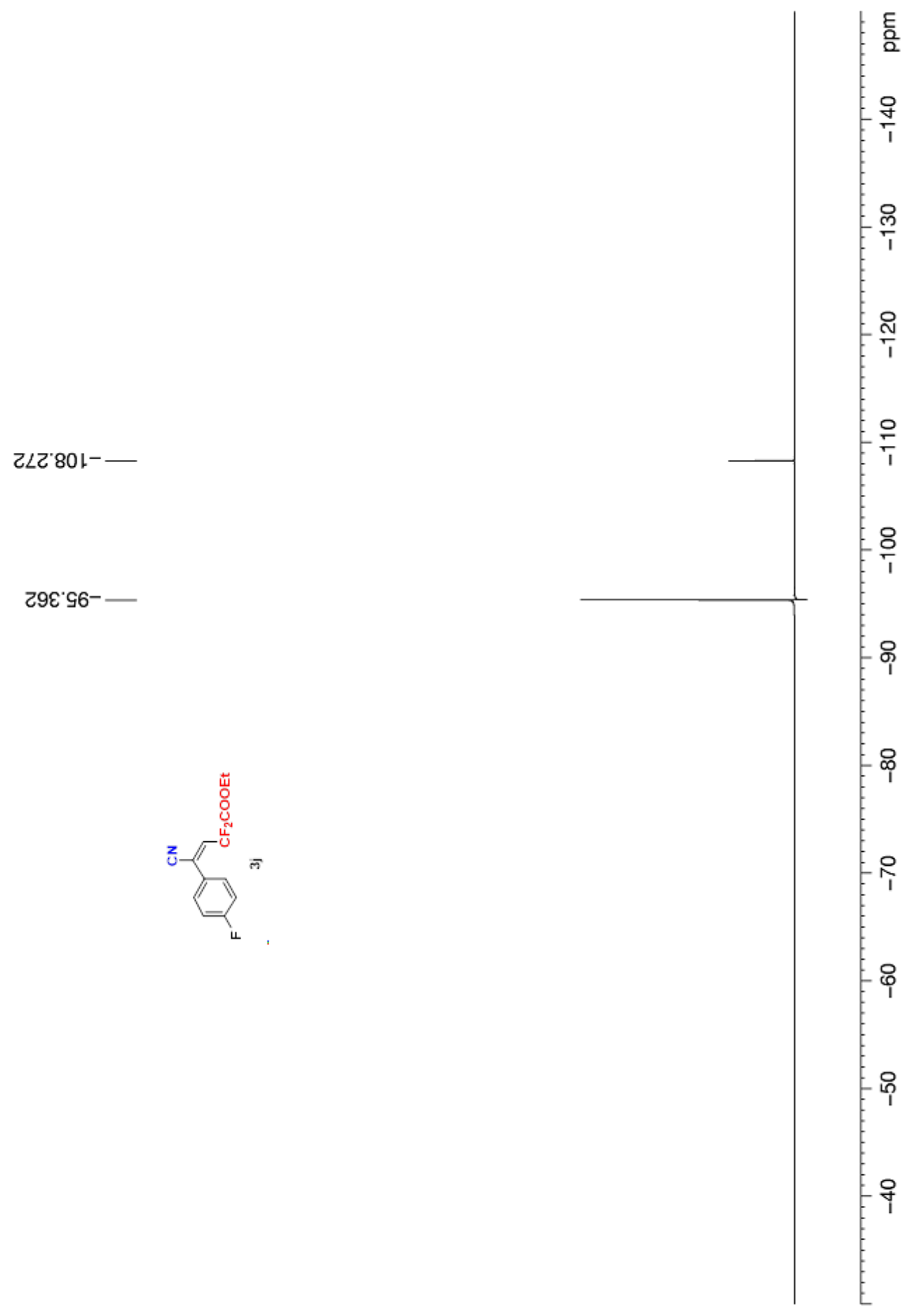

S40 


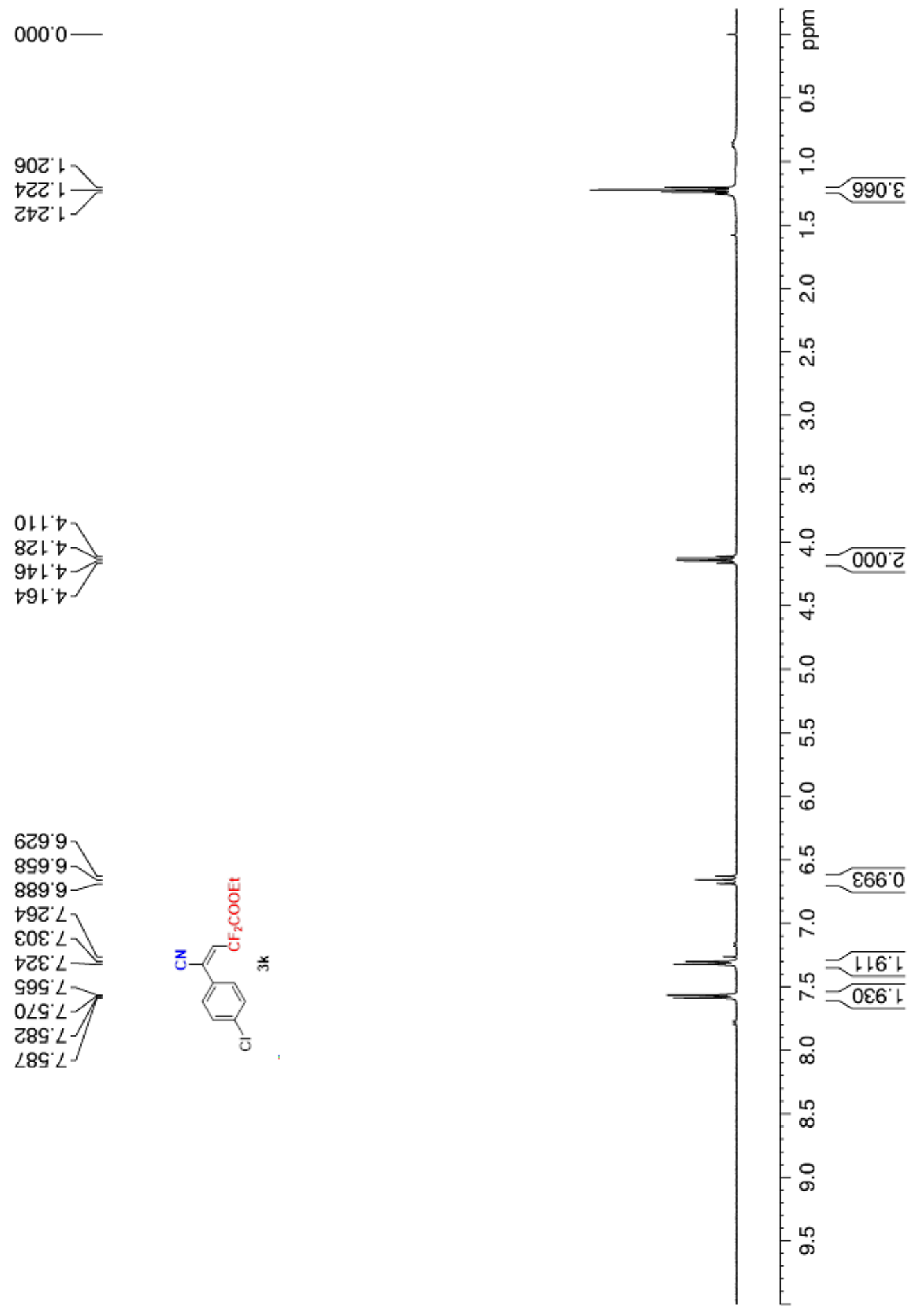


$089^{\circ} 9 L$

$666^{\circ} 9 L$

$91 \varepsilon^{\prime} L L$
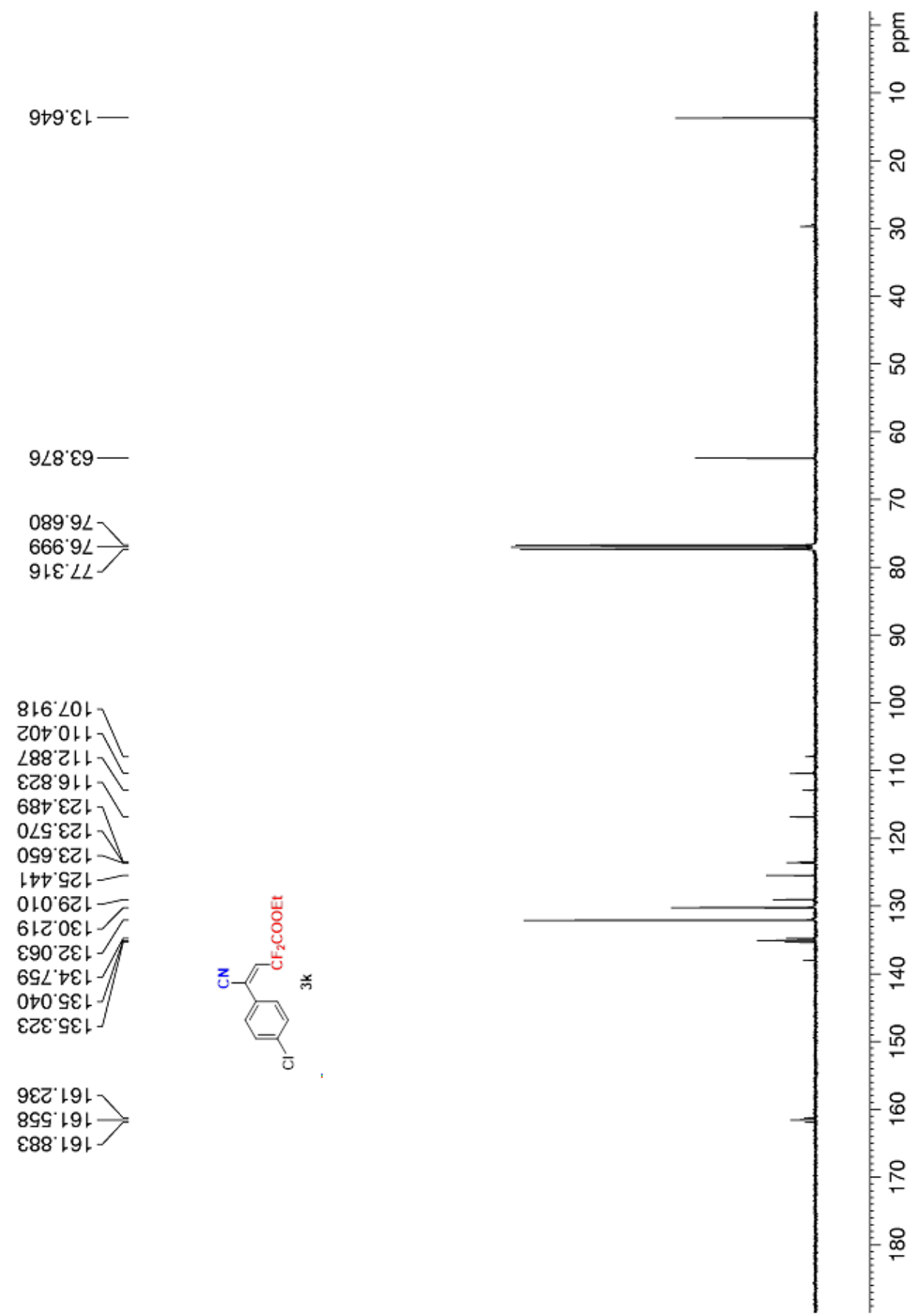

9๕ट เ9เ

89S'เ91

E88' เ9।

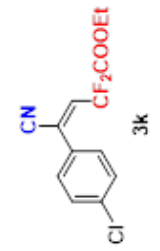

ㅇ

옴

$\stackrel{8}{\circ}$

옹

$\stackrel{\infty}{\circ}$ 


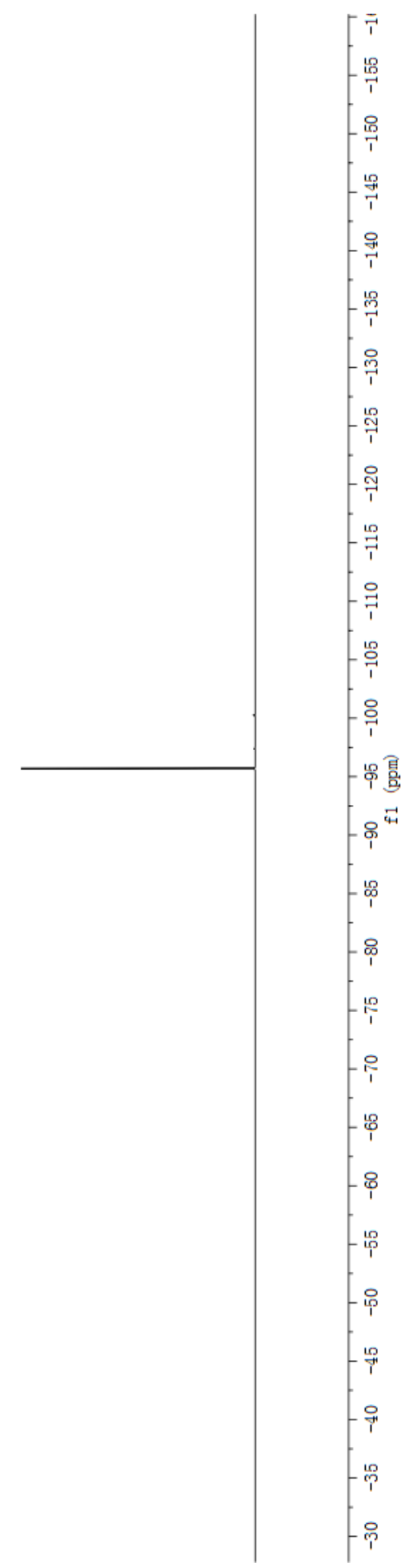




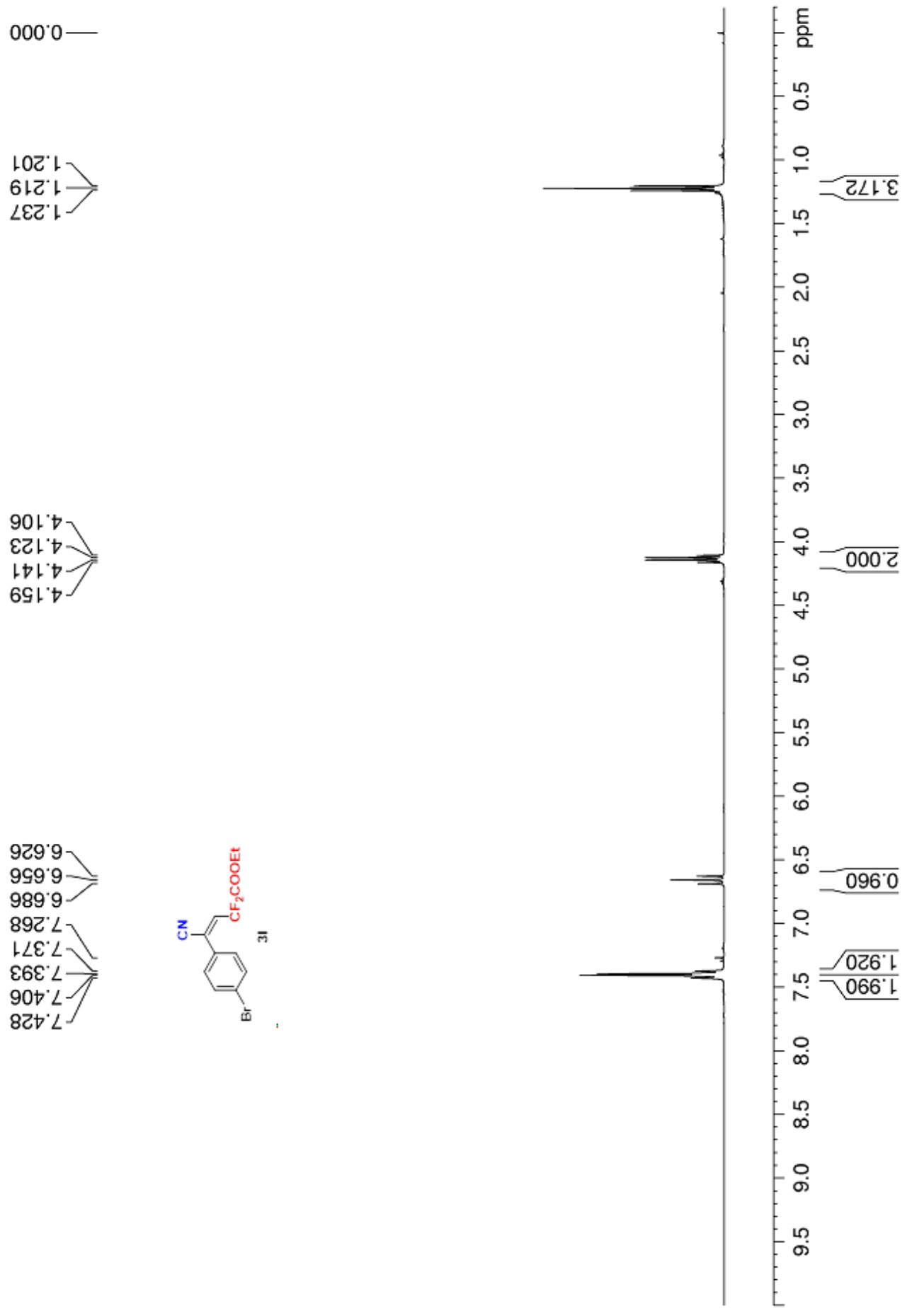




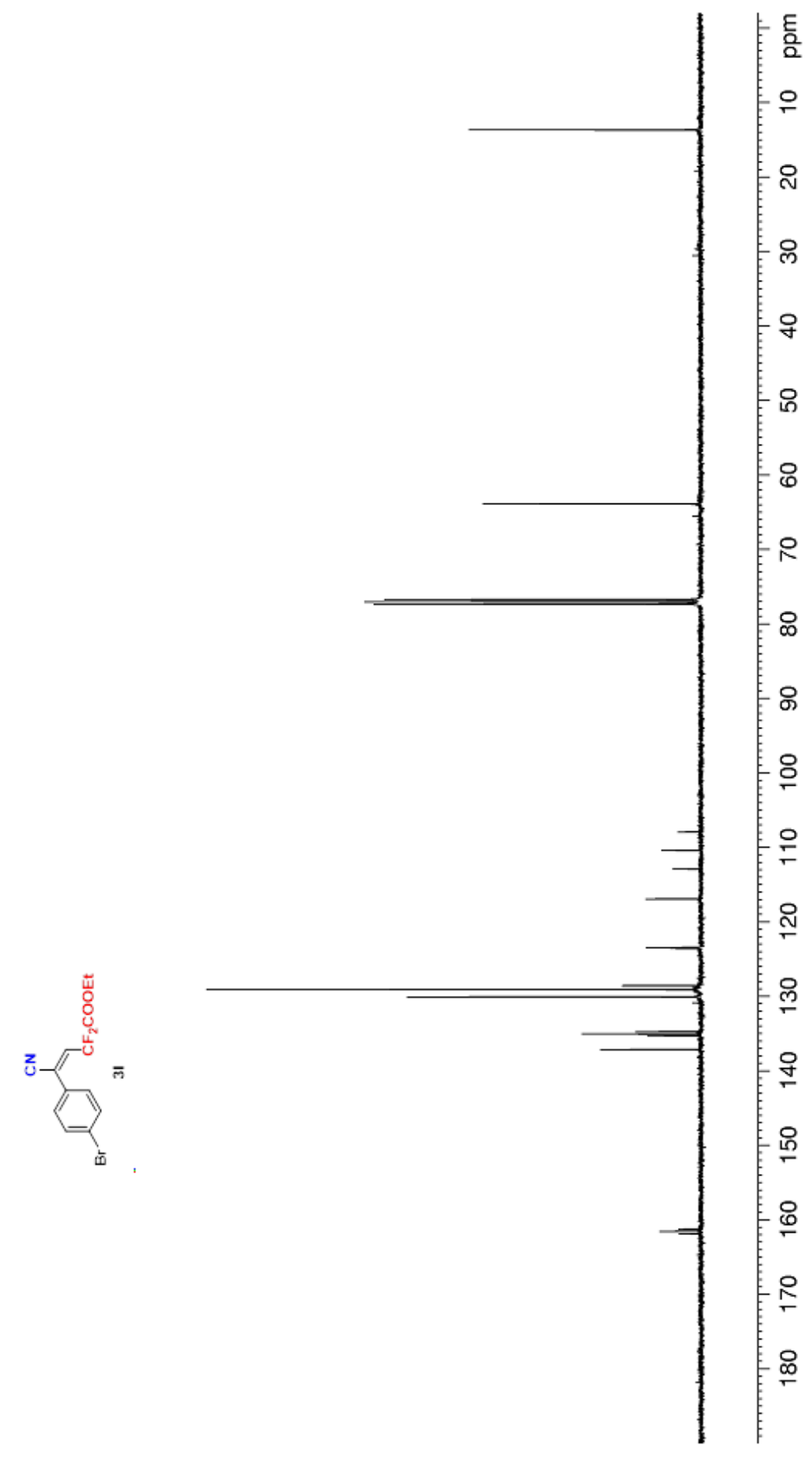

$806^{\circ} \mathrm{LOL}$

068'아

$\angle 68^{\circ} 9$ 1 .

เO॰ $\varepsilon 己$ เ

ย8॰ घट।

†9G' $\mathcal{L}$ ।

เEG 82 L

$1 \angle 062$.

8200 เ

ᄂSO'0E L

$\neg \angle 0.0$ \&

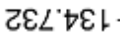

G। $0^{\circ} \mathrm{L} \mathrm{L}$

$\angle 6 Z \subseteq \varepsilon$

Sトเ'LE -

LCZ เ91

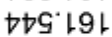


$18 \angle 99^{\circ-}$

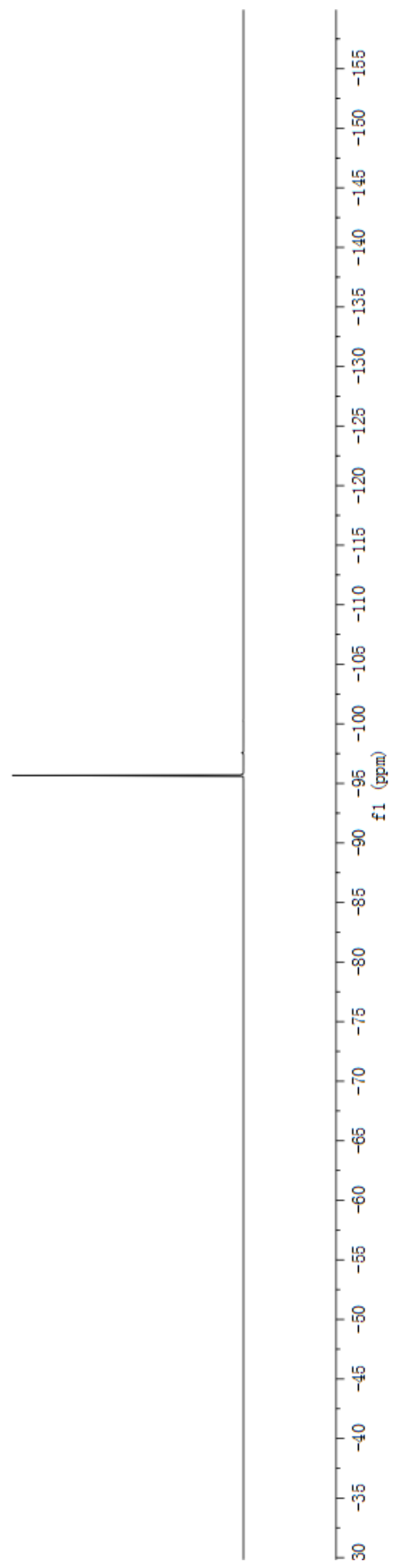




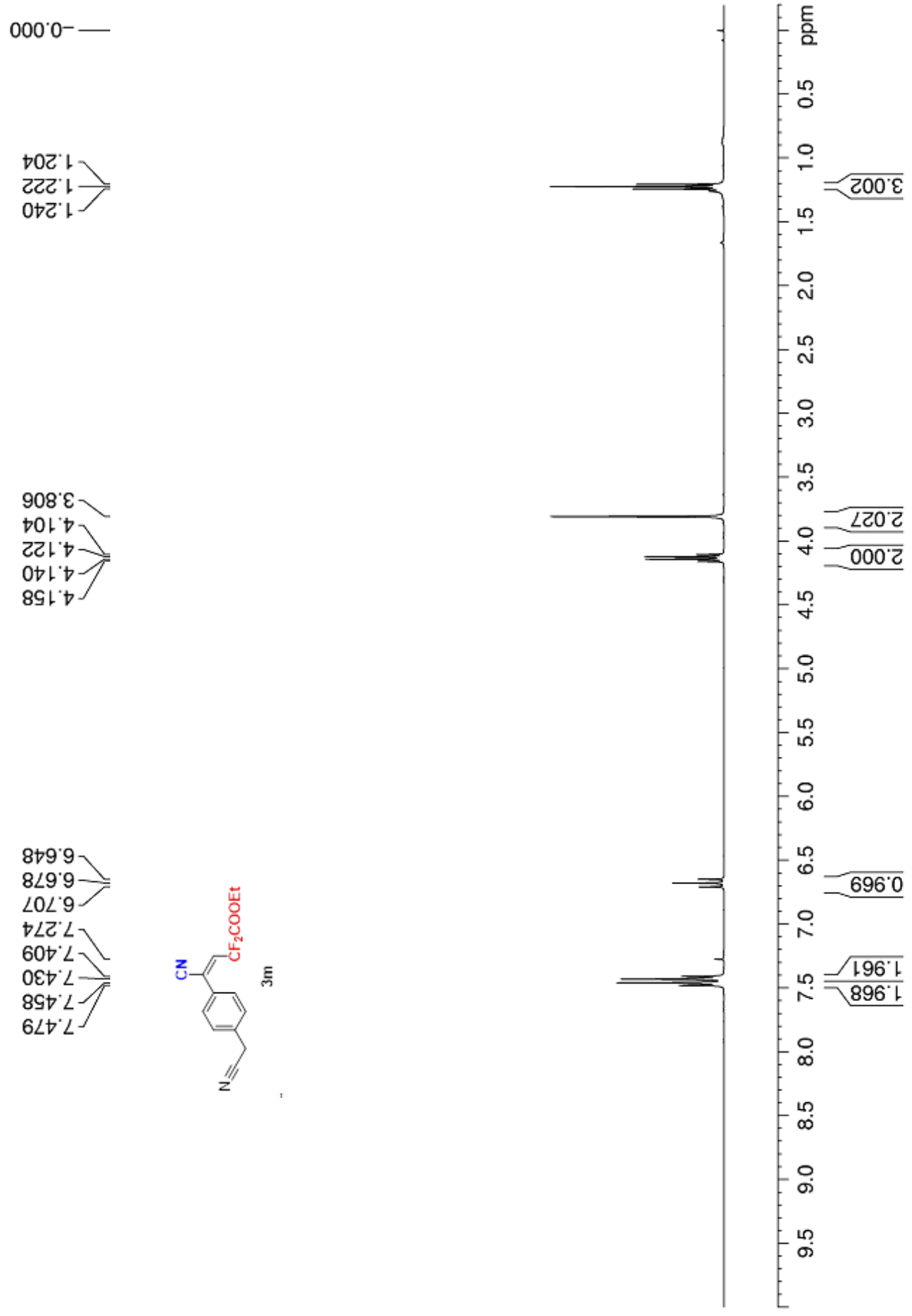




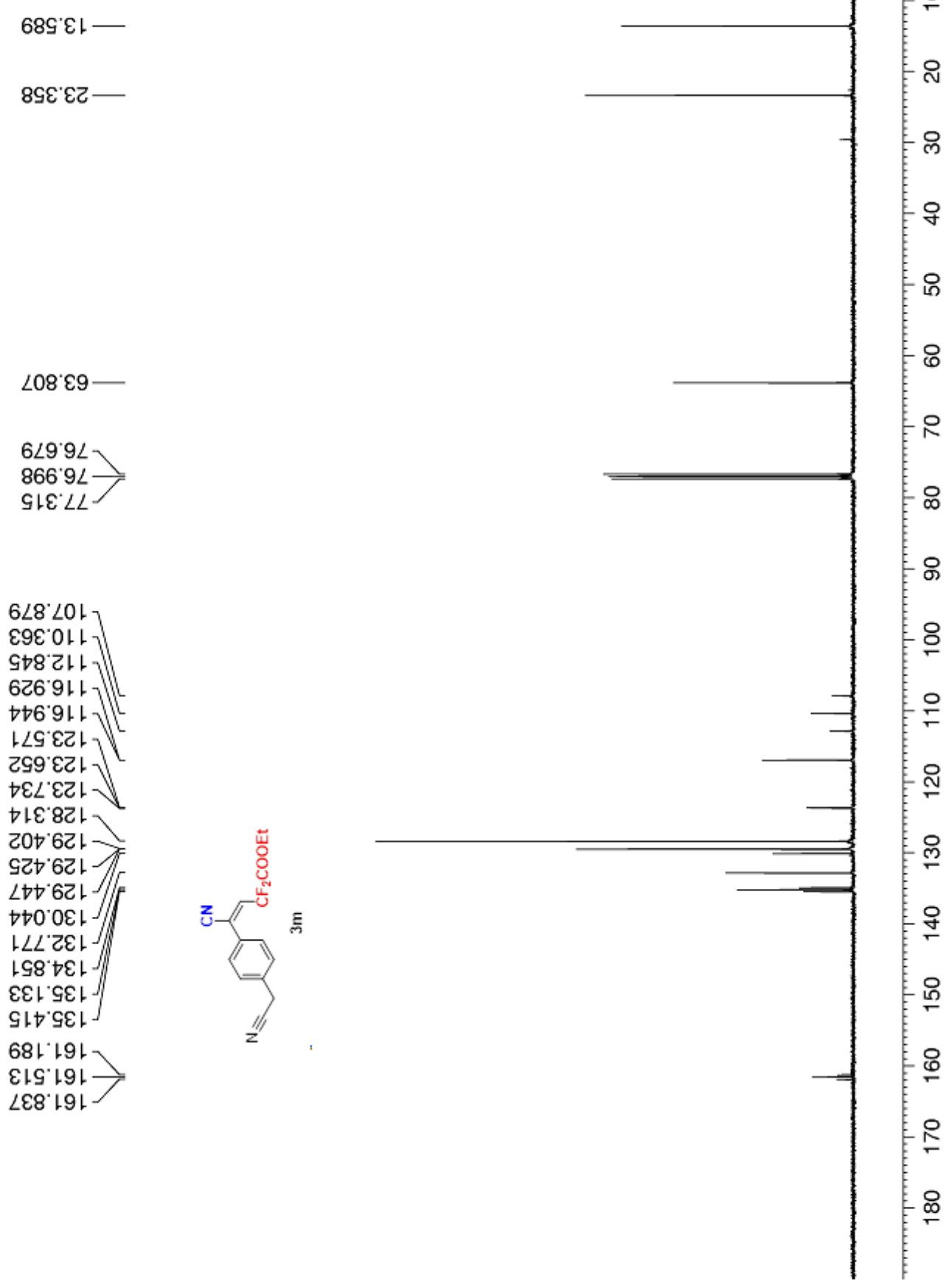




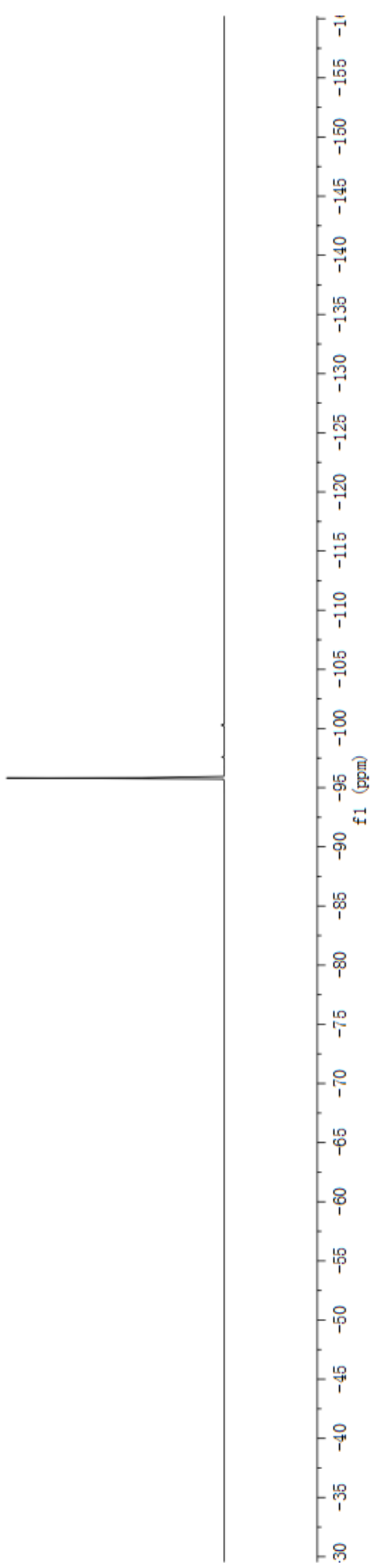




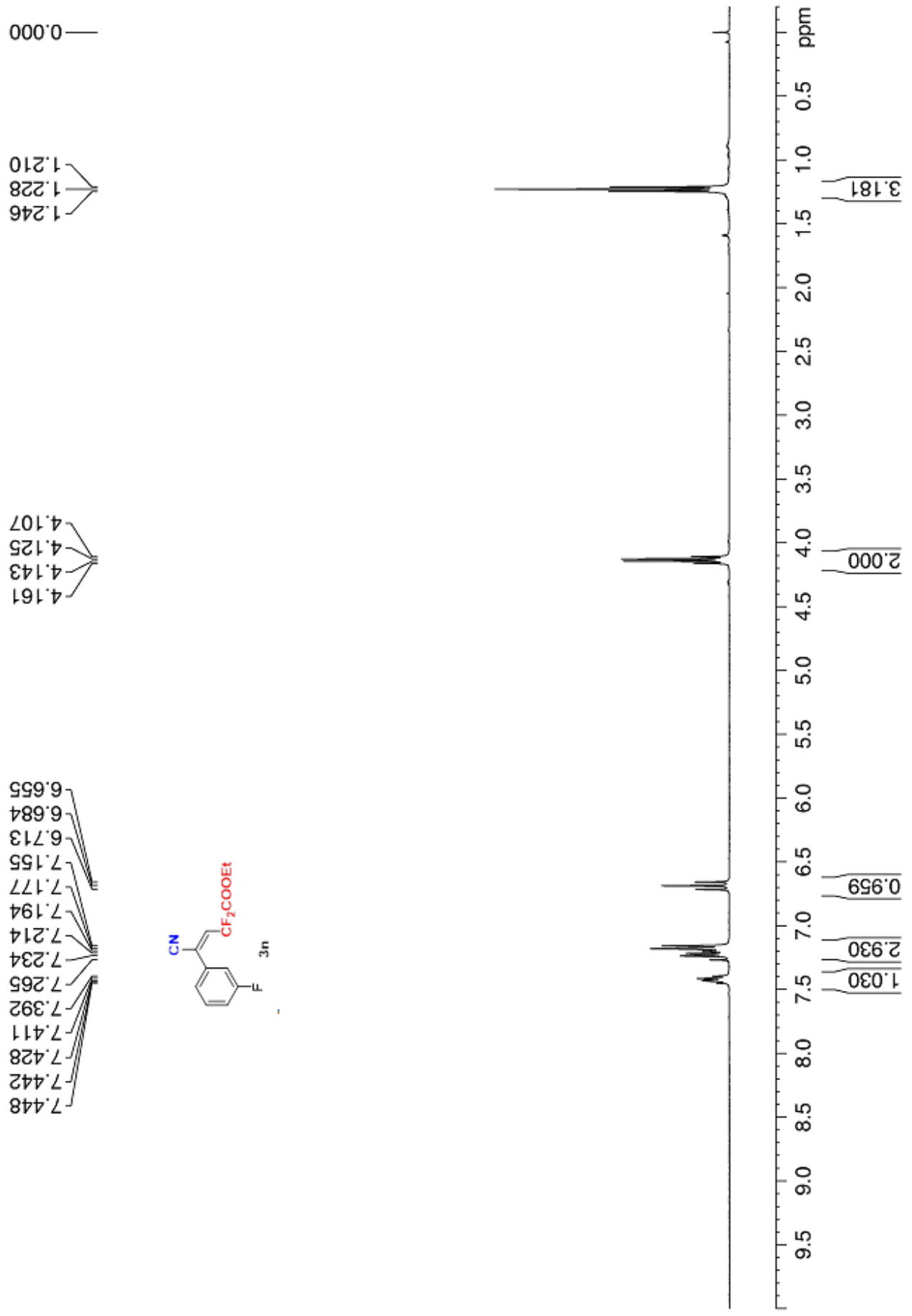




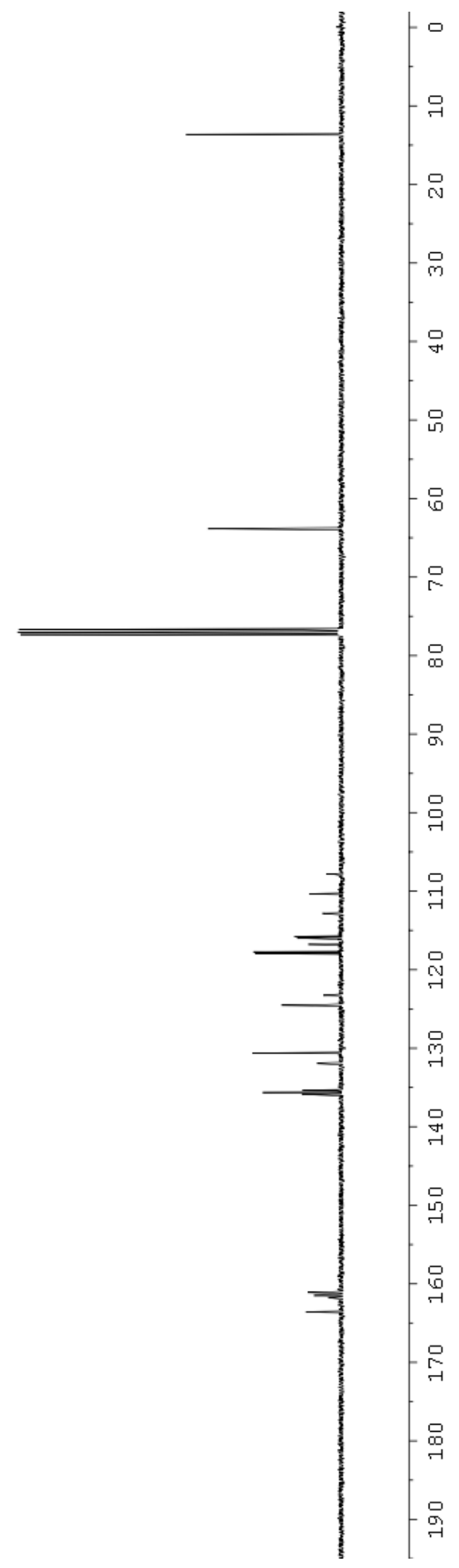

$58 \cdot \angle 0 T$

$\varepsilon \varepsilon \cdot 0 \tau \tau$

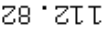

LL STt

$00 \cdot 9 \tau \mathrm{T}$

$\angle L \cdot 9 \tau t$

$\mathrm{ZL} \cdot \angle \tau \tau$

$\varepsilon \sigma^{\circ} \angle \tau \tau$

$6 \tau \cdot \varepsilon z \tau]$

$\angle Z \cdot \varepsilon z \tau$

$\mathrm{SE} \cdot \varepsilon \mathrm{\varepsilon \tau}$

$85 \cdot$ 一兀

५S.0Eโ

$\varepsilon 9 \cdot 0 \varepsilon \tau$

$\angle 8^{\circ} \tau \varepsilon \tau$

$56 \cdot \tau \varepsilon \tau$

ธع $\mathrm{se \tau}$ -

$\varepsilon 9 \cdot \mathrm{GET}$

$26 \cdot \mathrm{se \tau}$

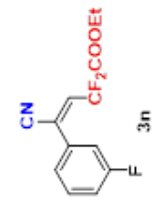

$0 \tau \cdot$ โ9 T

$\angle \tau \cdot \tau 9 \tau$

$66^{\circ}$ โ9T

โ8. T9T $^{-}$

$\angle S^{\circ} 89 \tau^{\top}$ 
$\angle 98^{\circ} 0 \mathrm{LL}^{-}$

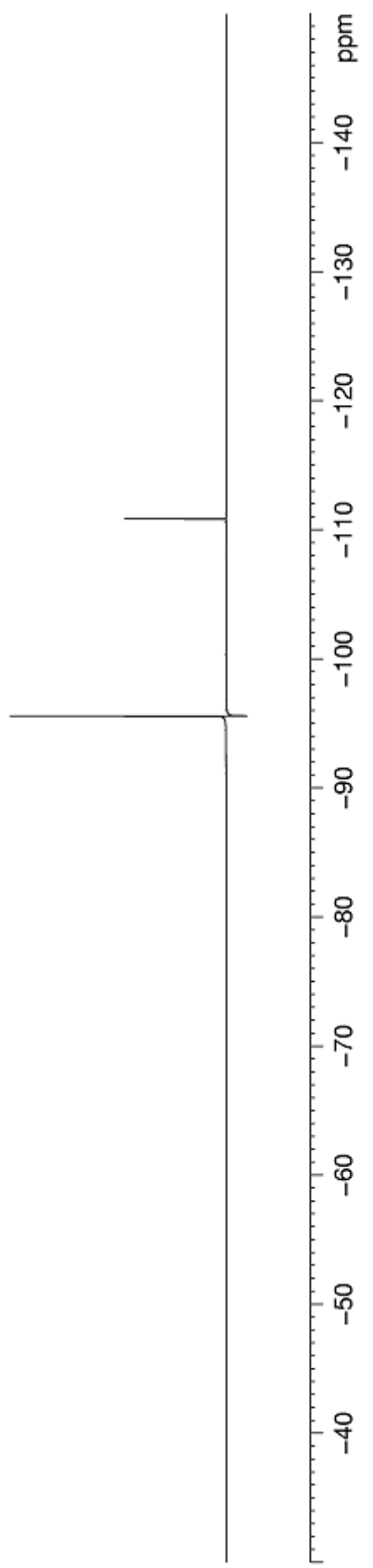




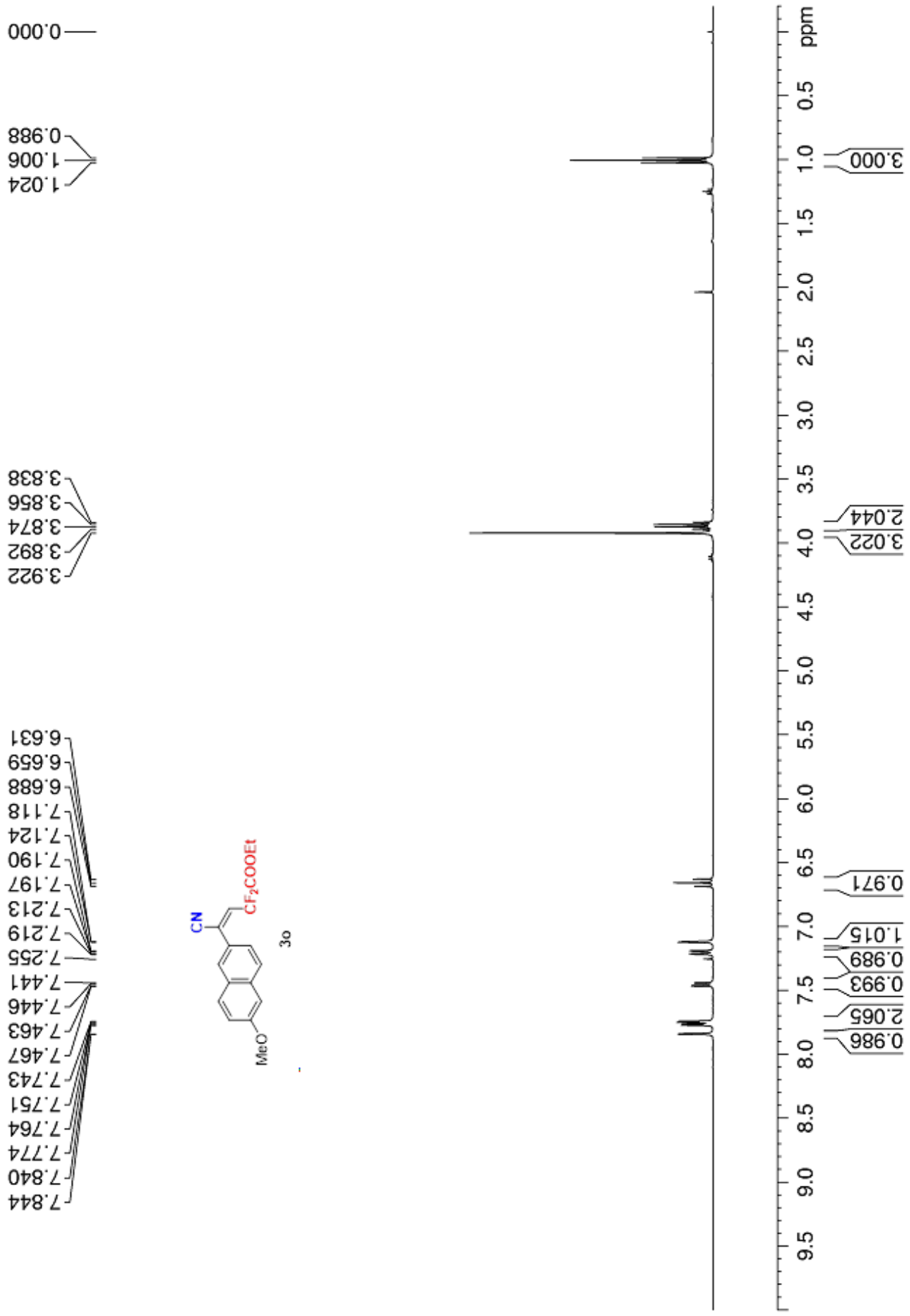




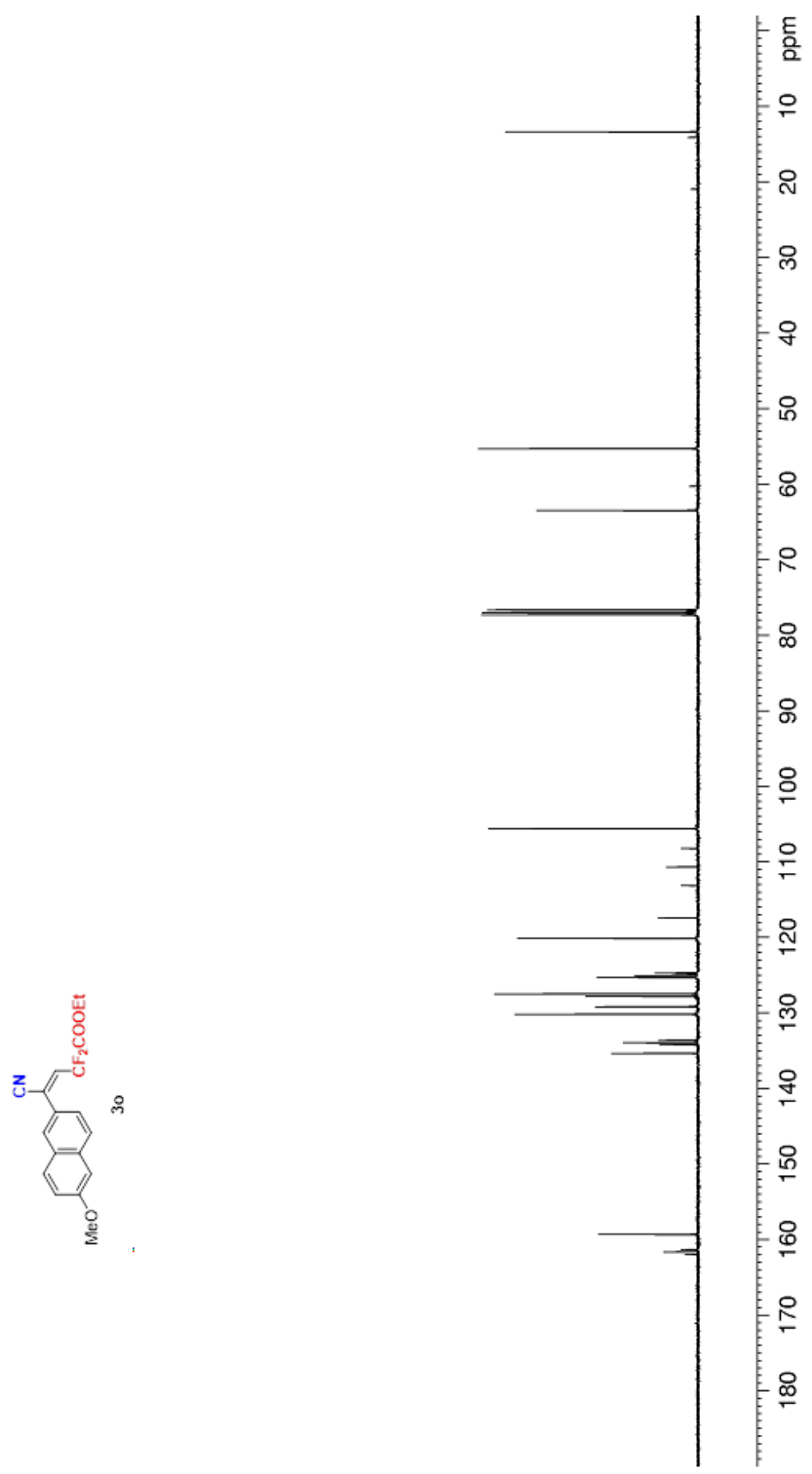

เยะ $\varsigma \varsigma$

$86)^{\circ} \varepsilon 9$

$789.9 L$

$200 \angle L$
$0 Z \varepsilon \angle L$

619.901.
$\angle \mathcal{C} \cdot 80$.

20L아

89 ํเ $^{\circ}$

8ट† Lト

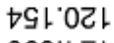

069" $\triangleright$ ट

$18 \angle \supset \mathrm{D}$.

SL8' $\square Z L$

†เ'G己L

टहE जट।

ट†T $\angle C+/ f$

$\rightarrow 8 L L C L$

9t다.

ट†ト $0 \varepsilon 卜$

टा9 $\varepsilon \varepsilon เ$

५06. $\varepsilon E$ ।

$\angle 6+{ }^{\circ} \nabla \varepsilon$

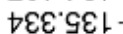

เ6己 6G -

$\varepsilon 62$ เ9! -

Gเ9'เ9L-

0†6. เ91 


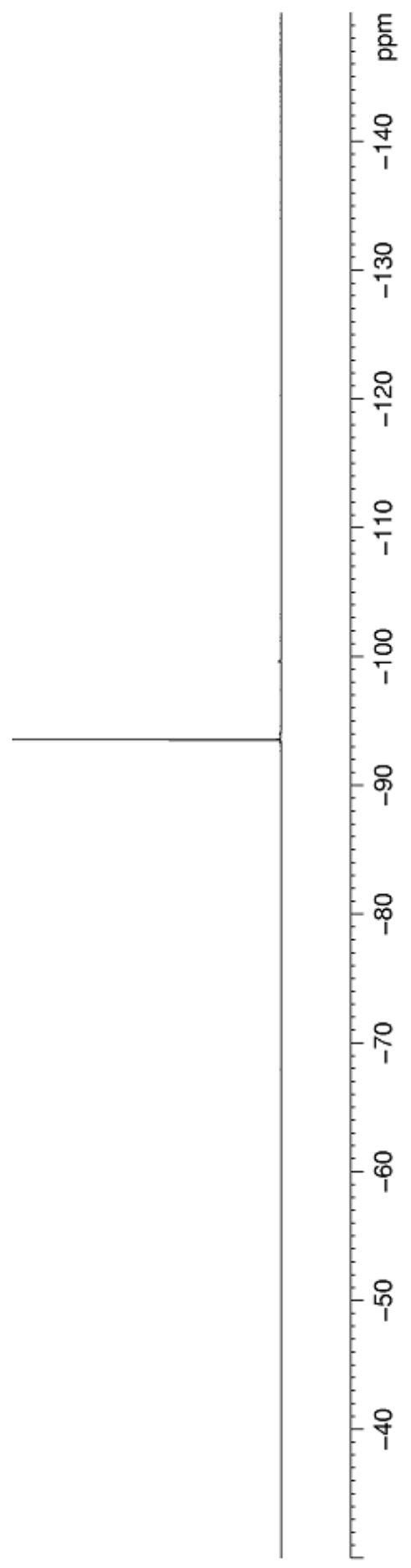




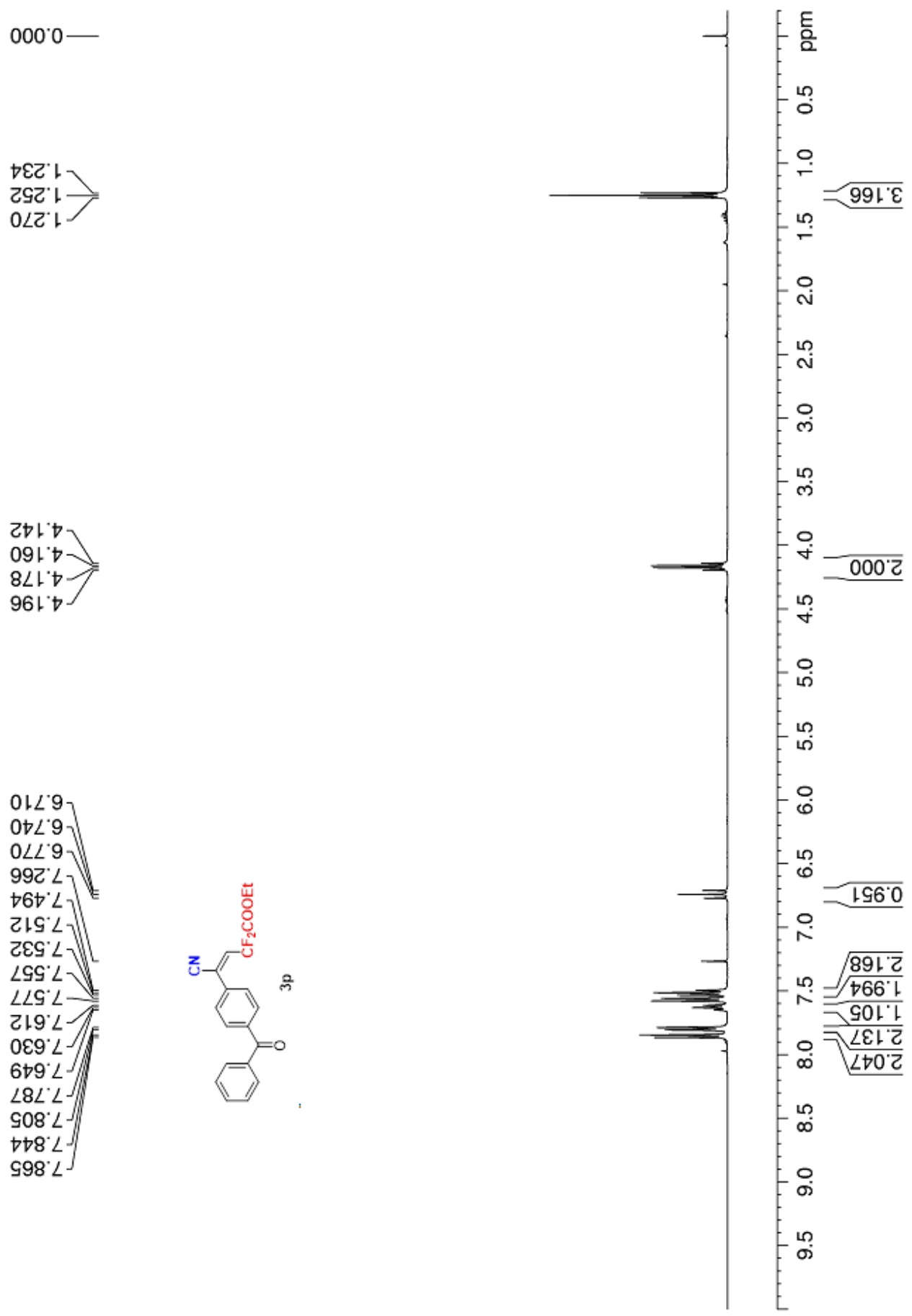


$869^{\circ} \varepsilon$

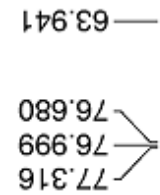

$\varepsilon 68^{\circ} \mathrm{LO}$

6LE"아

$\angle 98^{\circ} \mathrm{ZL}$

208.9.

เ09' $\varepsilon Z$ ।

$089^{\circ} \varepsilon 己$ ᄂ

$8 S \angle$ 'Eट।

987 $8 \mathrm{C}$ ᄂ

$789^{\circ} 8 \mathrm{~L}$

$60 \angle 82$

เEL 82 -

ट00"0हा-

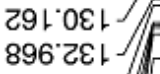

घ99 $\varepsilon \varepsilon\llcorner$ -

$\nabla \angle t \subseteq \varepsilon$

$\varepsilon \subseteq L \mathrm{G}$ เ

$\varepsilon \varepsilon 0^{\circ} 9 \varepsilon \downarrow$

¿GL' $9 \varepsilon$ ।

8टE"6ह।

E†Z" เ91-

999.เ9เ

$888^{\prime}$ '9

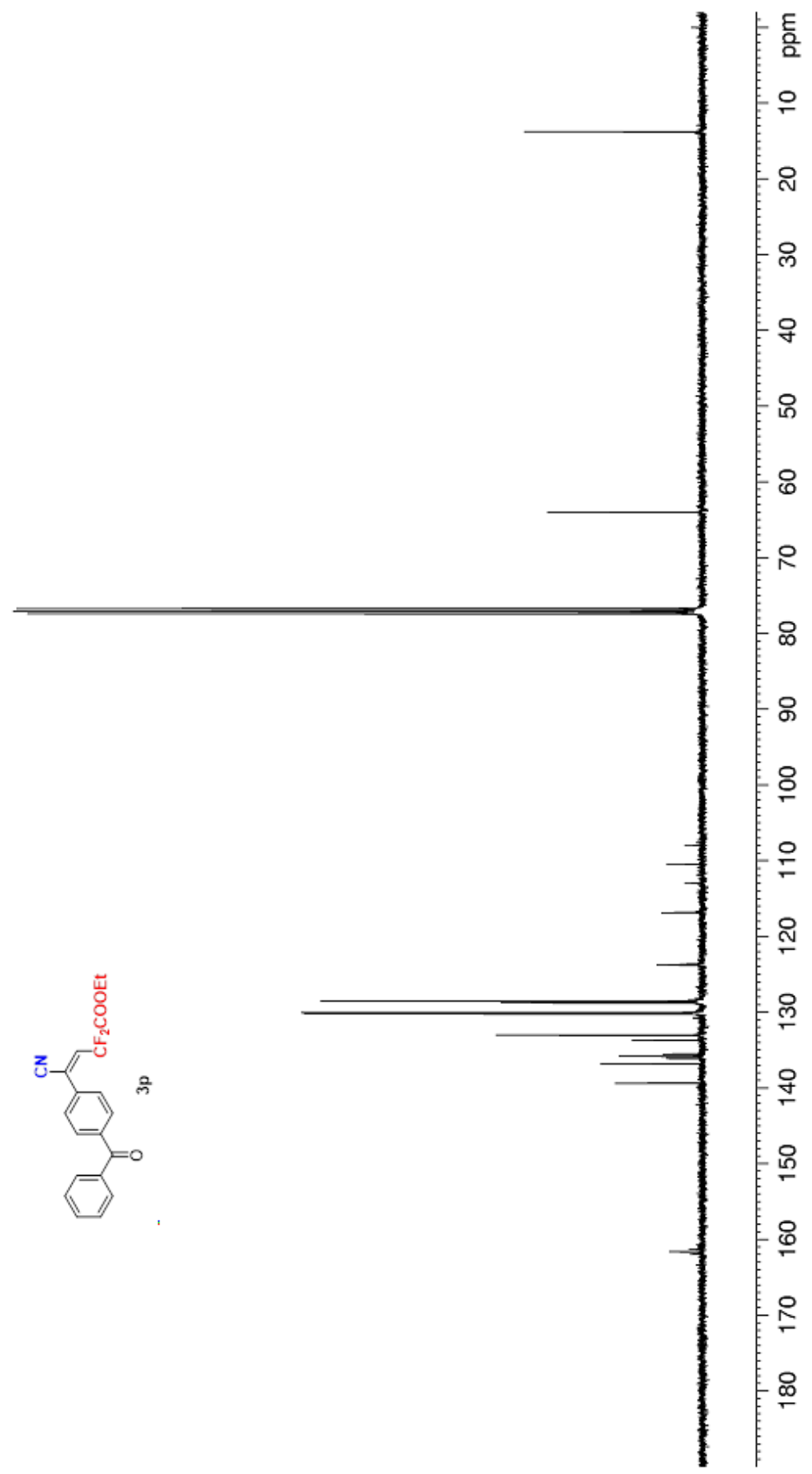




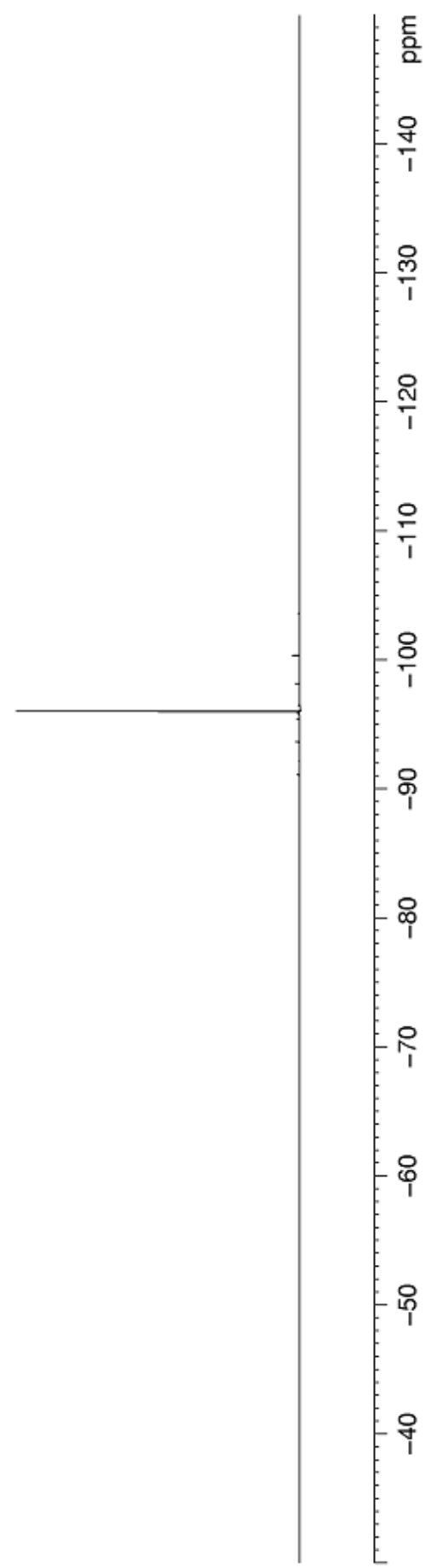




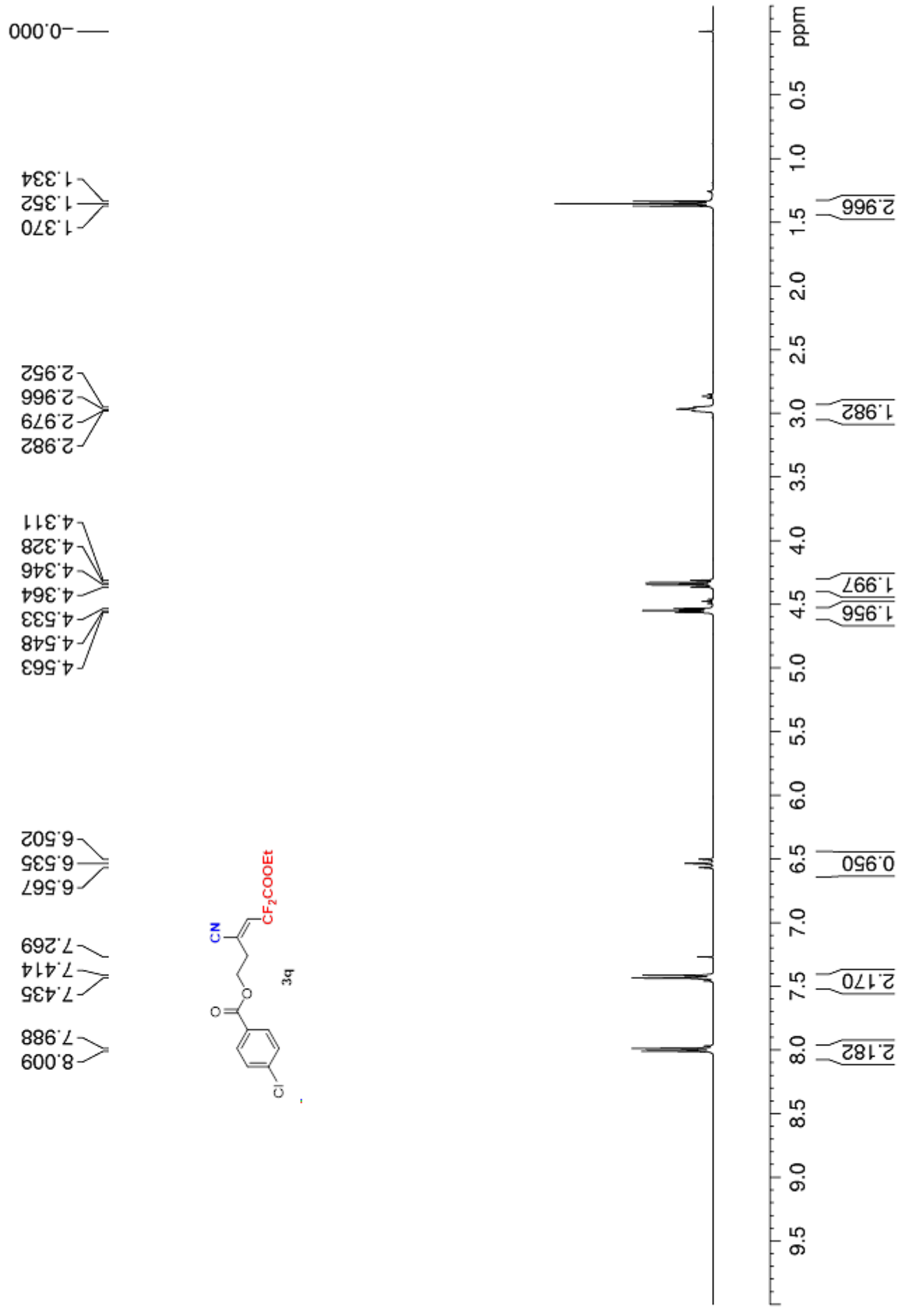


$\varepsilon เ 8^{\prime} \varepsilon\llcorner-$

$99 L 62$

$61+29$

$901+59$

†89 $9 L$

$100 \angle L>$

$6 เ \varepsilon^{\prime} L L$

$68 \varepsilon^{\circ} 80$ เ

S68. 나

$86 \varepsilon^{\circ} \varepsilon$ เ

LOL LL

$\angle 6 G^{\circ} \mathrm{ZZ}$

$\angle G 9^{\circ} \mathrm{ZZ}$

$\angle L \angle Z Z 1-$

$\angle 68^{\circ} \mathrm{LZ}$ -

$\varepsilon 8 \angle$ ' 82

เOL'เEL

$66 \mathrm{~S}^{\circ} 9 \varepsilon \mathrm{L}$

698.9ع -

เDเ $\angle \varepsilon$

CDL $6 \varepsilon+$

$6 \angle 9^{\circ}$ เ9เ

$\angle 00$ Z9 ।

9๕६'ट9।

† ¿' 99 เ

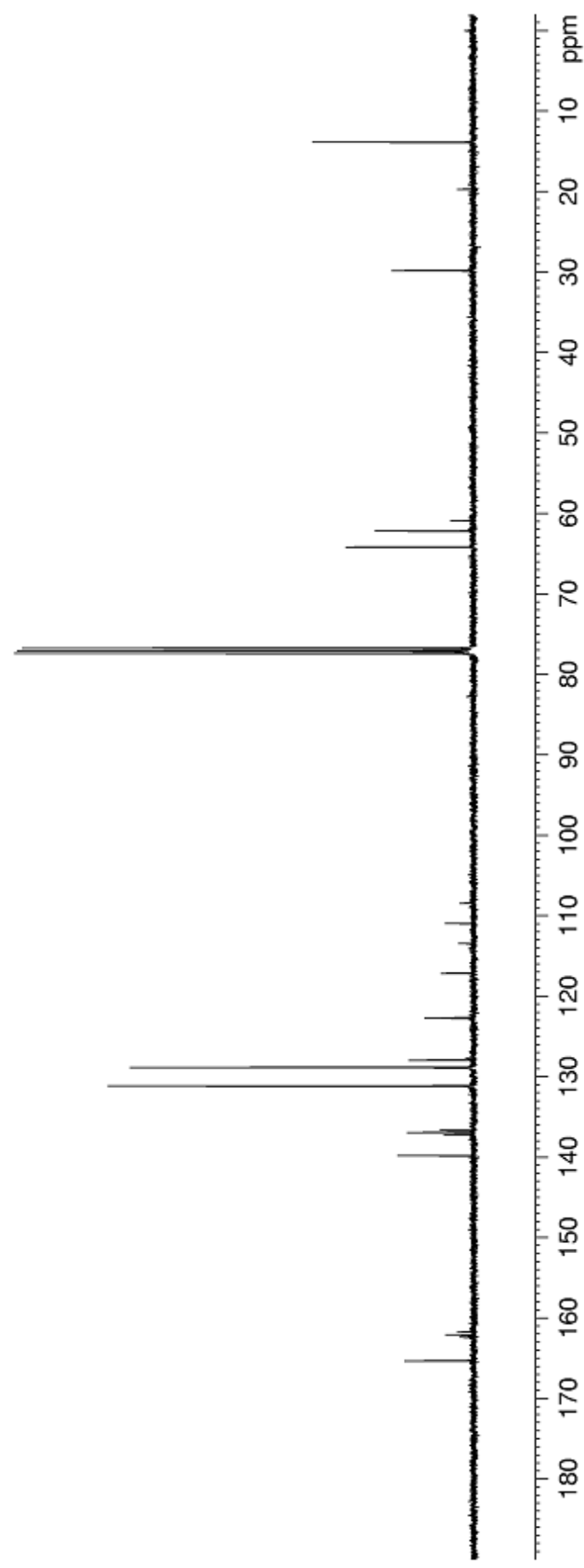


9t\&' I]

Z8E

ZS6' 2

SS6' 27

$696^{\circ} \mathrm{Z}$

$286^{\circ} \mathrm{Z}$

$\left.586^{\prime} \mathrm{Z}\right]$

$8 \angle 8^{\prime} \varepsilon-$

zZع'

6E\&'

LSE' $D-$

ors' ${ }^{-} f$

$9 \& S$ ' $t$

ISS' $D$.

$805^{\circ} 9$

ItS'9-

$\varepsilon \angle S^{\prime}{ }^{\prime}$

2\&6.9

$58 \mathrm{Z}^{\prime} \mathrm{L}-$

$700^{\circ}$
$400^{\circ}$
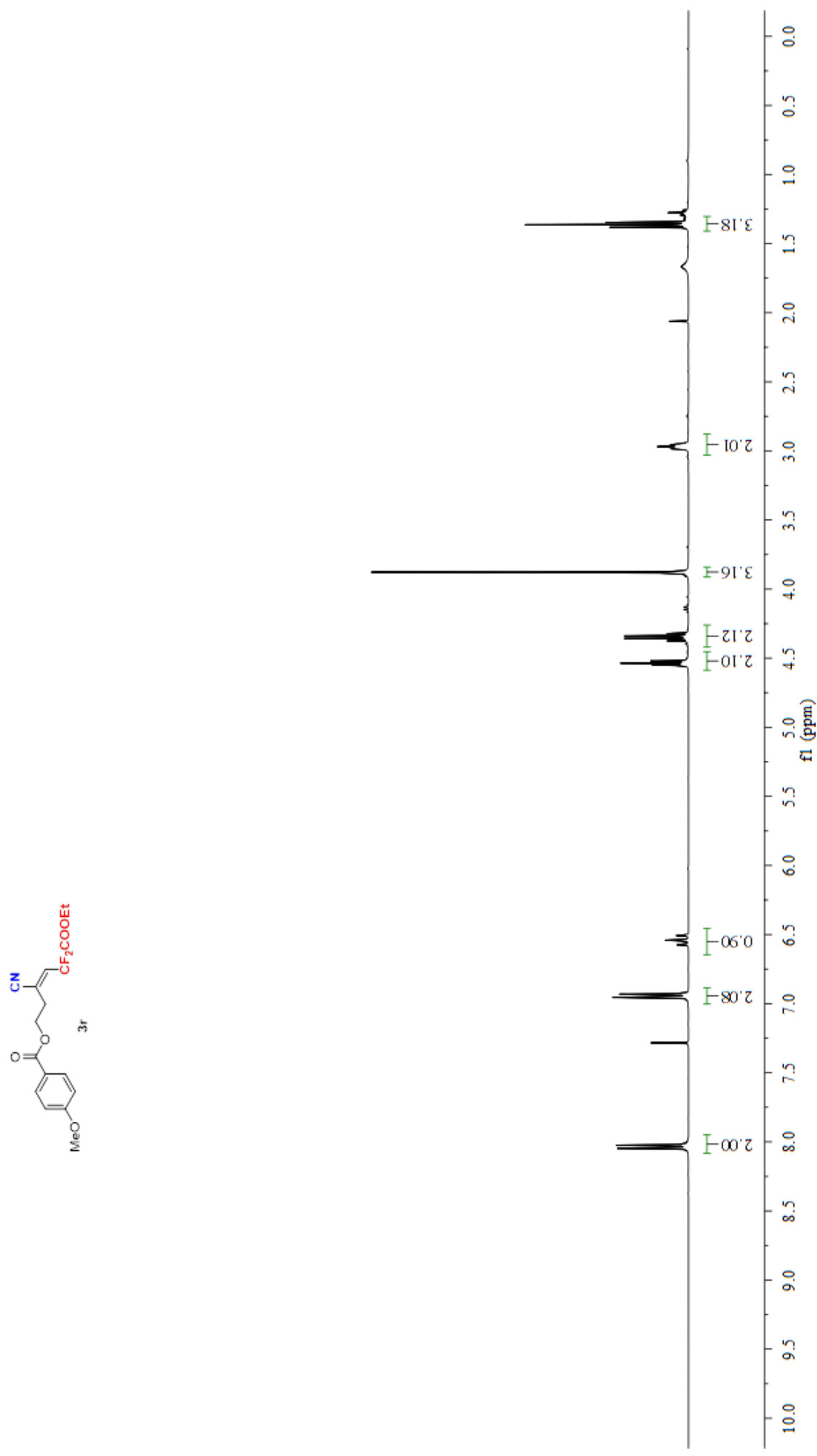

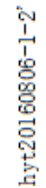




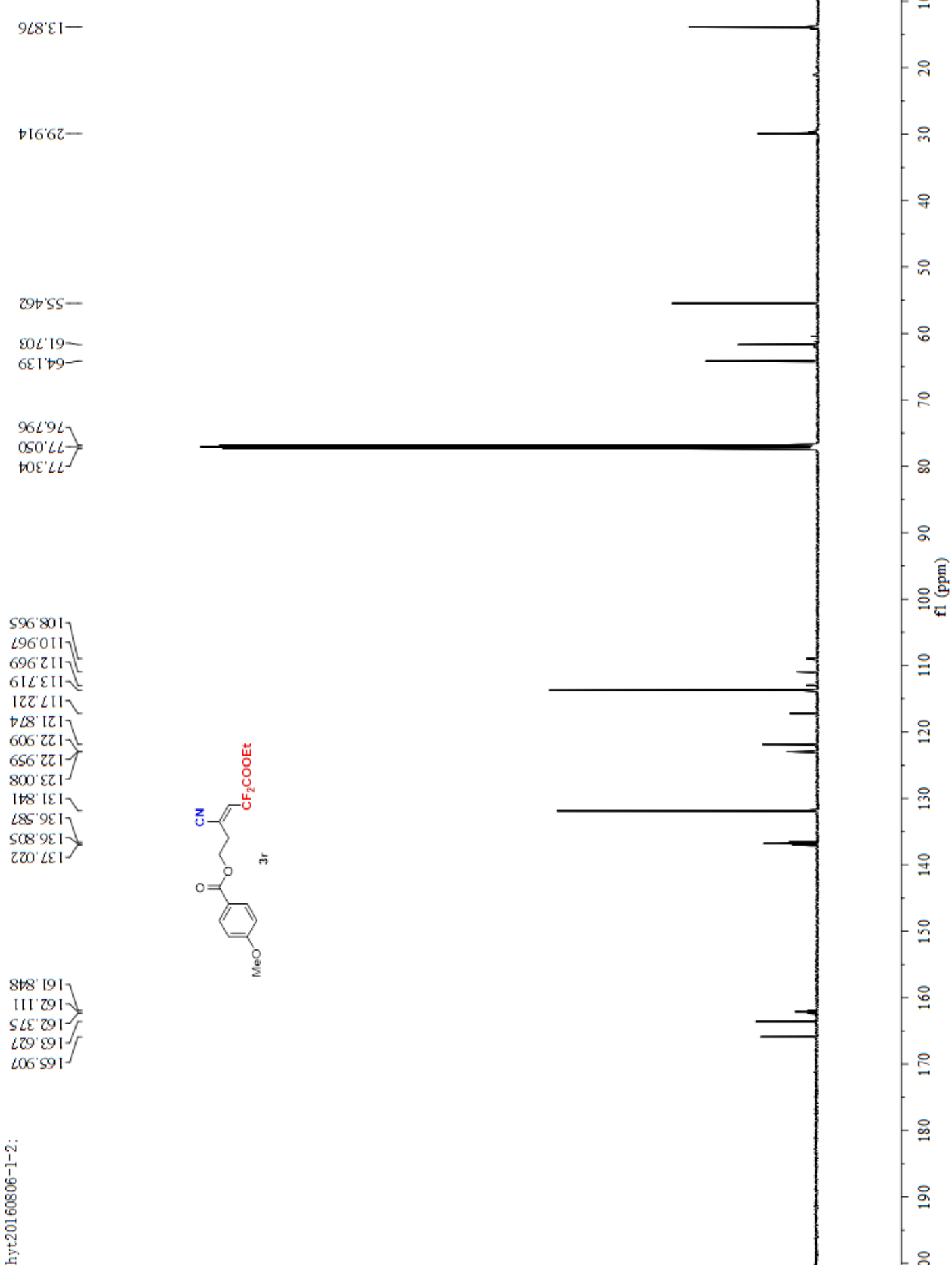




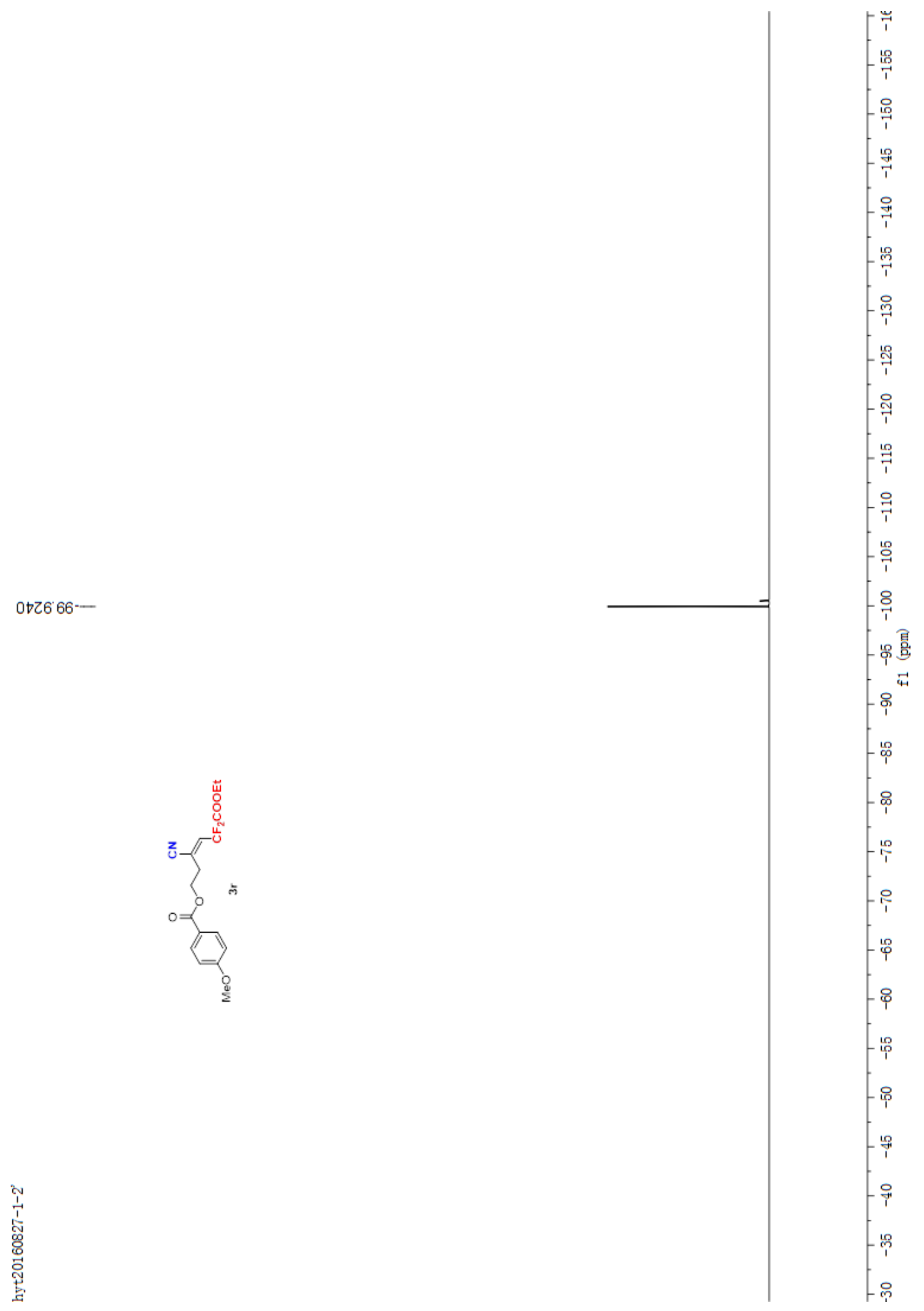


SSE' I-

06E, I]

$1 \angle 9^{\circ} \mathrm{Z}$

$269^{\prime} 2-$

$80 L^{\prime} Z$

$[1, Z]$

ocs'

$8 \not \varepsilon \cdot b-$

$99 \varepsilon D$

$\square 8 \varepsilon^{\prime}{ }^{\prime}$

$860^{\circ} 9$

LCI' $9-\frac{1}{2}$

$181^{\prime} L$

$86 I^{\circ} \mathrm{L}$

$\angle E Z ' L$

$S S Z L$

$D \angle Z L$

$\triangle 82^{\prime} L$

$S I \varepsilon^{\prime} L$

$\mathcal{E E}\llcorner$

ISE $L$

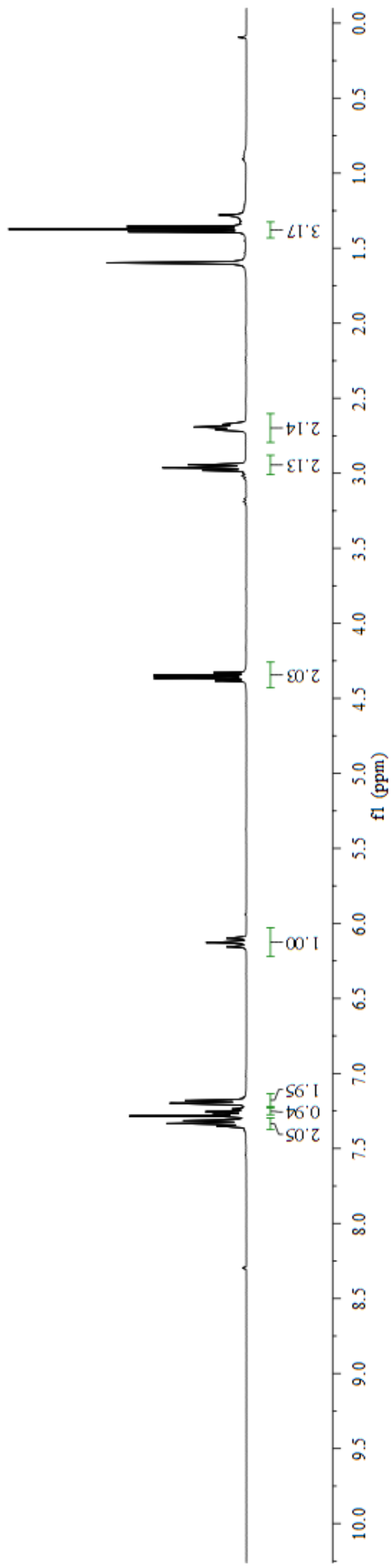




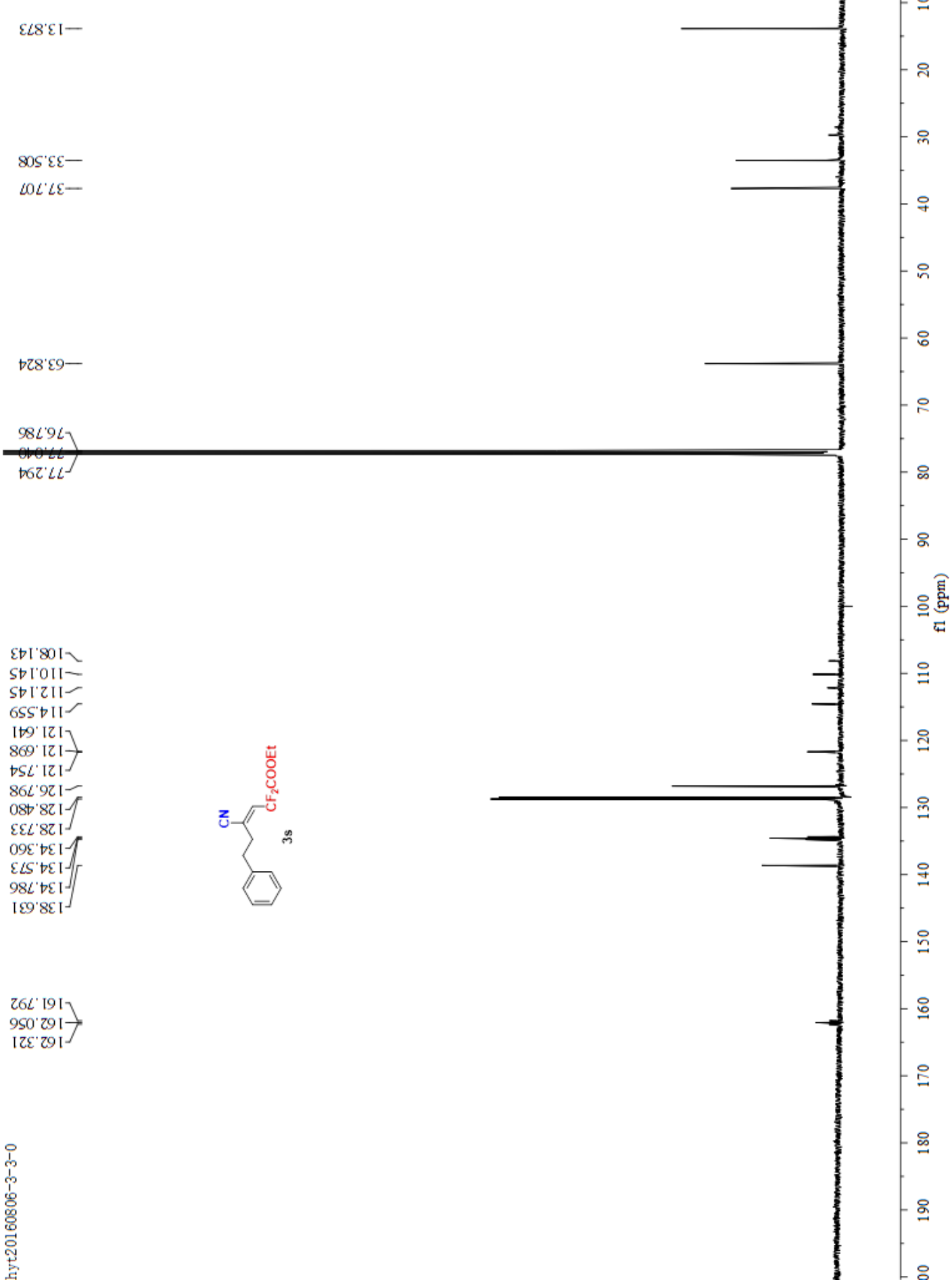


26ع' $10 \mathrm{I}^{-}-$

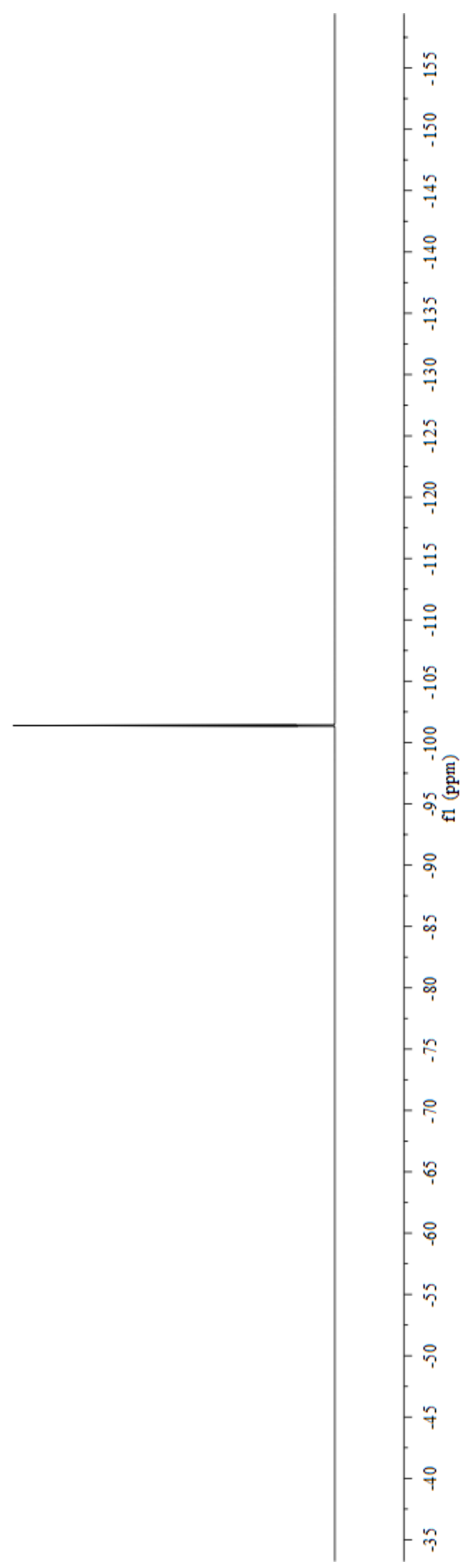




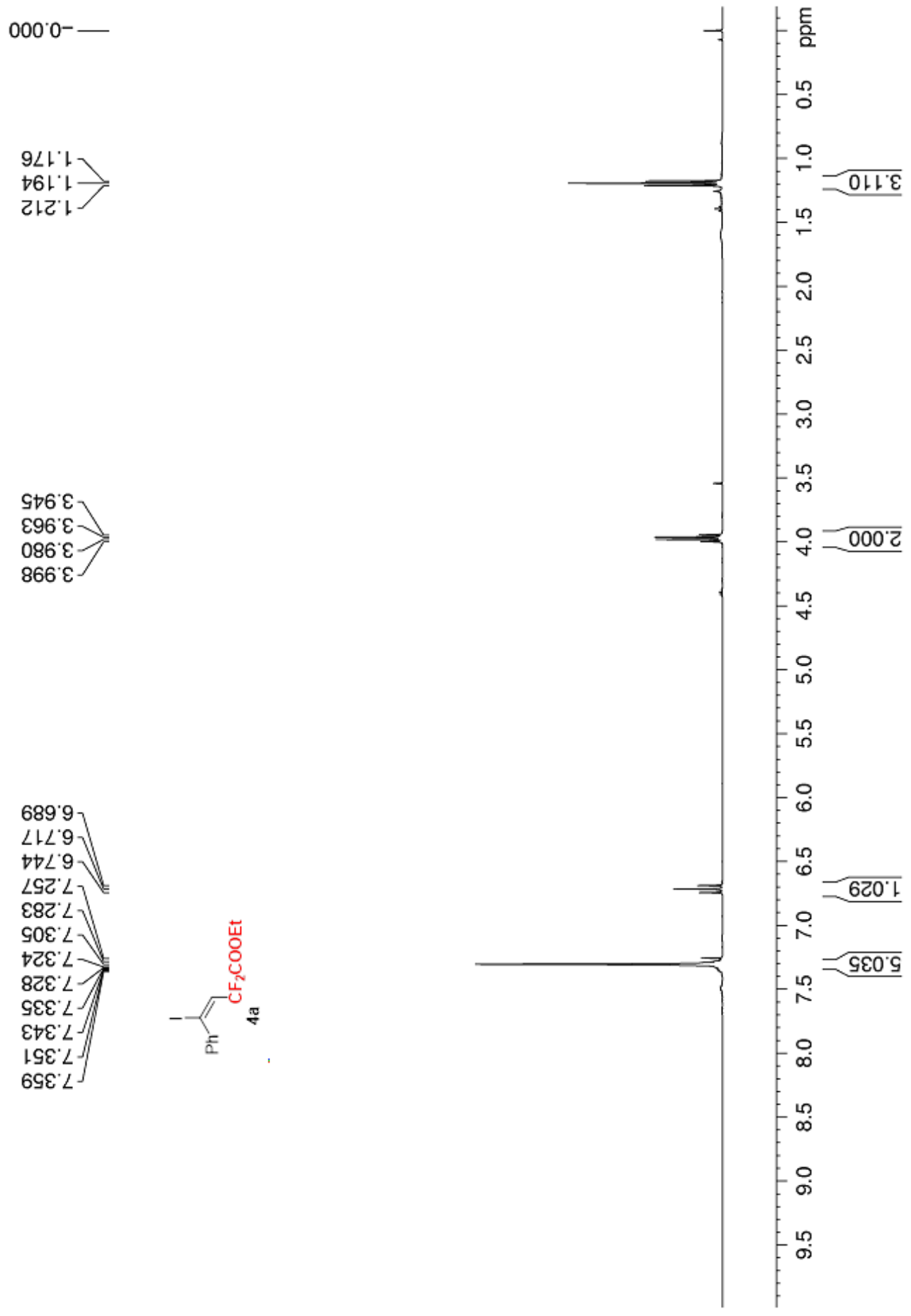


$999^{\circ} \varepsilon\llcorner-$

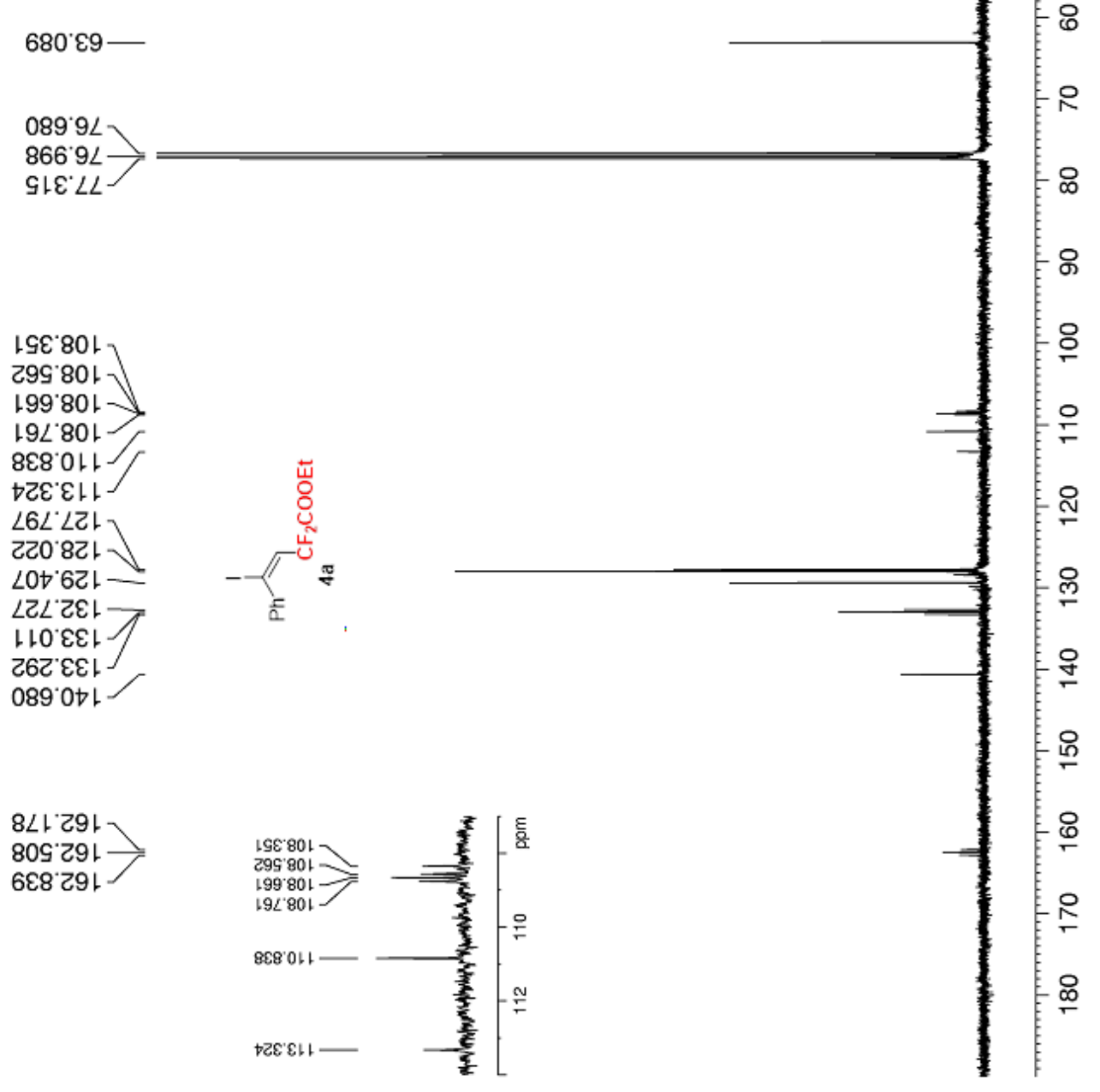




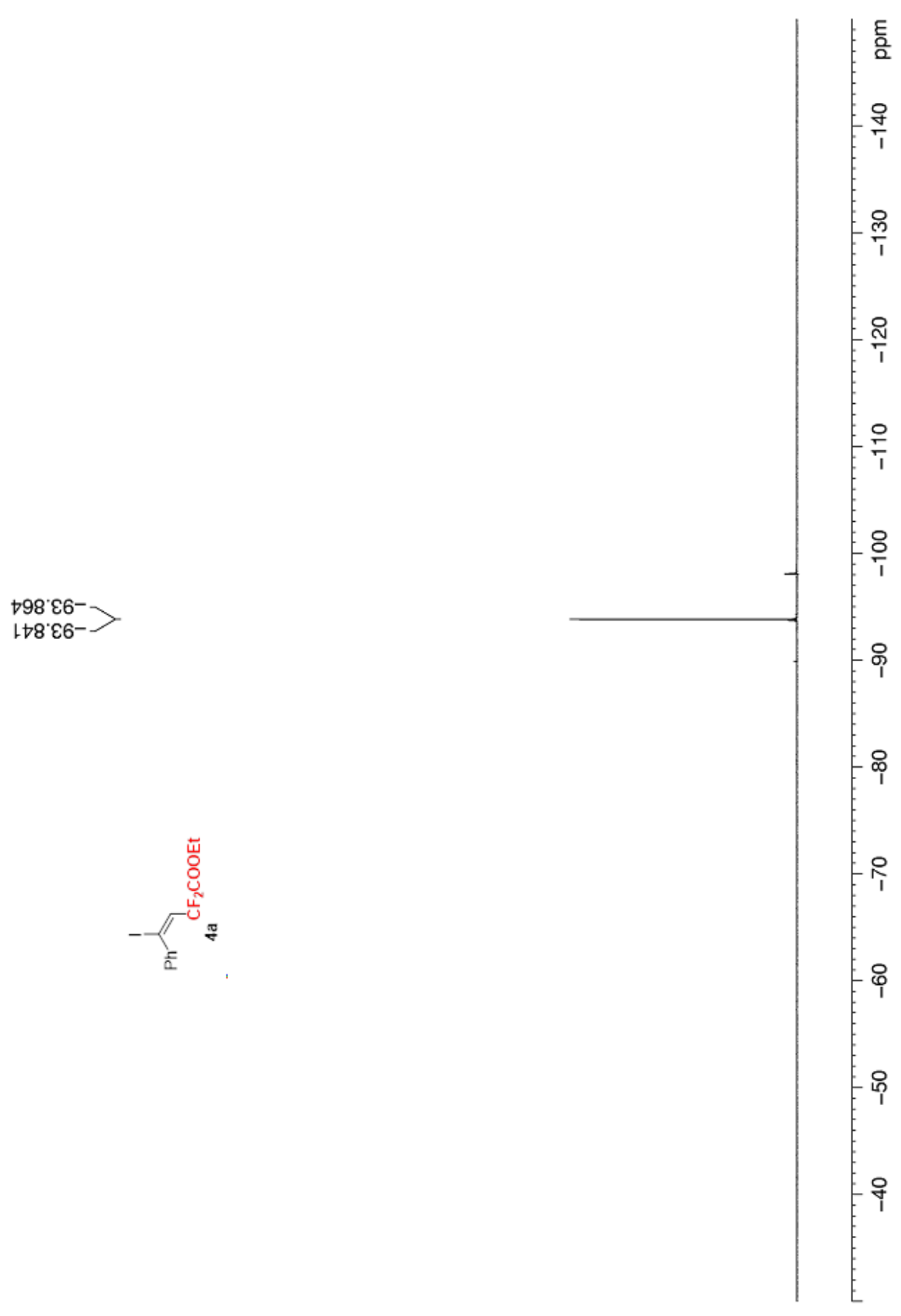



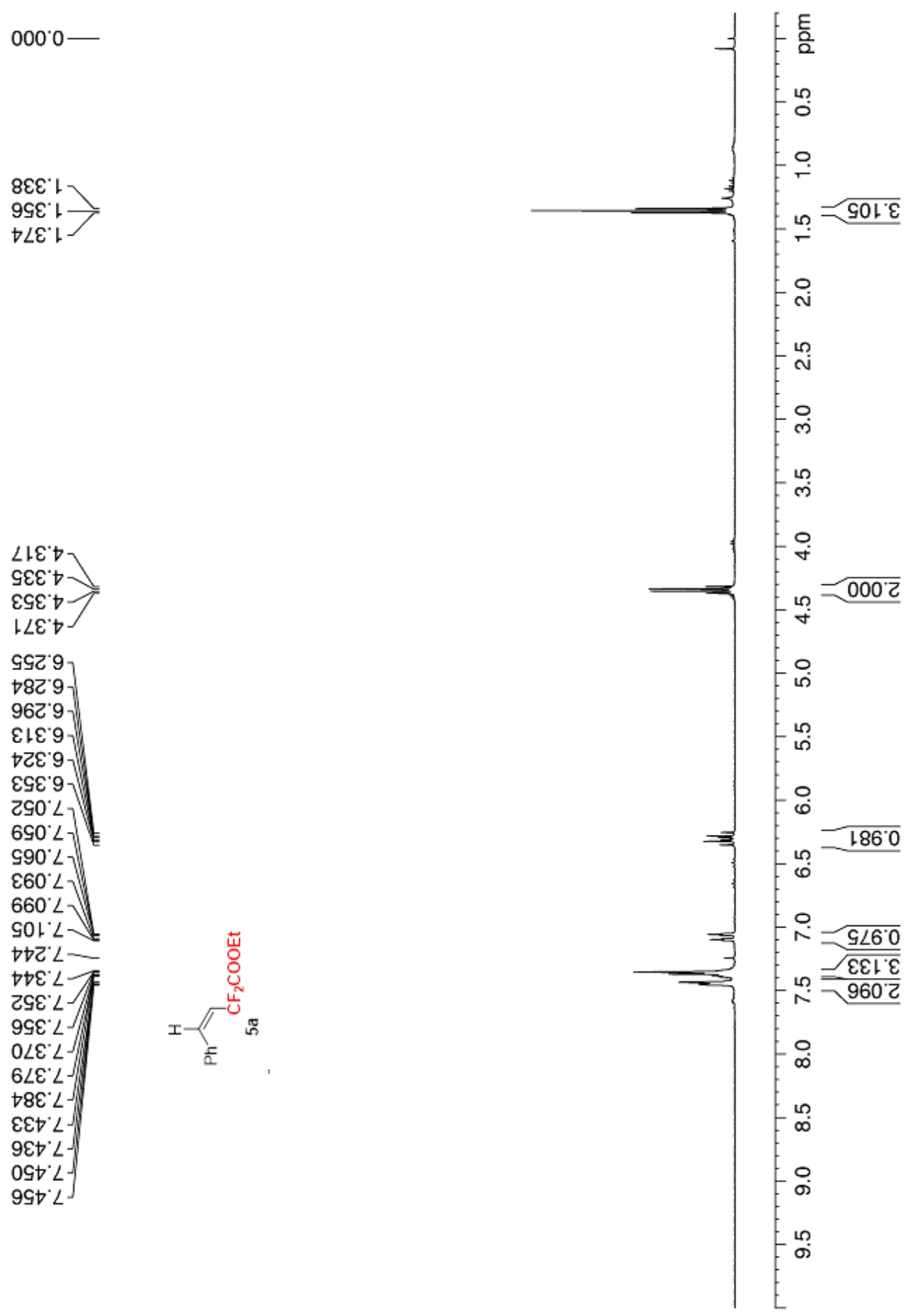
$606^{\circ} \varepsilon\llcorner$

SL0'๕9-

S89 $9 L$

$200 . \angle L>$

$0 Z E^{\prime} \angle L$
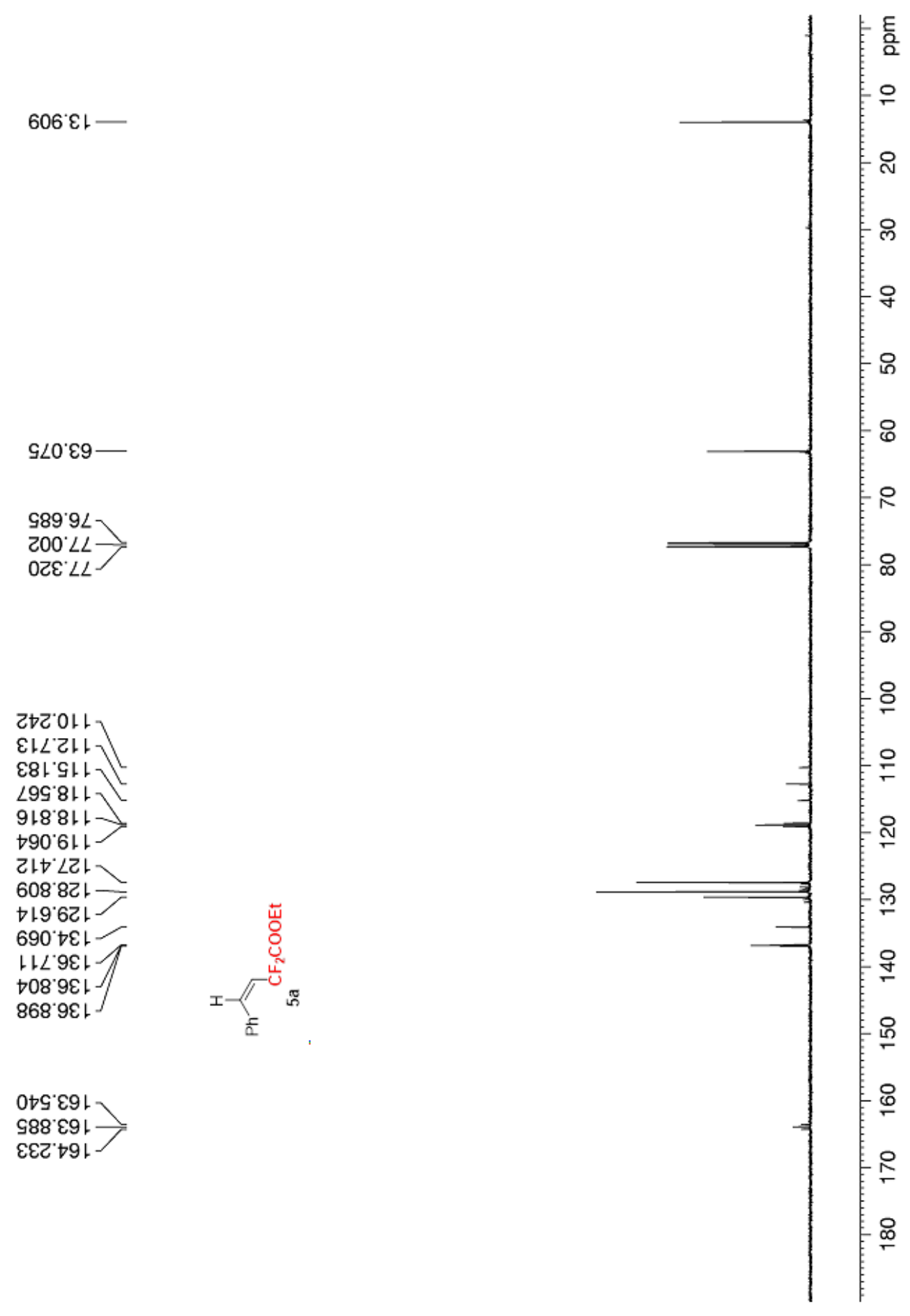

0†G' $\varepsilon 91$

५88. .9 -

๕๕ट เงเ - 


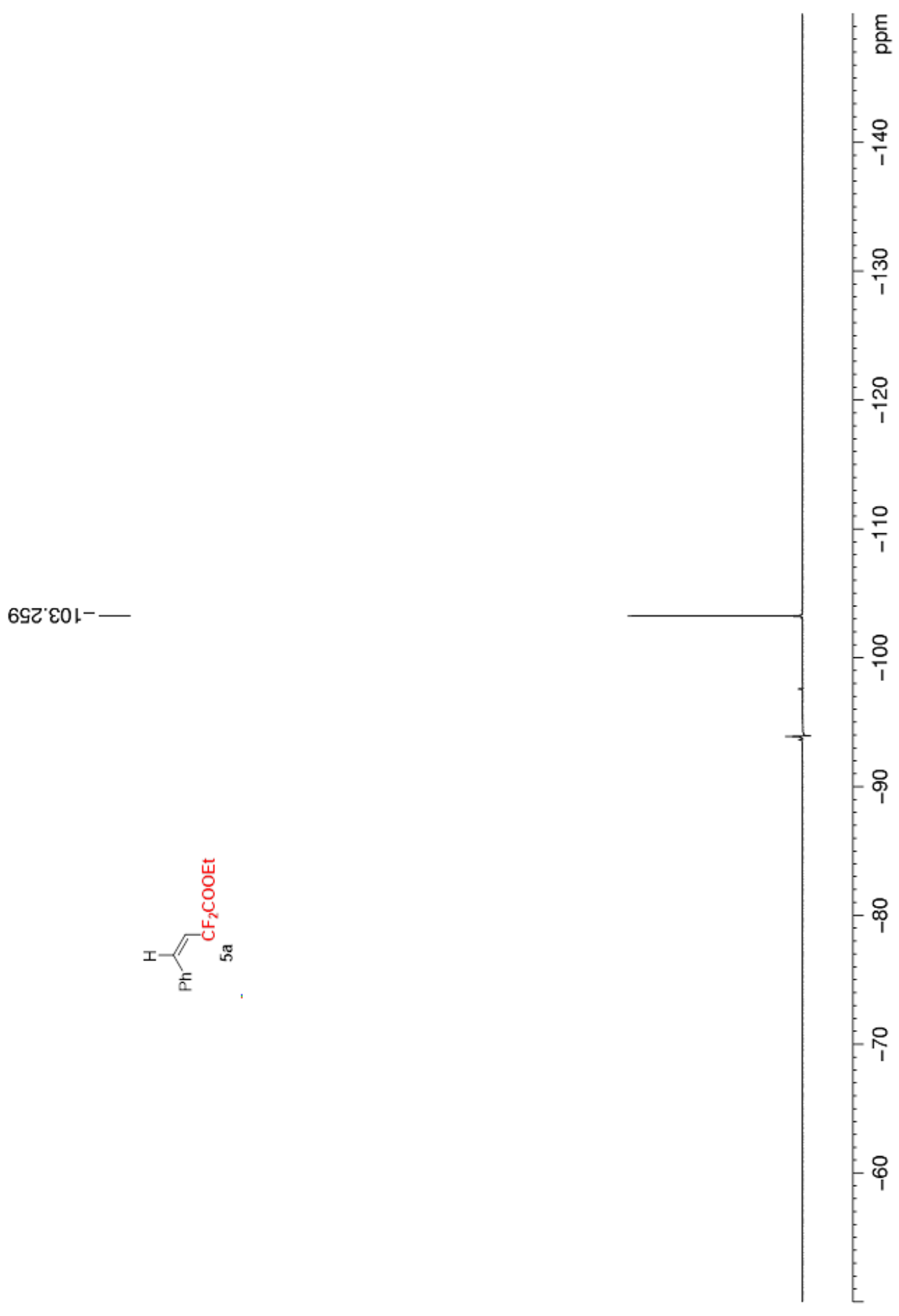

